

\section{DISCLAIMER}

This report was prepared as an account of work sponsored by an agency of the United States Government. Neither the United States Government nor any agency Thereof, nor any of their employees, makes any warranty, express or implied, or assumes any legal liability or responsibility for the accuracy, completeness, or usefulness of any information, apparatus, product, or process disclosed, or represents that its use would not infringe privately owned rights. Reference herein to any specific commercial product, process, or service by trade name, trademark, manufacturer, or otherwise does not necessarily constitute or imply its endorsement, recommendation, or favoring by the United States Government or any agency thereof. The views and opinions of authors expressed herein do not necessarily state or reflect those of the United States Government or any agency thereof. 


\section{DISCLAIMER}

Portions of this document may be illegible in electronic image products. Images are produced from the best available original document. 
MLM-2 237

TID -4500

$\mathrm{UC}-23$

\title{
Investigation of the Problems Associated with the Pt-20 Rh Clads of the Viking Heat Sources VF-3 and VF-7
}

\author{
R. E. Zielinski \\ Issued: July 25, 1975
}

\section{NOTICE}

This report was prepared as an account of work sponsored by the United States Government. Neither the United States nor the United States Energy Research and Development Administration, nor any of their employees, nor any of their contractors, subcontractors, or their employees, makes any warranty, express or implied, or assumes any legal liability or responsibility for the accuracy, com-

pleteness or usefulness of any information, apparatus, product or process disclosed or represents that its use would not infringe privately owned rights.

PRINTED IN THE UNITED STATES OF AMERICA

Available from

National Technical information Service

U.S. Department of Commerce 5285 Port Royal Road

Springfield, Virginia 22161

Price: Printed Copy $\$ 5.45$; Microfiche $\$ 2.25$

\section{MONSANTO RESEARCH CORPORATION}

A Subsidiary of Monsanto Company

MOUND IABORATORY

Miamisburg, Ohio

45342

operated for

\section{UNITED STATES ENERGY RESEARCH AND DEVELOPMENT ADMINISTRATION}

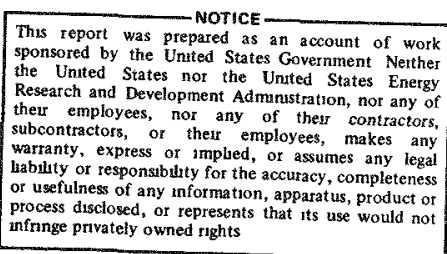

infinnge privately owned rights

U.S. Government Contract No. AT-33-1-GEN-53 


\section{DISTRIBUTION}

\section{EXTERNAL}

TIC, UC -23

D. K. Nowl in, ERDA/ALO

S. V. Rogers, ERDA/ALO

E. A. Walker, ERDA/DAO

T. J. Dobry, ERDA/DSNS

R. H. Kuhnaphe1, ERDA/DSNS

V. G. Redmond, ERDA/DSNS

W. C. Remini, ERDA/DSNS

N. Thielke, ERDA/DSNS
R. A. Kent, LASL

R. H. Harner, SLA

W. M. Rrittain, Teledyne Isotopes

R. S. Buxbaum, Teledyne Isotopes

E. T. Charyszyn, Teledyne Isotopes

H. K1ing, Fairchild

J. H. Masson, Martin-Marietta

R. C. Brouns, Viking Project office

R. A. Russell, Viking Project Office

INTERNAL
C. 0. Brewer
D. P. Ke11y
W. T. Cave
J. R. McClain
D. L. Coffey
B. D. Scearce
R. R. Jaeger
J. G. Villars
E. W. Johnson
R. E. Zielinski
L. V. Jones
Publications
W. H. Jones
Library 
TABLE OF CONTENTS

$\underline{\text { Page }}$

ABSTRACT ........................ 4

INTRODUCTION . . . . . . . . . . . . 5

VISUAL OBSERVATIONS . . . . . . . . . . . 6

$\mathrm{VF}-3$. . . . . . . . . . . . . 6

$\mathrm{VF}-7$. . . . . . . . . . . . . 7

DETAILED OBSERVATIONS ................. 9

Pt-20 Rh Clad ................ 9

A. $\mathrm{VF}-3 . . . . . . . . . . .99$

B. $V F-7 \ldots . . . . . . . .10$

Emissive Coating . . . . . . . . . . 14

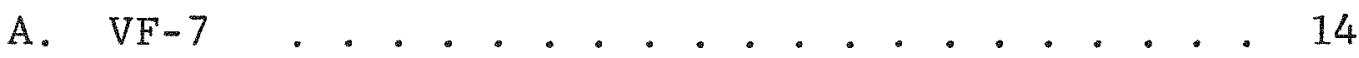

B. $\mathrm{VF}-3 . . . . . . . . .214$

DISCUSSION OF OBSERVATIONS ............ 16

SUPPORTING ADDITIONAL STUDTES . . . . . . . . . 26

CONCLUSTONS ................. 32

ACKNOWLEDGMENTS . . . . . . . . . . . . . 35

REFERENCES ................. . . 36

FIGURES . . . . . . . . . . . . . . 37 


\section{ABSTRACT}

The present investigation was undertaken to determine why the emissive coatings of the Viking Heat Sources VF-3 and VF-7 had flaked off the Pt-20 Rh clad material. During the course of the investigation, two additional, unusual phenomena were observed: a surface reaction zone on the uncoated Pt-20 Rh surfaces and grain boundary reactions in the weld zone of the clad.

It seems that aII three phenomena were the result of a complicated reaction couple that involved the heat source materials, storage container materials, and environment. Vapor transport mechanisms were responsible for the phenomena which were observed. The vapor transport mechanisms were probably initiated because of the impurities that were in both the heat source and storage container materials. The mechanisms resulted in significant changes in these heat sources because vapor transport was allowed to continue in a static environment for an unusually long period of time. 


\section{INTRODUCTION}

This investigation was initiated to determine the cause of the emissive coating flaking from the Pt-20 Rh clads of Viking Heat Sources VF-3 and VF-7. The investigation consisted of visual examination of the affected materials, detailed electron microscopy studies, and the performance of simulant tests.

The emissive coating of Viking Heat Source VF-7 was observed to be flaking off during the normal transfer operations that take place at Teledyne Isotopes. During these operations, the heat source shipping container is passed into a "submarine" chamber, where the heat source is removed from the shipping container and inserted into a converter. When VF-7 was removed from the shipping container, pieces of the emissive coating were observed to be flaking from its $\mathrm{Pt}-20 \mathrm{Rh}$ clad. The heat source was positioned back into the shipping container and returned to Mound Laboratory for examination.

The VF-3 heat source was never transferred from its shipping container at Teledyne Isotopes. During routine gas sampling operations of the shipping container's atmosphere, a high radon count was observed. The shipping container was returned to Mound Laboratory so that the radon problem could be evaluated. When the heat source was removed from its shipping container at Mound Laboratory, the coating was observed to be flaking off the Pt-20 Rh clad, and there was visual evidence that an air or water leak had occurred and that the heat source suffered oxygen contamination.

Both heat sources $V F-3$ and VF-7 were exposed to unusually long storage container times. 


\section{VISUAL OBSERVATIONS}

Before discussing the visual appearance of the heat source clads, a review of the shipping container geometry is in order. The heat source is maintained in a rigid position in the 304 stainless steel shipping container with the use of graphite cradles, which are positioned on the top and bottom uncoated domes of the Pt-20 Rh clad. The cylindrical portion of the clad is coated with Plasma Arc Sprayed (PAS) alumina and does not contact the shipping container. The top cap of the shipping container is sealed against the cylindrical portion using a double delta seal on an annealed copper gasket. The seal maintains a helium atmosphere in the shipping container.

This type of arrangement has been used successfully to ship Viking Heat Sources. Previous heat sources shipped in this manner have not suffered problems with their emissive coatings; however, their storage times in the shipping container with a static helium atmosphere have been much less than the storage times of $\mathrm{VF}-3$ and $\mathrm{VF}-7$.

$$
\mathrm{VF}-3
$$

Referencing Figure 1, the following visual observations were noted about the platinum-20 rhodium clad: The domed ends of both the end cap and body appeared shiny in the area that had been in contact with the graphite cradle. There were some isolated spots of brownish discoloration distributed in a random pattern on both domed ends. The domed ends were discolored from a region just beyond the graphite contact line down the sidewall to a line which would approximate the upper boundary line of the machined area of the cap and the beginning of the coated area of the body. The discolored area appeared to have gradients of color. The areas nearest the weld zone on the cap and the coating line of the body were darker than the areas near the graphite. This probably reflects the thermal gradient proceeding from the sidewall to the area of the cap in contact with the graphite, which acted as a heat sink. 
The area from the machined portion of the cap to the machined portion of the body was not as shiny as the domed ends but was brighter than the other metallic surfaces. The area that was electrolytically etched with sodium hypochlorite prior to welding was smoother than the machined area and appeared slightly darker. The weld zone itself appeared to have a bluish tinge. Between the machined area of the body and the top of the coating on the sidewall, another discolored area similar in appearance to the sidewall of the end cap was present. Where the coating had flaked from the body, the base metal appeared dark gray.

The interior surface of the clad was also discolored. It had a uniform dull gray appearance except for the weld zone bordered by the machined areas of the cap and body. The weld zone was brighter except for the lines marking the separation of the weld from the heat affected zone. These lines were darker than the rest of the weld zone.

When the clad was removed from VF-3, a powdery substance was found at the vent hole location. X-ray analysis of this black powder indicated it was $\mathrm{Ta}_{2} \mathrm{O}_{5}$.

$$
\mathrm{VF}-7
$$

The outer surface of this clad was very similar to that of VF-3. The following differences were observed: the sidewall of the cap from the graphite contact line to the machined portion, the band of the body between the machined portion and the coating, and the domed end of the body were much darker than the similar areas of VF-3. There was a color gradient up the sidewall of the cap and the dome of the body of VF-7 very similar to that observed for $V F-3$, except that it was much darker in color even at the top of the end cap and body dome.

The surface of the VF-7 body where the coating had flaked off appeared to be covered by a black powder, rather than simply discolored as was the body of $\mathrm{VF}-3$. Additional portions of the coating could be flaked off the sidewall of the body and again the black powder was present on the parent metal. The coating near the bottom domed end, however, could not be easily flaked off. 
The condition of the interior of the VF-7 clad is best explained by reference to Figure 2. It is different from the interior surface of the VF-3 clad. The body of the VF-7 clad had a yellowish appearance on the sidewall with the domes having a color gradient ranging from dark gray above the weld zone to a light gray near the top. The weld zone itself was yellowish with a blue border separating the weld from the rest of the heataffected zone. 


\title{
DETAILED OBSERVATIONS
}

\author{
Pt-20 Rh Clad
}

A. $\mathrm{VF}-3$

Figure 3 shows the top of the VF-3 clad end cap that had been in contact with the graphite cradle. The surface has obviously been abraded and some reaction zones are present. Figure 4 shows an enlarged portion of one of the light areas observed in Figure 3. Energy Dispersive X-ray Analysis (EDX) identified this material as being rich in aluminum with some evidence of tantalum being present. The presence of aluminum is the result of some loose surface particles of the emissive coating falling into the graphite cradle and being put in intimate contact with the surface of the clad material where they imbedded themselves. One of the dark areas observed in Figure 3 is shown at a higher magnification in Figure 5. The most intense impurity element observed in this area is tantalum. Aluminum and trace quantities of iron are also present.

The area shown in Figure 6 is on the sidewall portion of the end cap that sits in the graphite cradle. This area appears to be the same as it was prior to encapsulation.

One of the dark brown spots that was observed in this area during visual examination is shown in Figure 7. The bright area on the right-hand side of Figure 7 corresponds to the visually observed brown spot. Closer analysis of this area showed it to be alumina particles that were imbedded in the surface. Tantalum was also present in this area. The foreign objects sitting on the surface of the area shown in Figure 7 are composed primarily of silicon.

At an area of the end cap approximately half-way between the weld zone and the area which was in contact with the graphite cradle, the surface is observed to be significantly different from those observed previously. As shown in Figure 8, the surface is much rougher and foreign material is located at or near grain boundaries. This material contains silicon and calcium. Tantalum is also observed as a foreign element on the surface of the platinum-20 rhodium end cap in this region. 
In an area of the end cap that was located just above the weld zone, no foreign material was visually observed (Figure 9), but an EDX analysis of the surface showed aluminum, tantalum, and manganese to be present.

Figure 10 shows a typical area of the weld zone. The weld grains, the line marking the boundary between the weld and the heataffected zone, the grains in the heat-affected zone, and some of the grains on the sidewalls of both the end cap and clad body are decorated with foreign material. Figure 10 shows the reaction at a grain boundary in the weld. The boundary appears to be much wider than normally observed. The reaction zone contains manganese and aluminum.

Figure 12 shows the reaction zone at the weld/heat-affected zone interface. The zone shown at a higher magnification in Figure 13 appears to be a "slush" zone full of foreign material and contains manganese and aluminum.

Figure 14 shows an area of the clad sidewall where the emissive coating had flaked away. The surface roughness is not entirely due to the grit blasting prior to coating; and at higher magnification (Figure 15), it appears that a reaction layer is beginning to form on grains which appear much coarser than grains that have only been grit blasted (Figures 16 and 17). An EDX analysis of this surface of VF-3 indicates the presence of aluminum, tantalum, iron, and copper.

The powder found on the inside of the clad was also examined. Figure 18 shows a low magnification micrograph of a random sample of the powder. In addition to $B-\mathrm{Ta}_{2} \mathrm{O}_{5}$, flakes of $\mathrm{T}-111$ metal were also found in the powder. Figure 19 shows a sample of the powder at a higher magnification.

B. $V F-7$

The area of the end cap of VF-7 which was in contact with the graphite cradle was not as shiny as the same area of VF-3. Figure 20 shows a portion of this area of VF-7. This surface has a different texture than that observed previously on the VF-3 sample and a higher magnification micrograph of this area (Figure 21) shows a dispersion of what appears to be 
sma11 particles on the surface. EDX analysis of this area showed that aluminum and manganese were present.

Figure 22 shows the interface on the end cap where the contact line of the graphite cradle ends. The important features of this micrograph are detailed in Figure 23. The darker areas of the sidewall of the end cap are the result of an etching effect and a much greater concentration of the small particles on the surface. This is shown in both Figures 23 and 24 . The color gradient observed during the visual examination of the end cap is explained in Figure 25. This micrograph shows the random dispersion of particles graduated into a rather uniform coating on the clad surface. This gradation is evident in the micrograph and is the cause of the color gradient. The coating was analyzed using EDX and was found to contain aluminum, manganese, tantalum, iron, and silicon.

Visual examination of the $\mathrm{VF}-7$ clad indicated that like the VF-3 clad, the weld zone and the areas immediately adjacent to it appeared bright and shiny. Figure 26 shows a typical section of the weld zone. The area to the left of the weld zone is the bottom portion of the clad end cap, while the area to the right corresponds to the clad body. A close examination of the shiny area between the weld and the dark area of the end cap shows some very unusual features. Figure 27 shows a typical area in the "transition zone". The uniform coating found on the sidewall of the end cap ends at the top of this micrograph. In this transition zone, surface texturing is visible, along with reaction zones in the grain boundaries. Pores found on the surface and the small particles found dispersed in a random pattern on the surface are rich in aluminum and manganese. The area directly above the weld does not have particle dispersion or surface texturing present; instead, as Figures 28, 29, and 30 show, grain boundary reaction zones are present and the surface texturing has proceeded to the point where whatever was causing the texturing has left the surface, leaving a high concentration of sma11 pores well distributed across the sample area.

Figures $31,32,33$, and 34 show that the weld zone is similar in appearance to the area immediately adjacent to it. Reaction zones are present in essentially all the grain boundaries. Porosity is also present in the weld but not as extensively as found in the adjacent area. Some of the weld grains have 
porosity uniformly distributed throughout them (Figure 33), while in others only small isolated zones of porosity are visible (Figure 34).

Figure 35 shows the backside of the VF-7 clad weld as well as the sidewall of the clad body. Viewed from right to left, the following features are observable on the micrograph: the etched area of the end cap, the weld, the etched area of the clad body, the machined area of the clad body (vertical machine lines), and the sidewall of the clad body. Figure 36 shows the weld zone in greater detail. The grain boundaries' also appear to be decorated on this side of the weld. Figure 37, however, shows that the decoration is somewhat of an optical effect caused by alternating areas of grain boundary separation and areas of normal grain boundary contact. Some isolated impurity particles are also found along the grain boundaries.

Figure 38 shows the etched zone between the weld and machined area of the clad sleeve. Grain boundary separation seems to be quite prevalent in this area. Figures 39 and 40 show this effect in greater detail. Also visible in these micrographs are some of the impurity particles located at isolated spots along some of the grain boundaries. The apparent grain boundary separation is probably the effect of the electrolytic etch.

Figures 41 and 42 show the machined area of the clad body. Some isolated grain boundary separation is observed in this area. The grain surfaces are not smooth, and foreign particles are found on some of them (Figure 43).

The sidewall of the body (Figure 44) has a thin film on the surface. This can better be seen in Figures 45 and 46, which show that under the film the surface grains are beginning to develop a texture and some form of grain boundary etching is taking place.

The sidewall of the end cap (Figure 47) exhibited porosity in the grains and boundary reaction zones.

A sample of the weld was cross-sectioned and examined using normal optical metallographic techniques. As Figure 48 shows, no unusual features were visible at this magnification or even at $200 \mathrm{x}$. A neighboring portion of the weld was mechanically 
fractured by bending. Figure 49 shows the cross-section of the fractured weld zone as seen on the SEM. The reaction zone seen earlier in the grain boundaries of the surface extends throughout the weld zone cross-section at all the grain boundaries. This can better be seen in Figures 50 and 51 . Also seen in Figure 51 is another unusual feature: the concentration of impurities in a low-density area of the grain. Some porosity is also present in the weld along with impurity particles such as those observed on the cross-sectional surface shown in Figure 52. These inclusion particles are rich in silicon.

Returning to the outside of the clad and referring back to Figure 26, the area to the left of the weld zone represents the top of the clad body. The dark band in this area corresponds to the light zone observed in the same approximate area of the VF-3 clad. Physically, these zones are located at the interface between the area that was only dress machined and the area that received the electrolytic etch prior to welding. Figure 53 shows the dark band of $\mathrm{VF}-7$. It appears to be a weld slush zone that has a uniform distribution of aluminum on its surface with some localized areas of high aluminum concentration as shown in the aluminum X-ray map of Figure 54. Figure 55 shows the rather sharp interface that exists between the dark band and the shiny area of the clad body. This bright area as seen in Figures 56 and 57 is exactly the same as the corresponding area of the end cap. The next area observed on the body is a transition zone. This zone, seen in Figures 58 and 59, is again very similar to that observed earlier on the end cap.

Between the transition zone and the area of the body that was coated is another dark band as seen in Figure 60. This dark band apparently marks the end of the reaction zone that appeared at the clad/coating interface. This reaction can best be described as a film that appeared porous at the top of the clad sidewall where the emissive coating began, but grew thicker and more uniform as it proceeded down the sidewall (Figure 61). A scratch was deliberately made with a steel probe at an area where the film appeared uniform and thick. This scratch failed to completely remove the film from the clad surface (Figure 62). High spots on the film (Figure 63) were found to have high concentrations of aluminum. This film was analyzed using $X$-ray diffraction, emission spectroscopy, and EDX analysis. The X-ray 
diffraction analysis indicated that the film was primarily a single-phase Pt-Rh alloy very similar in composition to the Pt-20 Rh clad material. Emission spectroscopy and EDX confirmed that the film was primarily $\mathrm{Pt}-\mathrm{Rh}$ but also found aluminum, silicon, manganese, iron, and tantalum impurities present along with some trace amounts of other impurities.

\section{EMISSIVE COATING}

\section{A. $V F-7$}

Portions of the emissive coating that had flaked off the clad were also examined. For comparative purposes, Figures 64, 65, and 66 show the outside and inside surfaces of the coating simultaneously. In these micrographs, a very definite difference is observed in the inside surface of the coating. It appears that as the reaction film was forming at the clad/coating interface, it altered the interface bond and in effect pushed the coating away from the clad surface. High spots of the reaction layer are still adhering in a sparse pattern to the inside surface of the emissive coating, and this accounts for the visible difference of the coating surfaces.

\section{B. $V F-3$}

The emissive coating of the VF-3 clad appeared significantly different from that of the VF-7 clad. Figure 67 shows the outside surface of the coating of VF-3. The coating was charging* and could not be examined without a carbon coating. This effect was probably caused by the oxygen contamination. Figures 68 through 70 show the outside of the coating after it was

\footnotetext{
" "Charging" in SEM analyses is an effect caused by the nonconductive nature of certain materials (insulators). This can, in many cases, be alleviated by coating the material with a conductor such as carbon.
} 
carbon coated. The coating surface appears very similar to the sample from VF-7. The inside of the coating (Figure 71), however, is different. It has no reaction zone, and the surfaces of the particles are rougher. EDX analysis shows calcium, chlorine, coppper, and chromium impurities on the surface; and, thus, it can be speculated that the oxygen contamination assisted in some sort of reaction that effectively eliminated the clad/coating bond and permitted the coating to separate from the clad. The fact that the coating surface was chemically changed is substantiated by the fact that it had to be carbon coated for SEM examination. The coating from VF-7 did not have to be carbon coated for examination. 
The main thrust of this investigation was to identify the reason or reasons why the emissive coating flaked off the Pt-2n Rh clads of Viking Heat Sources VF-3 and VF-7. Both heat sources were exposed to unusually long storage times but somewhat different environments at the end of the storage period. VF-7 was exposed to only vacuum and a helium atmosphere, while VF-3 at some time during its life was exposed to either water vapor or air contamination. Both heat sources after encapsulation were stored in exactly the same manner for approximately 60 days. The heat sources were positioned in two POCO AXF-5Q graphite cradles in 304 stainless steel containers. The interior of these containers was protected from the outside environment by a double delta compression seal of an annealed copper gasket.

Heat Source VF-3 was never passed into the submarine facility at Teledyne Isotopes, while $\mathrm{VF}-7$ was. The operation employed to pass the heat source into the submarine facility involves a vacuum pump-down of the transfer pass box at which time no type of cooling is used on the outer surface of the storage container. During this operation, a contact thermocouple is used to monitor the sidewall temperature of the storage container. The temperature of the sidewall is not supposed to exceed $1000^{\circ} \mathrm{F}$. This operation, however, did expose VF-7 to a higher temperature than that of $\mathrm{VF}-3$.

While the above review shows that the histories of both heat sources are somewhat different, the results of the present examination show that the emissive coating flaked off both heat source clads because of essentially the same reason: the coating/ clad interface was altered. The modification of the interface changed the bonding characteristics of the coating and effectively made it behave like a fragile ceramic shell. The mechanism that effectively altered the clad/coating interfaces appears to have been vapor transport in nature. The clad/coating interface of both heat sources appears different because of two significant variables: one (VF-7) was exposed to higher temperatures, while the other (VF-3) was exposed to an atmosphere contaminated at some time by either water vapor or air. The variables could have accelerated or modified a vapor transport phenomenon that naturally occurs in the reducing environment present in this storage system.

Observations made during this investigation have not been previously reported, but earlier tests did not simulate the 
present storage system. No data exist on an $\mathrm{Al}_{2} \mathrm{O}_{3} / \mathrm{Pt}-\mathrm{Rh} / \mathrm{Ta}$ alloy/stainless steel/graphite system maintained in a static helium atmosphere. Early engineering studies performed by Atomics International and TRW Systems were designed to study diffusion couples of some of the materials used in the present system, but did not simulate either the complete system or the system environment.

The Atomics International datal were gathered on a series of diffusion couples of $\mathrm{T}-111 / \mathrm{Pt}-20 \mathrm{Rh} / \mathrm{platinized} \mathrm{Al}_{2} \mathrm{O}_{3} / \mathrm{AXF}-5 \mathrm{Q}$ graphite. These couples, however, were tested in a dynamic hard vacuum $\left(\sim 10^{-7}\right.$ to $10^{-8}$ torr) at temperatures in excess of the Viking temperatures. These tests could not evaluate vapor phase transport, since very few residual gases were present in a system that was being dynamically maintained at $10^{-7}$ to $10^{-8}$ torr. Any volatile species formed in the test system were likely to migrate away from the couple and be pumped away from the test system before they could accumulate to the extent necessary to initiate reactions. This premise is supported by the data ${ }^{2}$ accumulated at TRW Systems. In an early set of experiments using diffusion couples of $\mathrm{Pt}-10 \mathrm{Rh} / \mathrm{PAS}-\mathrm{Al}_{2} \mathrm{O}_{3} / \mathrm{T}-111$, no gross interactions were found for periods up to 30 days at $2600^{\circ} \mathrm{F}$ in a dynamic vacuum environment of approximately $10^{-5}$ torr.

In a later study, however, the same test couple was welded in a tantalum can with a residual static vacuum of $5 \times 10^{-5}$ torr. This couple showed a marked interaction in 18 days at test temperatures as low as $2200^{\circ} \mathrm{F}$. One of the conclusions of this study was that vapor-phase transport of one or more of the chemical species present played a dominant role in the reaction process.

Another phase of the TRW Systems study involved the study of reactions between samples of tantalum and platinum metal which were separated by an 0.06 -in. gap. One particular experiment showed that, after 30 days at $1600^{\circ} \mathrm{F}$, considerable reaction occurred. At least four Pt-Ta phases were present on the platinum with no reaction zone observed on the tantalum. The total penetration depth was approximately $120 \mu \mathrm{m}$ with an intermetallic zone of $46 \mathrm{um}$. This zone was primarily $\mathrm{Pt}_{3} \mathrm{Ta}$ with a narrow band of $\mathrm{Pt}_{2} \mathrm{Ta}$ at the interface. The operating mechanism that was postulated as causing these results was called an "oxygen molecular shuttle". In this process, oxygen and tantalum combined to form gaseous $\mathrm{TaO}$ and $\mathrm{TaO}_{2}$. These species diffused to the platinum, where tantalum-platinum intermetallic compounds were formed. The oxygen atoms were released to return 
to the tantalum and the process repeated itself. The oxygen which initiated the reaction came from the $10^{-4}$ torr residual atmosphere which was present in the test capsule.

In a static environment, therefore, $\mathrm{Pt}-20$ Rh can react with the other materials present. In a reducing atmosphere, Darling ${ }^{3}$ and his associates at Mathey-Bishop have also shown that the metal released by the dissociation of a refractory can be removed by platinum. The slightest dissociation will evolve oxygen, and the reaction rate will be controlled by the rate of gas removed. Darling has also shown that an $\mathrm{Al}_{2} \mathrm{O}_{3}-\mathrm{Pt}$ reaction couple will proceed faster in argon rather than vacuum, since the aluminum alloy will develop in an inert atmosphere but will evaporate in vacuum as soon as or even before it is formed.

The other factors that will affect reactions of platinum and its alloys are the impurity concentrations of the noble metal or the other materials present. Below $1000^{\circ} \mathrm{C}$, platinum is often contaminated by impurities present in ceramics. These impurities are primarily iron, silicon, and sodium compounds which are thermodynamically unstable. Walker et al. ${ }^{4}$ have suggested that platinum metals in a neutral atmosphere reduce or decompose iron compounds and iron is vaporized to the platinum metals according to the scheme of Baak and Hornyak. ${ }^{5}$

$$
\begin{aligned}
2 \mathrm{Fe}_{2} \mathrm{O}_{3}+\mathrm{Pt} & \rightleftharpoons 4 \mathrm{FeO}+\mathrm{PtO}_{2} \\
2 \mathrm{FeO}+\mathrm{Pt} & \rightleftharpoons 2 \mathrm{Fe}+\mathrm{PtO}_{2} \\
2 \mathrm{Fe}+2 \mathrm{Fe}_{2} \mathrm{O}_{3} & \stackrel{\mathrm{Pt}}{\rightleftharpoons} 6 \mathrm{FeO}
\end{aligned}
$$

In the last reaction, platinum is indirectly involved.

In an argon atmosphere, contamination with iron proceeds at such a fast rate that the initial steps of the above process occur but are not observed.

The above data indicate that vapor transport reactions are a distinct possibility. The data gathered during examination of the Viking clads, VF-3 and VF-7, support the vapor transport mechanism as a viable cause of most of the phenomena that have been observed. 
Reviewing the previously presented data on VF-7, several features can be recalled that would support the premise that vapor transport mechanisms are operating. These would include the fact that a gradient of foreign material was observed on the sidewall of the end cap. The gradient was probably the result of the volatile species following the thermal gradient. The greatest reaction would occur at the edge of highest temperature. The material found on the sidewall contained primarily aluminum, silicon, manganese, tantalum, and iron. The only way for species such as tantalum to appear on the outside surface of the clad would be by a vapor transport mechanism.

The unusual appearance of the interior of the clad, which was for the most part not in contact with the T-111, would also support the operation of vapor transport mechanisms. The appearance of a very thin film on the interior sidewall of the clad seems to suggest that perhaps an "oxygen molecular shuttle" was in operation. Since the temperature and environment of the present system are different from those used in the TRW study, the effect would be somewhat reduced. The film, the grain texturing, and grain boundary etching could be the initial result of the "oxygen molecular shuttle". The film did discolor the clad interior; and yet, visually, the T-11l appeared unaffected. This would imply that the reaction was taking place on the clad surface and not the T-111 surface. This same phenomenon was observed in the TRW study.

The film found between the clad surface and the emissive coating appears to have been the result of a vapor transport mechanism also. The coating by nature is not impervious to gases, and a reaction mechanism could have been initiated by the gaseous environment of the storage container. The fact that the coating was intact and appeared to have been moved away from the clad strongly suggests a vapor transport reaction. The observation that high spots of the interface film were attached to the coating would also suggest that a void space was created between the coating and clad and abnormal growth of the film created a high spot, which put a tensile load on the coating. The detection of tantalum on the film would also suggest that vapor transport is occurring.

The weld zone area also possessed some unique features to support a vapor transport reaction mechanism; these will be discussed at some length later in the report. 
Integrating into this discussion the observations of VF-3, similarities can be noted. Figure 72 shows a portion of what was previously called the slush zone of the VF-3 clad weld. Figure 73 is a section of that slush zone at higher magnification. X-ray maps of this area show the appearance of iron (Figure 74), chromium (Figure 75), nickel (Figure 76), manganese (Figure 77), tantalum (Figure 78), and aluminum (Figure 79). Tantalum could have only reached this surface by vapor transport. The fact that the constituents of stainless steel are also present would suggest that the stainless steel storage container is also involved in the complicated vapor transport mechanism. Visual observations of the interior of Viking shipping containers indicate that they are discolored after use. Since no other heat sources suffered any deleterious effects, this discoloration was thought to be a naturally occurring effect due to temperature and was not investigated, Aluminum in an area away from the coating is also very difficult to explain by any other mechanism than vapor transport.

The fact that there are some differences between the two clads is not surprising. VF- 7 had been maintained in a static helium environment for most of its life and had seen a higher temperature than $\mathrm{VF}-3$. VF-3, on the other hand, was exposed to $\mathrm{O}_{2}$ and possibly $\mathrm{H}_{2}$ at some point during its life. No other unusual events or environments were reported for either heat source.

The higher temperature can effectively increase reaction rates, while the introduction of $\mathrm{O}_{2}$ and $\mathrm{H}_{2}$ can also alter the appearance of reaction products and create new ones. If indeed no other perturbations occurred to either heat source, the higher temperature seemed to have the greatest effect on the vapor transport phenomena as observed on the clad end caps and coating/ clad interface. Such effects were not noted previously, since no other Viking heat sources were maintained in the shipping container environment for as long a period of time as VF-3 and VF-7. The storage time of these two sources was estimated to be 50 to 60 days; and, obviously, that long a period of time permits the vapor transport mechanism to cause a significant effect. Also, the temperature increase that occurred during the transfer operation at the Teledyne Isotopes facility could have resulted in some previously unobserved deleterious effects.

Since these phenomena occurred at relatively low temperatures, the primary actuators were probably impurities that were present in the system components. As stated earlier, Walker and his 
associates" showed that iron impurities in $\mathrm{Al}_{2} \mathrm{O}_{3}$ can initiate a reaction with platinum. At first glance, it would appear that the system was composed of all high-purity elements; however, in light of the observations made on the clads, it was decided to investigate the purity of the system.

The graphite cradles were the first system components to be examined. These parts were heat treated in vacuum for approximately $1 \mathrm{hr}$ at $1000^{\circ} \mathrm{F}$ prior to use in the shipping container. This temperature is a low temperature for graphite outgassing. Earlier tests ${ }^{6}$ performed at Mound Laboratory in support of the Pioneer Program showed that water vapor outgassed from a sample of POCO graphite at temperatures up to approximately $1140^{\circ} \mathrm{F} ; \mathrm{CO}, \mathrm{CO}_{2}$, and organic species were observed as outgassing products up to $1500^{\circ} \mathrm{F}$. A recent review ${ }^{7}$ of graphite outgassing presented some quantitative numbers for the outgassing constituent of Poco graphite. A sample of previously untreated POCO graphite was heated in the temperature range of 620 to $1340^{\circ} \mathrm{F}$, and the offgas was composed of the following constituents: $2 \% \mathrm{H}_{2}, 80 \% \mathrm{CO}, 13 \% \mathrm{CO}_{2}$, and $5 \%$ hydrocarbons. The offgassing of $\mathrm{CO}$ continued even as the sample was, heated to $3680^{\circ} \mathrm{F}$. A total of $7.5 \times 10^{-4}$ torr-1iters of gas was evolved per square centimeter of surface area as the sample was heated from 620 to $3680^{\circ} \mathrm{F}$.

Based on the above studies, it can be concluded that $\mathrm{CO}$ and $\mathrm{CO}_{2}$ can still be offgassed from the Viking graphite cradles and CO would be the major species evolved at the Viking storage temperature.

The platinized alumina coating material was furnished to Mound Laboratory as a GFE item. Because it was obtained in this manner, no analytical tests were performed on the material prior to use. TRW Systems processed the starting material; and in their compatibility report, they list what can be assumed to be a typical impurity analysis of the feed material prior to plasma arc spraying (PAS) and the coating after spraying. These data are presented in Table 1 along with data obtained during this present study at Mound Laboratory.

It is quite obvious that the feed powder used by Mound Laboratory was different from the typical material used by TRW. The material furnished Mound had very high impurity levels with iron and silicon being the major impurities. Several other observations 
Table 1

PLATINIZED ALUMINA ANALYTICAL DATA ${ }^{a}$

\begin{tabular}{|c|c|c|c|c|}
\hline \multirow[b]{2}{*}{ Element } & \multicolumn{2}{|c|}{ TRW Analysis } & \multirow{2}{*}{$\begin{array}{l}\text { Mound Analysis } \\
\text { before PAS }\end{array}$} & \multirow[b]{2}{*}{ Coating from VF-7 } \\
\hline & before PAS & after PAS & & \\
\hline $\mathrm{A} 1$ & $\begin{array}{c}\text { Major } \\
\text { Constituent }\end{array}$ & $\begin{array}{c}\text { Major } \\
\text { Constituent }\end{array}$ & $\begin{array}{c}\text { Major } \\
\text { Constituent }\end{array}$ & $\begin{array}{c}\text { Major } \\
\text { Constituent }\end{array}$ \\
\hline $\mathrm{Ca}$ & -- & 0.027 & 0.03 & 0.02 \\
\hline $\mathrm{Cr}$ & -- & 0.063 & 0.004 & $<0.005$ \\
\hline $\mathrm{Cu}$ & 0.002 & 0.17 & $0.03-0.002$ & 0.01 \\
\hline $\mathrm{Fe}$ & 0.005 & 0.022 & $0.1-0.05$ & 0.03 \\
\hline $\mathrm{Ga}$ & 0.001 & 0.0058 & 0.02 & 0.004 \\
\hline $\mathrm{Mg}$ & -- & 0.033 & $<0.0005$ & $<0.005$ \\
\hline Mn & -- & 0.023 & 0.002 & 0.02 \\
\hline $\mathrm{Ni}$ & -- & 0.0059 & 0.02 & 0.015 \\
\hline Pt & 1.0 & 0.41 & $>0.6$ & $>0.6$ \\
\hline $\mathrm{Rh}$ & -- & $<0.01$ & N.D. & 0.05 \\
\hline Si & 0.10 & 0.42 & $0.1-0.05$ & 0.2 \\
\hline $\mathrm{Ti}$ & -- & 0.0040 & $0.006-0.0005$ & 0.002 \\
\hline $\mathrm{Zn}$ & - & 0.060 & -- & -- \\
\hline $\mathrm{Zr}$ & -- & - & $0.01-0.005$ & - \\
\hline Mo & - & -- & 0.02 & 0.006 \\
\hline B & - & -- & $0.006-0.0005$ & 0.005 \\
\hline
\end{tabular}

${ }^{a}$ Concentrations are expressed as weight percent. 
can be made with the data of Table 1. The TRW analysis showed that immediately after plasma arc spraying the amount of impurities and their levels had increased. The platinum concentration, however, had decreased. The coating sample from VF-7 showed an opposite trend. The fact that the concentration of iron decreased suggests that perhaps iron impurities were reacting with the Pt-20 Rh clad in the manner described earlier. The sample analyzed was taken from a portion of the coating that had cleanly separated from the clad, and yet rhodium was detected and the concentration of platinum present in the sample was the same as previously observed in the feed powder. These two observations would suggest that some platinum and rhodium vapor transferred to the coating. Manganese and silicon were also found at higher concentrations in the coating sample.

The impurity levels present in the Pt-20 Rh clad material were also substantially different than previous data had indicated. Again, the analytical data used for this material were supplied by the vendor. Table 2 lists the vendor analyses along with the results of the analyses performed during this study on the archive sample of the end cap of VF-7.

While the analytical results are surprising, they do serve to support the premise that impurities present in the heat source materials and storage container formed some sort of complicated reaction couple because of the long-time storage in the static environment.

Pioneer Heat Sources were fabricated with essentially the same materials and some of these sources were stored for long periods of time. Post-storage visual observations failed to detect any of the phenomena observed on $\mathrm{VF}-3$ and $\mathrm{VF}-7$. This does not rule out the pussibility that these reactions were taking place; however, if they were, they had no visible effect on the Pt-20 Rh clad surface.

A review of the Pioneer storage data showed that these heat sources were stored in a different manner than Viking heat sources. In addition to the materials present in the Viking storage containers, tantalum foils and felt were present in the Pioneer storage containers. These materials were positioned on the top surfaces of 
Table 2

\section{ANALYSIS OF Pt-20 Rh CLAD MATERIAL ${ }^{2}$}

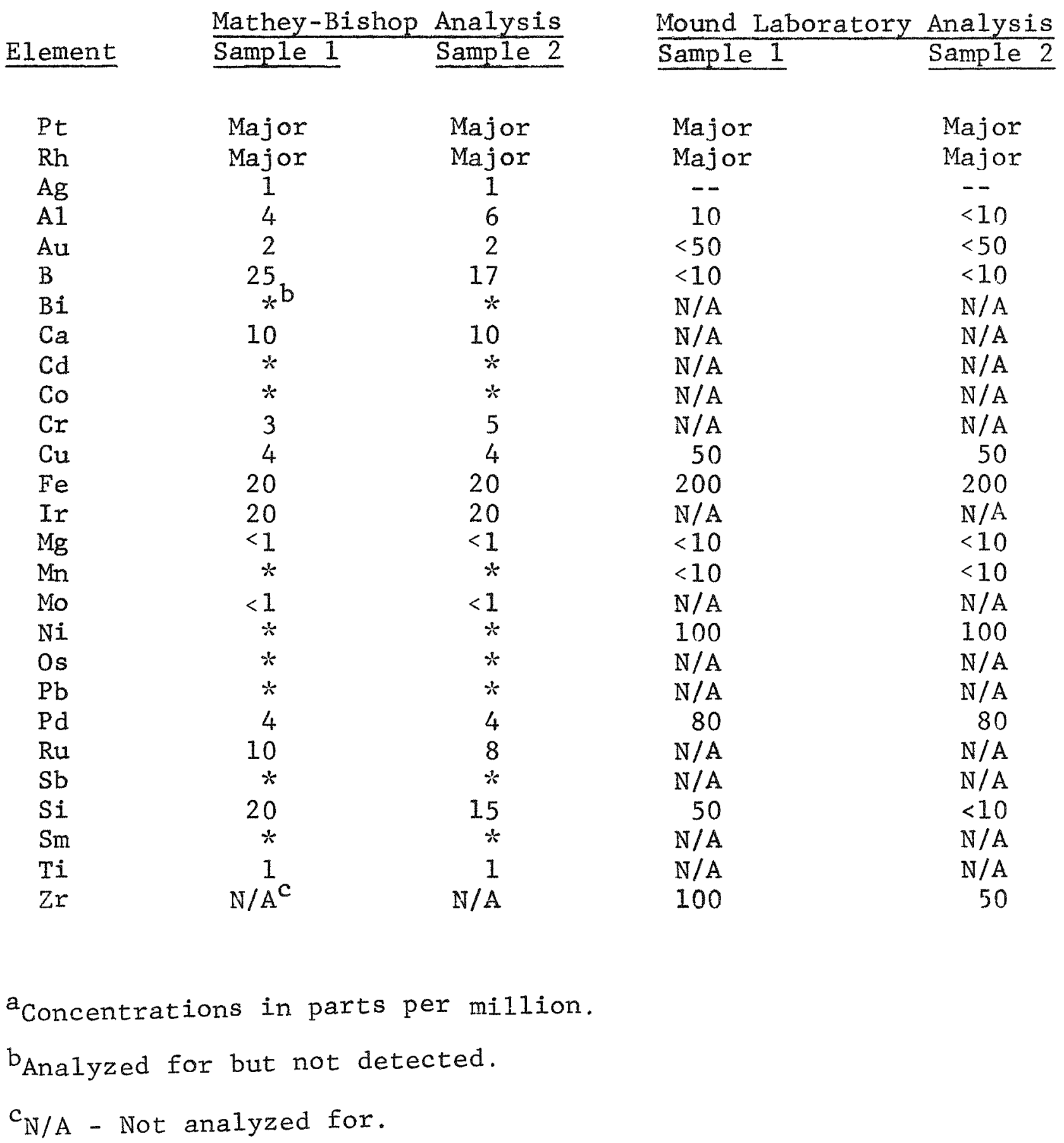


the graphite cradles. Since tantalum was present, it could have acted as a getter and prevented the phenomena that occurred on the Viking Heat Sources.

No data are available, however, concerning the post-storage condition of the tantalum components of the Pioneer storage containers and no detailed data are available on the Pioneer clads. Without these data a valid comparison of the two systems cannot be made. 
In addition to the examination of the VF-3 and VF-7 clads, several additional studies were performed. One of these studies involved heating a clad body in air to determine the effects that this treatment could cause. The sample used for this study was the clad body used for the post-example weld for VF-7 Remake. The sample clad in contact with graphite was placed in an air furnace and heated to $1350^{\circ} \mathrm{F}$. After $48 \mathrm{hr}$ at temperature the graphite, as expected, had disintegrated and the uncoated surfaces of the clad body were a blue-gray color, indicative of rhodium oxide. The coating appeared to be still intact. However, when the edge of the clad body was mechanically bent, small pieces of coating could be flaked off the surface. The sample was returned to the furnace to observe the effects from additional air exposure. After $122 \mathrm{hr}$ of additional heat treatment, the sample was removed from the furnace; and, upon visual examination, no further changes were observed in its appearance.

Portions of the clad body were examined using the SEM. Figures 80,81 , and 82 show the surface of the dome. The air atmosphere has resulted in oxidation of the impurities, which for the most part align themselves on the grain boundaries of precious metals. This resulted in the grain boundary etching effect. The grain surface coarsening is the result of the oxidation of the impurities on the surface of the grains. A sample of coating was flaked from the sidewall. It could not be examined without first carbon coating it. Figure 83 shows the outside surface of the coating. Foreign material is observed on this surface, and this material is rich in iron, silicon, and manganese. The most surprising feature observed during this examination was the sidewall surface of the clad where the coating was removed. This surface as shown in Figure 84 is very different from those observed previously on $\mathrm{VF}-7$ and $\mathrm{VF}-3$. Very little reaction has taken place.

There were essentially no similarities between this sample and $\mathrm{VF}-7$ and VF-3. In this sample, it seems that the reaction products volatilized away from the surface and no couple could be set up at the coating/clad interface. This was probably the result of both the air atmosphere and the fact that a static atmospheric condition did not exist. 
The final study concerned the weld zone. As was seen in Figures 10, 11, and 26 through 34, the weld and heat affected zones of both the $\mathrm{VF}-3$ and the $\mathrm{VF}-7$ clad were decorated with a reaction zone. This reaction zone was not confined to the surface but continued through the weld cross-section (Figures 49 through 52). An analysis of the surface of the reaction zone shows manganese as the major impurity. Figure 85 shows one of these zones present in the VF-3 clad weld, while Figure 86 shows the manganese $\mathrm{X}$-ray map of this area. Silicon, iron, and calcium impurities are also observed.

A detailed chemical analysis was performed on the weld zone, the machined area, and the top sidewall portion of the end cap of $\mathrm{VF}-7$. The results are listed in Table 3 . In comparing these results with those of the archive sample listed in Table 2, a greater-than-five-fold increase in manganese content is noted in the weld zone and machined zone samples; concentration in the end cap sample remained constant. The iron concentration is significantly reduced in the weld zone and the machined zone; however, no change is noted in the end cap sample. Nickel and copper concentrations have been reduced in the end cap sample; the aluminum concentration, however, has increased. Since the end cap sample was taken from a region where the graphite cradle acted as a heat sink, it did not see the higher temperatures that the other samples did. It also was in contact with the graphite and no straight vapor transport path was available. The reduction in nickel and copper concentrations in the end cap sample does suggest that the graphite contact did result in some effect; the aluminum pickup might be the result of loose alumina powder.

The manganese increase in the machined zone and weld zone samples apparently manifested itself by the surface decoration and grain boundary concentration.

One phase of the weld zone study was to determine if the change in the weld zone occurred as a result of the welding. To accomplish this task, samples of the post example weld for VF-6 and VF-7 and the post-example weld for VF-7 Remake were examined with the SEM.

Figures 87 through 90 show the appearance of the weld zone, and Figures 87 and 88 show the appearance of the etched area of the end cap from the post-example weld clad of VF-6 and VF-7. Figures 93 through 95 show the weld and Figure 96 the etched area of the end cap from the post-example weld clad of the VF-7 Remake. In all of these figures, it is obvious that none of 
Table 3

ANALYSIS OF VF-7 CLAD MATERIAL ${ }^{a}$

\begin{tabular}{|c|c|c|c|}
\hline Element & Weld Zone & Machined Zone & $\begin{array}{l}\text { End Cap } \\
\text { Sidewal1 }\end{array}$ \\
\hline Pt & Major & Major & Major \\
\hline $\mathrm{Rh}$ & Major & Major & Major \\
\hline $\mathrm{A} 1$ & 10 & $<10$ & 20 \\
\hline $\mathrm{Au}$ & $<50$ & $<50$ & $<50$ \\
\hline B & $<10$ & $<10$ & $<10$ \\
\hline $\mathrm{Cu}$ & 50 & 30 & $<10$ \\
\hline $\mathrm{Fe}$ & 40 & 40 & 200 \\
\hline $\mathrm{Mg}$ & $<10$ & $<10$ & $<10$ \\
\hline Mn & 50 & 50 & $<10$ \\
\hline $\mathrm{Ni}$ & 100 & 100 & 30 \\
\hline $\mathrm{Pd}$ & 50 & 30 & 100 \\
\hline $\mathrm{Si}$ & 50 & 50 & $<10$ \\
\hline $\mathrm{Zr}$ & -- & -- & 30 \\
\hline
\end{tabular}

${ }^{a}$ Concentrations in parts per million. 
the unusual features observed on similar surfaces of the VF-3 and VF-7 clads were found in these samples. This ruled out an effect that occurred during welding.

The next phase of the study involved simulating as close as possible the storage container environment to see if this caused the reaction. The two samples that were examined previously were placed in a 304 stainless steel container with graphite. The container was welded in $0.5 \mathrm{~atm}$ of helium. The welding atmosphere contained $17 \mathrm{ppm} \mathrm{O}_{2}, 1 \mathrm{ppm} \mathrm{N}_{2}$, and $1 \mathrm{ppm} \mathrm{H}_{2} \mathrm{O}$ at $1350^{\circ} \mathrm{F}$ for $143 \mathrm{hr}$. This specific test temperature was chosen because it was a possible maximum temperature to which the actual heat source could be exposed in the storage container.

When the couple was removed from test and opened, the interior of the stainless steel container was discolored. The observation was made that this discoloration was similar to that present on the interior surface of the actual heat source storage container. The container was then set aside for later examination if necessary.

Figures 97 through 99 show the weld zone of the post-example weld $\mathrm{VF}-6$ and $\mathrm{VF}-7$ clad sample. Figures 100, 101, and 102 show the etched area of the end cap, and Figures 103 and 104 show the machined area of the end cap of the same sample. It is quite obvious that some reaction has taken place. The surface of the post-example weld VF-7 Remake sample appeared identical to this sample.

Closer examination of the reaction material showed it to be aligned on grain boundaries and deep surface scratches. It is primarily manganese. While it appears somewhat different, visually, from the material found on VF-3 and VF-7, it is located in essentially the same areas where the previous reaction zones were observed. The reaction product seems to be diffusing to the surface from the interior of the sample.

Another feature observed in Figure 97 is the large bright area in the weld zone. This was not observed previously. In fact, most of the $\mathrm{AI}_{2} \mathrm{O}_{3}$ contamination that was observed on the sample prior to heating has disappeared. This would imply that some changes are occurring on the surface that have caused the particles to be removed. This one unusual area, however, is present. Closer examination of the area (Figures 105 and 106) shows it to be an imbedded particle which is rich in aluminum and calcium. 
There are some unusual features present in the area surrounding the particle. Some of the grain boundaries near the particle are free of the reaction product, while on one side of the particle there is a concentration of the reaction product. It seems that the reaction product has an affinity for the particle and was migrating to it. This is somewhat substantiated when the surface of the particle is examined (Figure 107), and it is observed that the product is distributed on the surface and in some areas interacting with the surface. This shows that in the presence of aluminum the reaction product tends to react further.

Since the fracture cross-section of the VF-7 weld showed that the reaction product extended throughout the weld cross-section, the post-example weld $V F-6$ and $V F-7$ was similarly fractured. Grain boundaries near the surface appeared as shown in Figures 108, 109, and 110. The grains were separated and particles were observed. These particles were similar to those observed on the surface. It also appeared that other impurities concentrated at the grain boundaries and these impurities formed somewhat of a slush zone. Unfortunately, the sample geometry prevented any $\mathrm{X}$-ray data from being accumulated. Further into the cross-section, what appeared to be unreacted particles were found as shown in Figures 111 and 112. At a grain boundary in the middle of the cross-section, the features observed in Figure 113 were found. In this figure, it seems that particles are being formed by a refinement process taking place at the impurity zone between parent grains. In the total cross-section, it seems that the different steps of the reaction mechanism are found.

To determine the influence of the stainless steel container on the reaction, a sample of the containex was mounted and examined using the optical microscope. Figure 114 shows an etched crosssection of the container, while Figure 115 shows a higher magnification picture of the inside edge. From these photographs, it appears that erosion of the inner surface wall is occurring and the stainless steel is apparently sensitized. SEM analysis of the same sample shows that chromium carbide is present in the grain boundaries. The interior side of the sample appeared to have a much greater concentration of the carbide as is shown. in Figures 116 and 117. In Figure 116, the heavy concentration of the carbide is shown to be present on the inside of the stainless steel. Figure 118 shows a typical grain structure near the outside edge. The carbide structure is not as predominant here as it is on an interior grain boundary. This suggests that carbon might be reacting with the interior of the container. 
SEM analysis of the interior sidewall of the stainless steel container verified a rather extensive reaction zone. Figures 119,120 , and 121 show the sidewa11. A typical unreacted sidewall surface would appear very similar to the surface shown in Figures 122 and 123. Since EDX analysis could not detect any unusual elements present on the reaction surface, a sample of the discolored area was analyzed using X-ray diffraction. The results of this analysis showed that the reaction product on the surface was carbon, an element that cannot be detected in normal EDX analysis.

The presence of carbon on the stainless steel surface confirmed the fact that graphite/stainless steel/Pt-20 $\mathrm{Rh}$ formed a reaction couple in the static helium atmosphere. The fact that a reaction product is present on the surface of the $\mathrm{Pt}-20 \mathrm{Rh}$ portion of this couple after a short period of time would suggest that the same reaction product could be present on all Viking clads. The fact that the appearance of the reaction product on the VF-3 and VF-7 clads was different from that observed in this study suggests that other materials present in the heat source system contribute to the reaction. 
CONCLUSIONS

The present investigation was undertaken to determine why the emissive coatings of the Viking Heat Sources VF-3 and VF-7 had flaked off the Pt-20 Rh clad. During the course of the investigation, two additional, unusual phenomena were observed. These included a surface reaction zone on the uncoated Pt-20 Rh surfaces and grain boundary reactions in the weld zone of the clad.

It seems that all three phenomena were the result of a complicated reaction couple that involved the heat source materials and storage container materials and environment. Vapor transport mechanisms were responsible for all the phenomena which were observed. The vapor transport mechanisms were probably initiated because of the impurities that were in both the heat source and storage container materials. The mechanisms resulted in significant changes in the heat sources because vapor transport was allowed to continue in a static environment for an unusually long period of time. (In most instances, Viking heat sources were maintained in the storage container for a period of less than 14 days.)

The fact that the reactions were more severe on VF-7 would indicate that the thermal excursion to which it was exposed during the normal transfer operations at Teledyne Isotopes significantly accelerated the rates of the reactions. This is hard to conceive, because the transfer time and temperature are reportedly not that severe; however, the transfer operation is the only reported significantly different operation to which $\mathrm{VF}-3$ was not exposed.

It appeared that three different reactions were taking place. A reaction film was formed between the clad and the coating. Volatile species were deposited on the uncoated Pt-20Rh surfaces and the fact that they followed the thermal gradient would suggest that they were reacting with the surface impurities present on the Pt-20 Rh. The weld zone area, which was also uncoated, appeared significantly different. It had a much cleaner surface. This area was machine dressed, cleaned, and electrolytically etched prior to welding; therefore, its surface was effectively much different from the rest of the $\mathrm{Pt}-20 \mathrm{Rh}$ clad. 
The weld zone did not, however, escape reactions. It appeared that impurities aligned along the grain boundaries in this zone reacted with the vapor species present in the system. It was shown that the Pt-20 Rh/stainless steel/graphite couple could result in a similar reaction. This reaction product or the fact that it extends through the weld zone should have no deleterious effect on Viking heat sources. An effect of this type significantly reduces the strength of a material and can result in cracking at high temperatures. The Viking clad, however, is not a structural member and the only extreme temperature excur sion that it could be exposed to would occur during re-entry and would last for a short period of time. If cracking of the clad occurred at this time, a situation would occur that would be no worse than some of the possible re-entry modes that result in a clad melt.

While it was determined that vapor transport caused most of the phenomena which were observed on $V F-3$ and $V F-7$, the exact vapor transport reactions were not determined. Similar types of reactions have been reported in the literature, as was detailed earlier. Most of these phenomena were observed in systems maintained at higher temperatures; this does not, however, preclude the fact that they could not happen at lower temperatures. The present system is unique in its physical makeup and the fact that more impurities are present in this system than in the highpurity systems tested at higher temperatures. Chaston ${ }^{8}$ reports that platinum supplied to industry contains less than 200 ppm of total impurities. Pt-20 Rh clad used in the present system had a significantly greater amount of impurities. When the impurities present in the alumina are added, the total system impurity level becomes significant. Add to those impurities the availability of CO in a static enviromment and it seems entirely possible that the phenomena observed in this study can be initiated and continue unchecked until the system's environmental conditions are altered.

The exact vapor transport reactions which occurred were not identified. They appeared to be complex; and extensive, additional studies and analyses would be required to classify them. These studies were not initiated because the Viking Heat Source Production Program is effectively completed; and, based on the observations made on earlier units which did not have longstorage times, the VF-7 Remake and VF-8 heat sources should not suffer the same fate as did VF-3 and VF-7, since their storage times were less than one week. 
The information gathered during this study, however, does indicate that detailed materials studies simulating actual storage and operational environments should be performed during future heat source development programs. This would be especially true for future heat source programs involving platinum or platinum alloys.

The information gathered during this study, however, does indicate that detailed materials studies simulating actual storage and operational environments should be performed during future heat source development programs. This would be especially true for future heat source programs involving platinum or platinum alloys. 


\section{ACKNOWLEDGMENT}

The work of the Heat Source Development and Fabrication Group in preparing the samples for examination and conducting, the special tests was an integral part of this study and is gratefully acknowledged. 


\section{REFERENCES}

1. R. G. Brengle, Large Radioisotope Heat Source Capsule Program. Topical Report No. 11. Materials Compatibility, AI-AEC-12966, Atomics International, Canoga Park, Calif. (July 3, 1970), 108 pp.

2. Development of a High-Temperature Vented Radioisotope Capsule. Volume 3. Preliminary Compatibility Testing, TRW(A)-11069-0068, TRW Systems Group, Redondo Beach, Calif. (August 1972), $85 \mathrm{pp}$.

3. A. S. Darling, G. L. Selman and R. Rushforth, Platinum Metals Review, 14:2, 54; 14:3, 95; 14:9, 124 (1970).

4. B. E. Walker, C. T. Ewing and R. R. Miller, Rev. Sci. Instr., 33:10, 1029 (1962).

5. T. Baak and E. W. Hornyak, Jr., J. Am. Ceram. Soc. 44:11, 541 (1961).

6. R. E. Zielinski and D. E. Etter, Investigation of Supplementary Materials Used in the Pioneer RTGs and Capsule Shipping Containers, MLM-1882 (Jan. 12, 1972), 24 Pp.

7. A Feasibility Study of the Use of Graphite in High-Vacuum Applications. Summary Technical Report, NASA-CR-111829, Midwest Research Institute, Kansas City, Mo. (December 1970), 49 pp.

8. J. P. Chaston, Platinum Metals Review, 15:4, 122 (1971). 

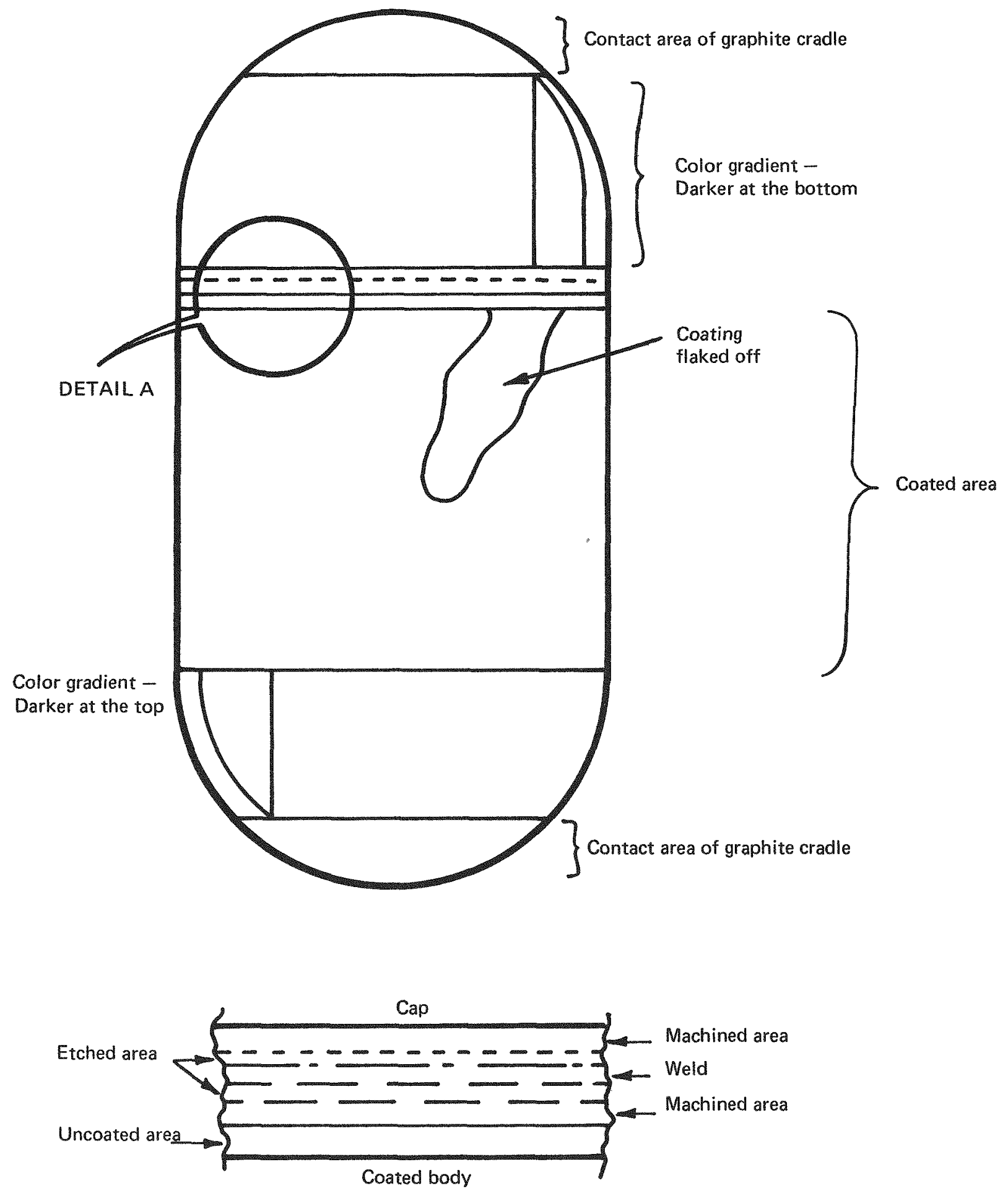

Detail A

FIGURE 1: VF-3 PT-20 RH CLAD EXTERIOR. 

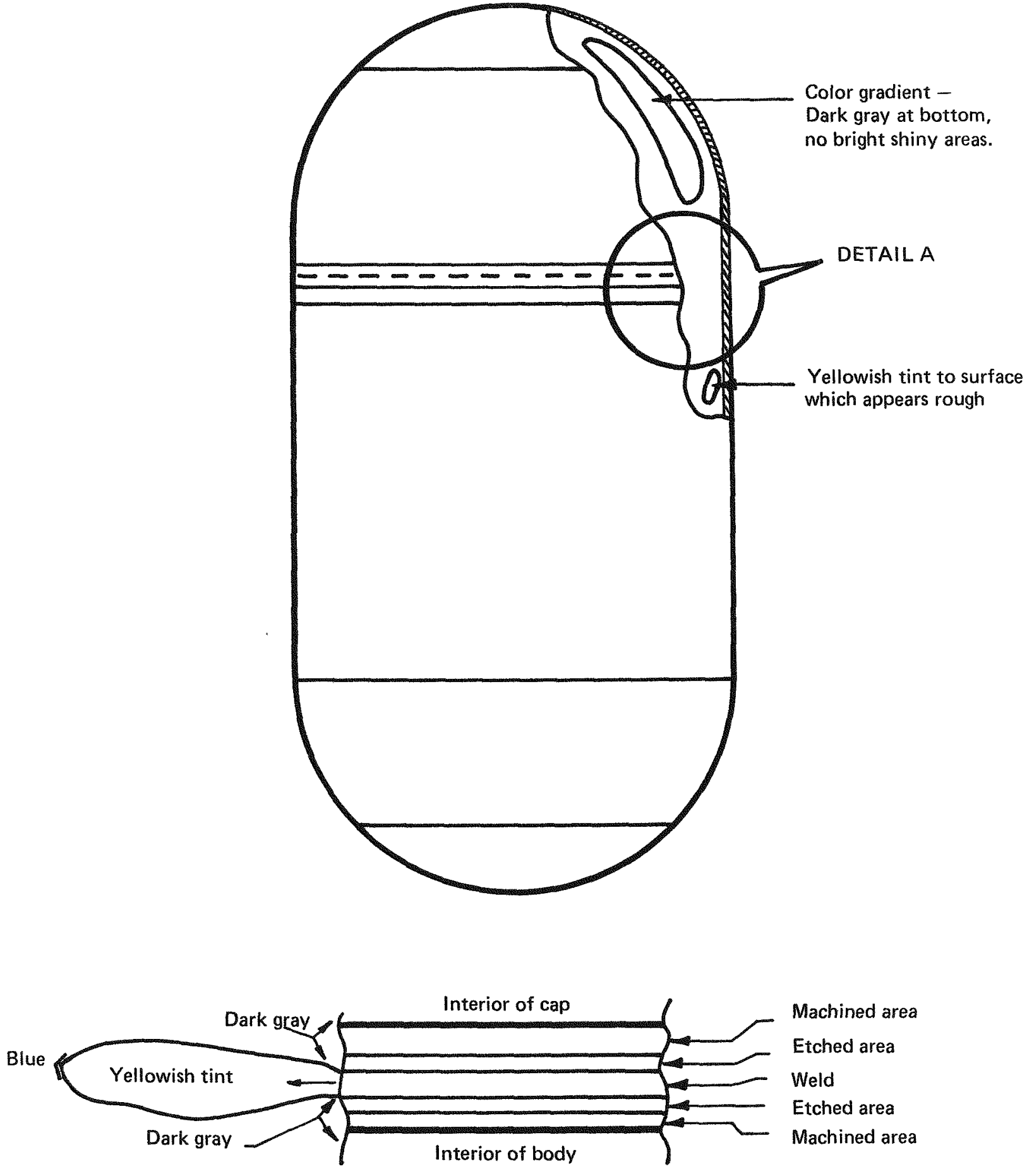

Detail A

FIGURE 2: INTERIOR OF VF-7 PT-20 RH' CLAD. 


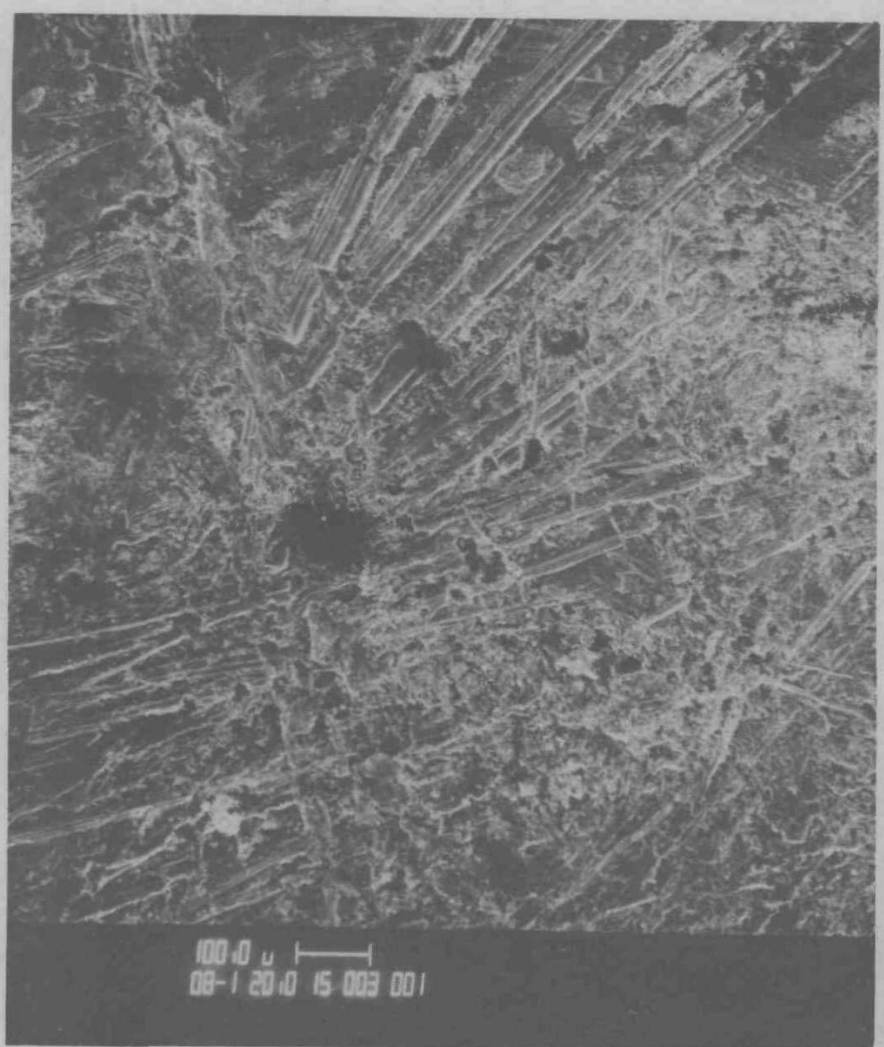

FIGURE 3: THE GEOMETRIC TOP OF THE VF-3 CLAD END CAP.

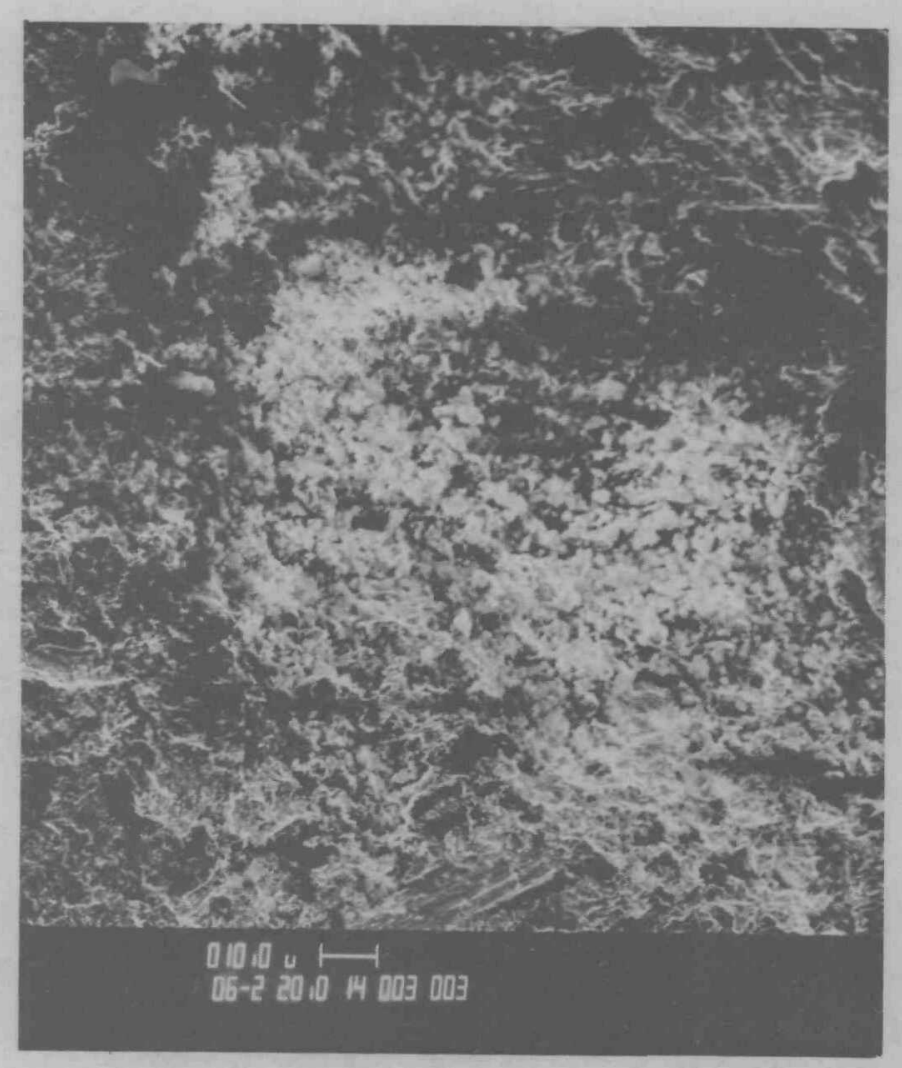

FIGURE 4: REACTION ZONE FOUND ON THE TOP OF THE VF-3 CLAD END CAP. 


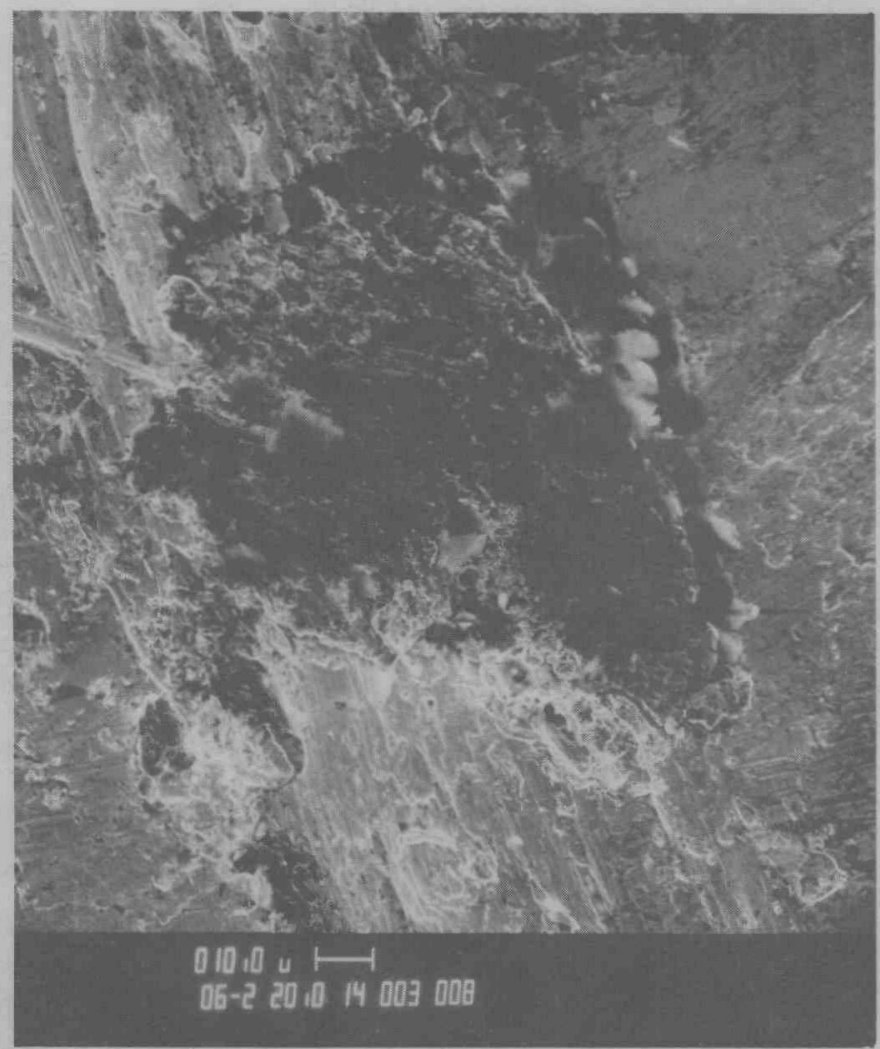

FIGURE 5: REACTION PRODUCT FOUND ON THE TOP OF THE VF-3 CLAD END CAP.

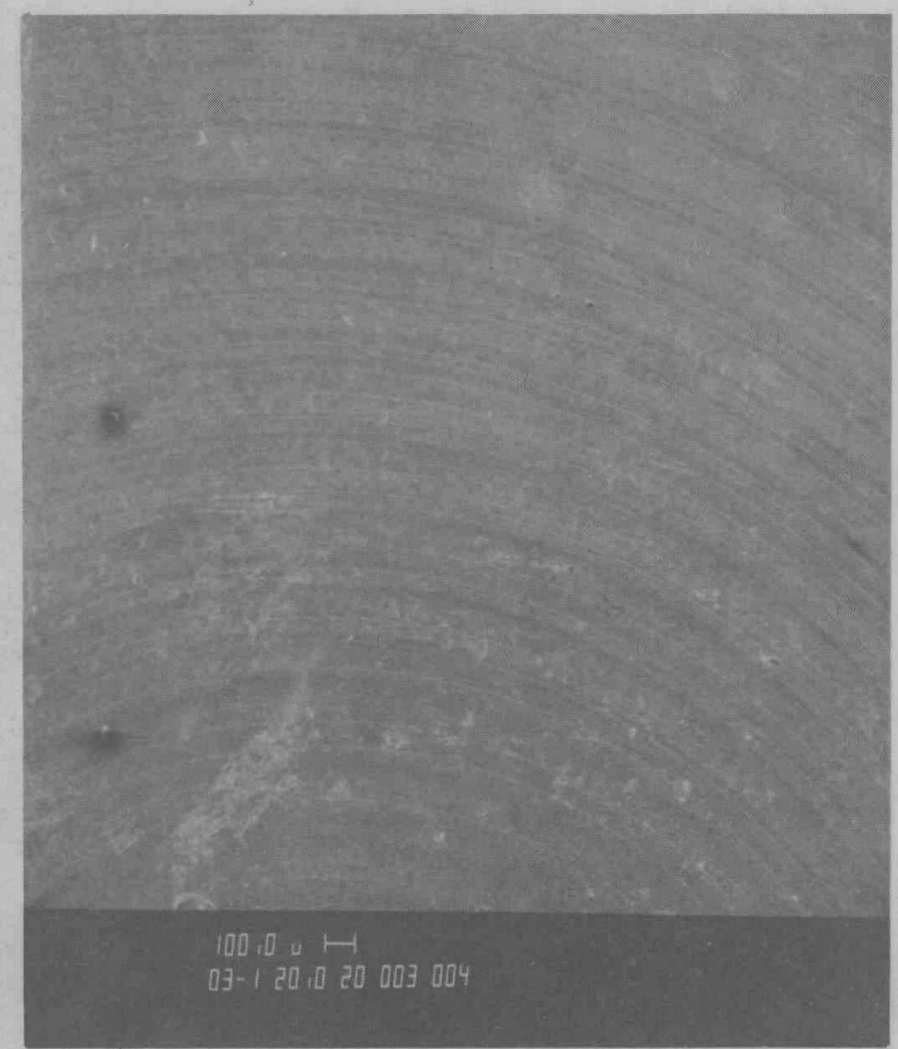

FIGURE 6: TOP SIDEWALL SURFACE OF THE VF-3 CLAD END CAP. 



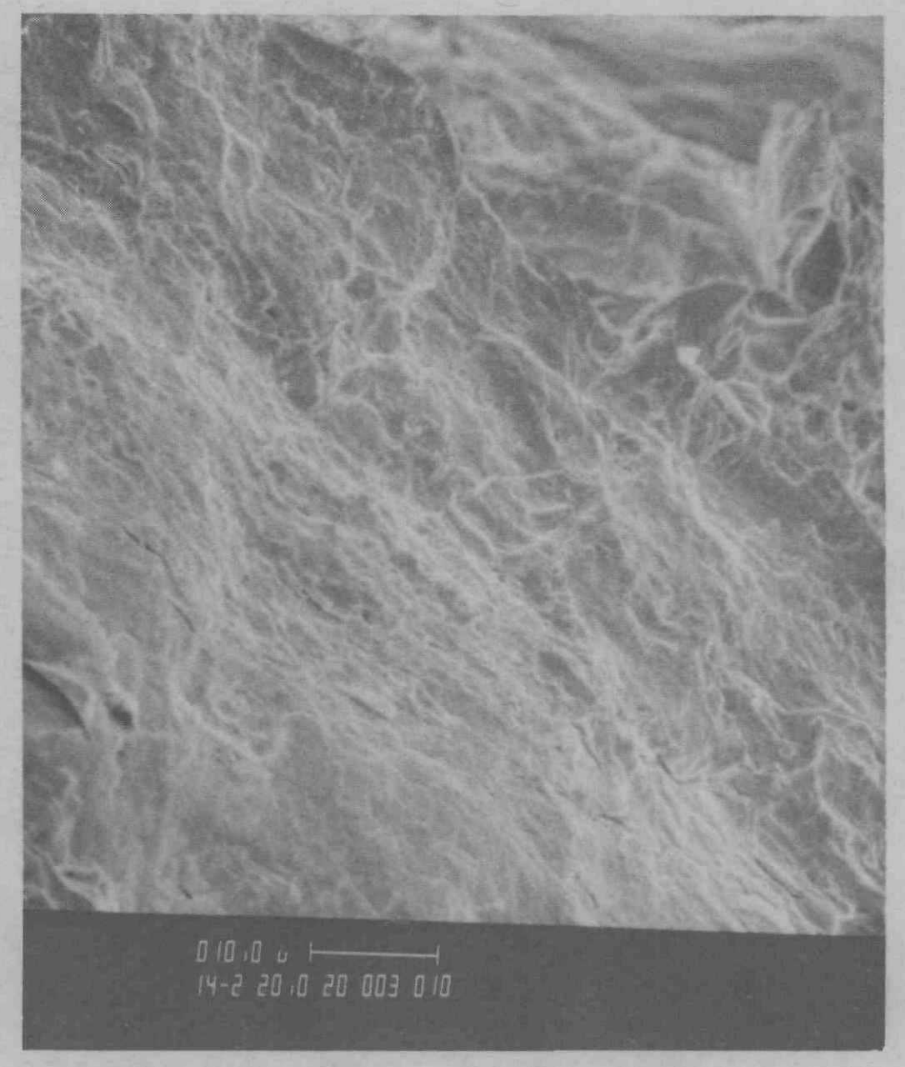

FIGURE 9: SURFACE OF THE VF-3 CLAD END CAP AT AN AREA JUST ABOVE THE WELD ZONE.

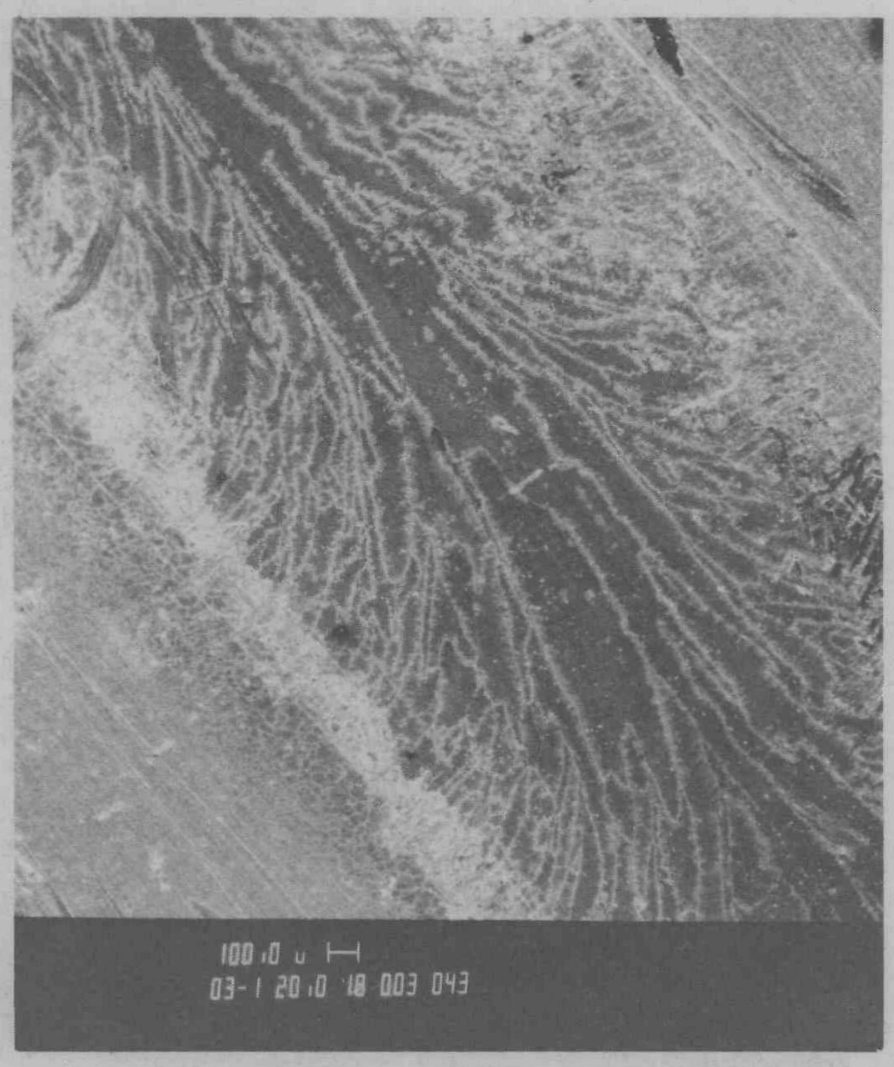

FIGURE 10: WELD ZONE OF THE VF-3 CLAD. 


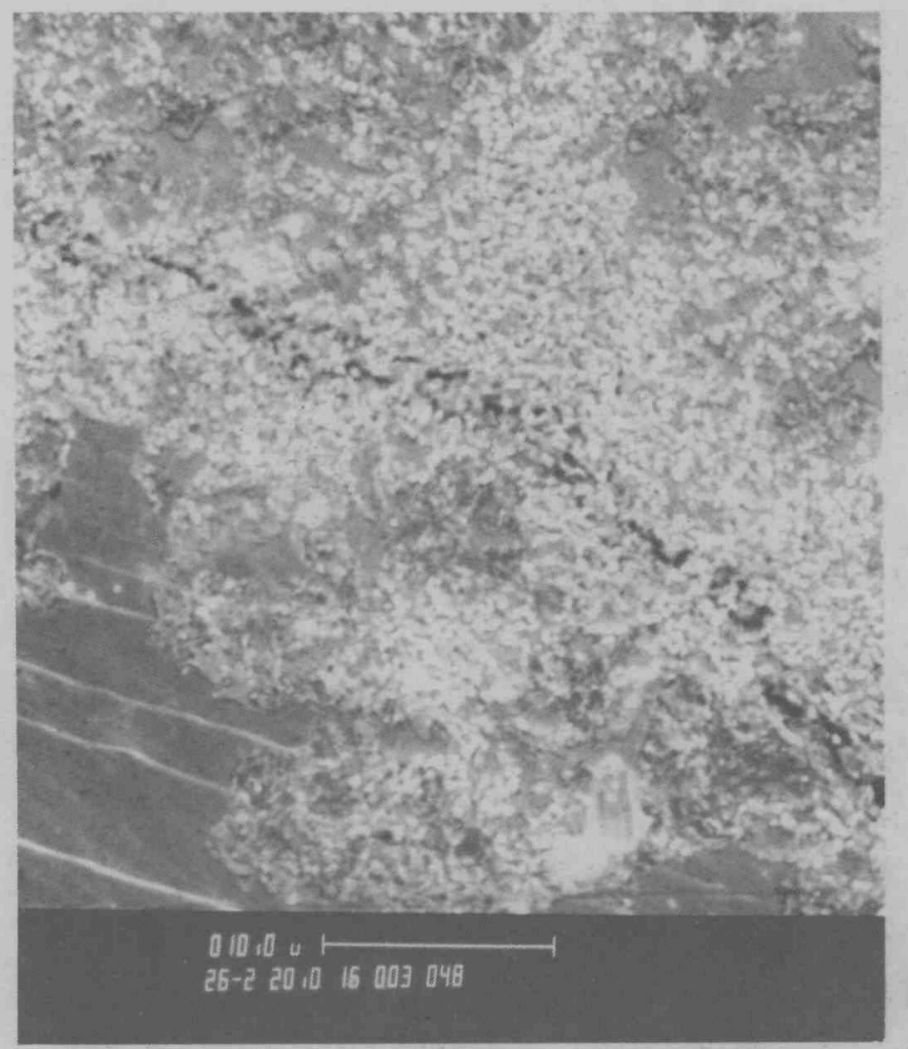

FIGURE 11: REACTION ZONE AT A

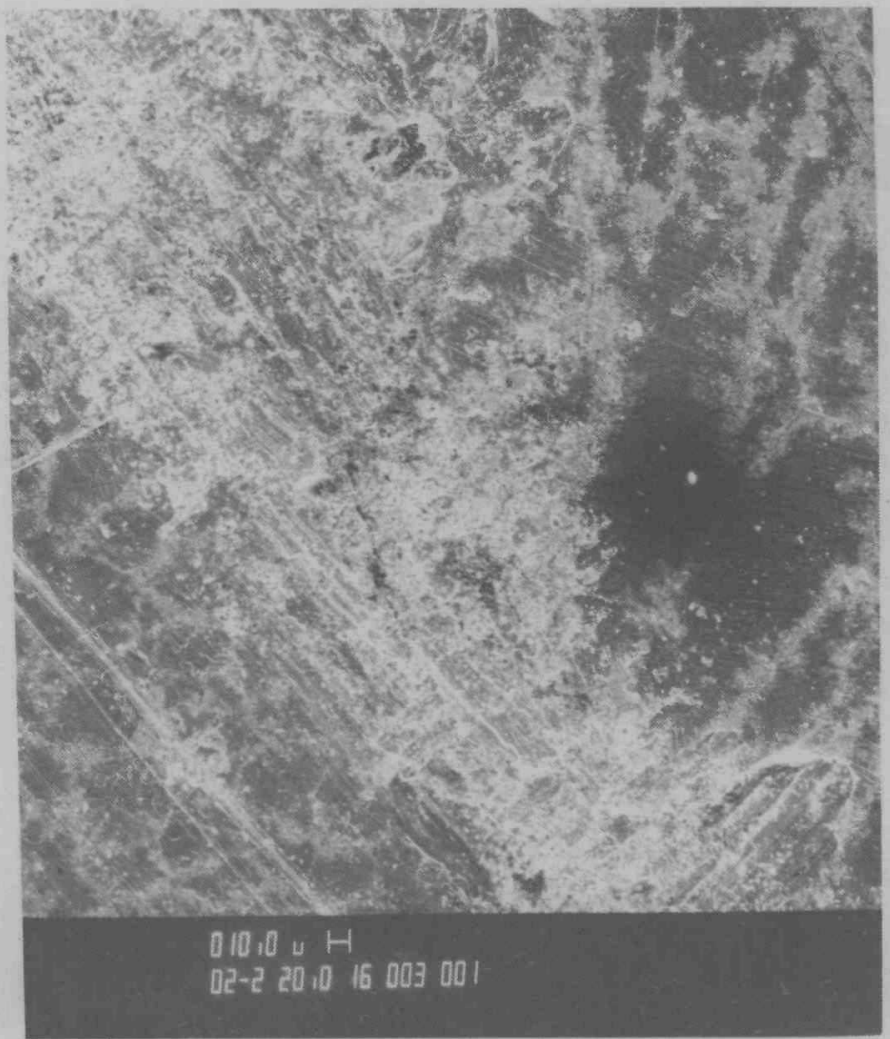

FIGURE 12: REACTION AT THE WELD HEAT-AFFECTED ZONE INTERFACE OF THE VF -3 CLAD. 


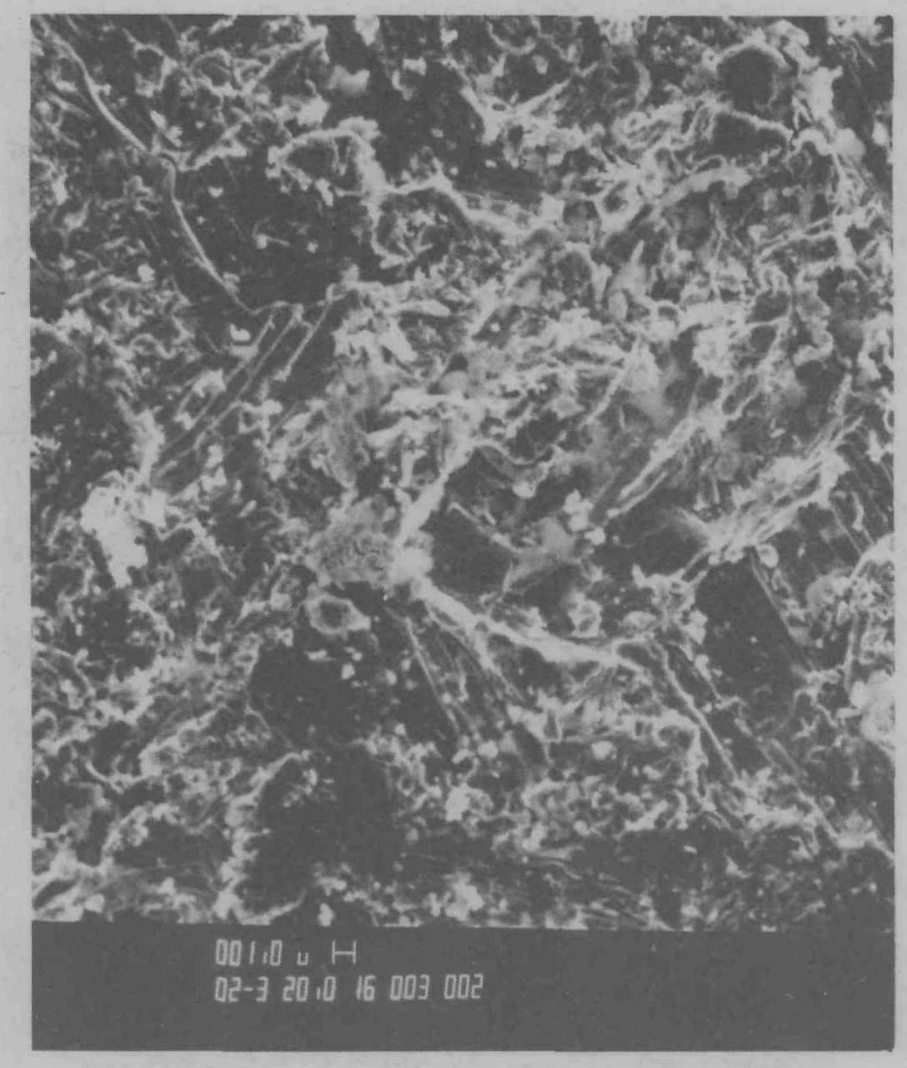

FIGURE 13: BASE OF THE WELD ZONE OF THE VF-3 CLAD.

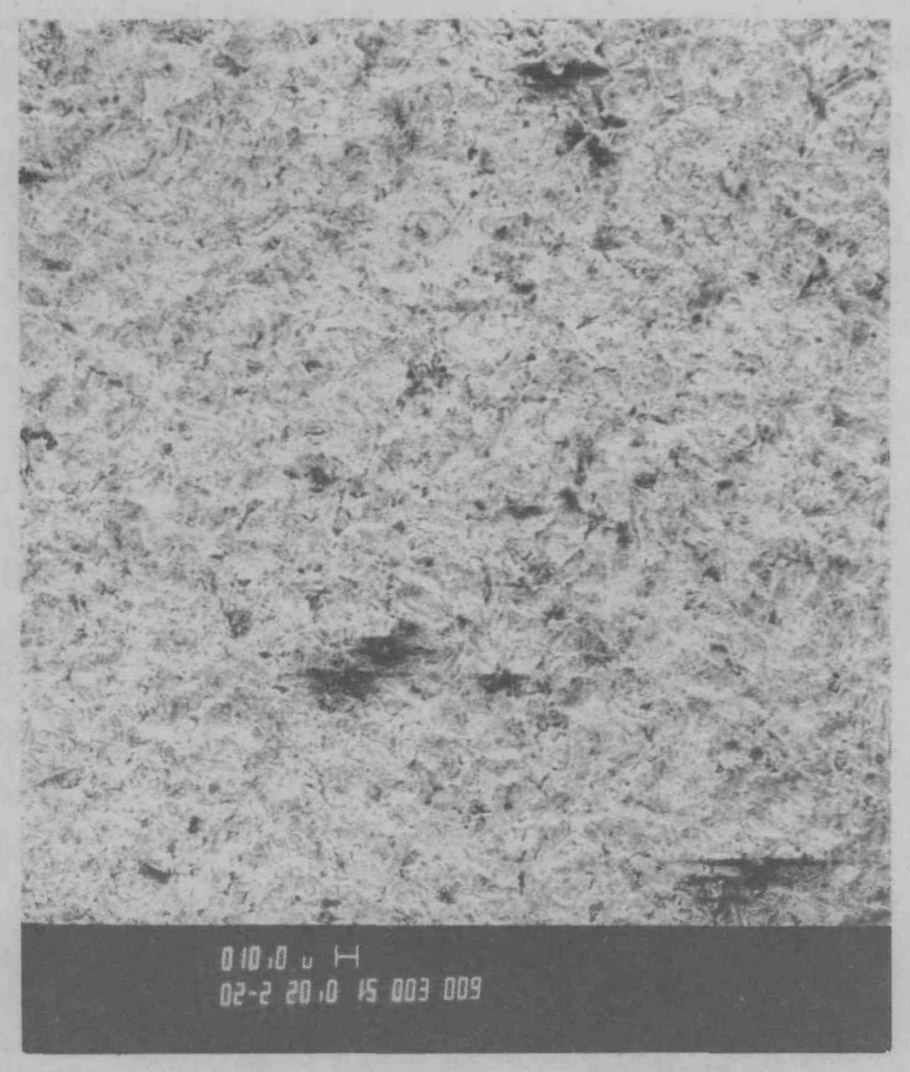

FIGURE 14: AREA OF THE SIDEWALL OF THE VF-3 CLAD BODY WHERE THE COATING HAD FLAKED AWAY. 


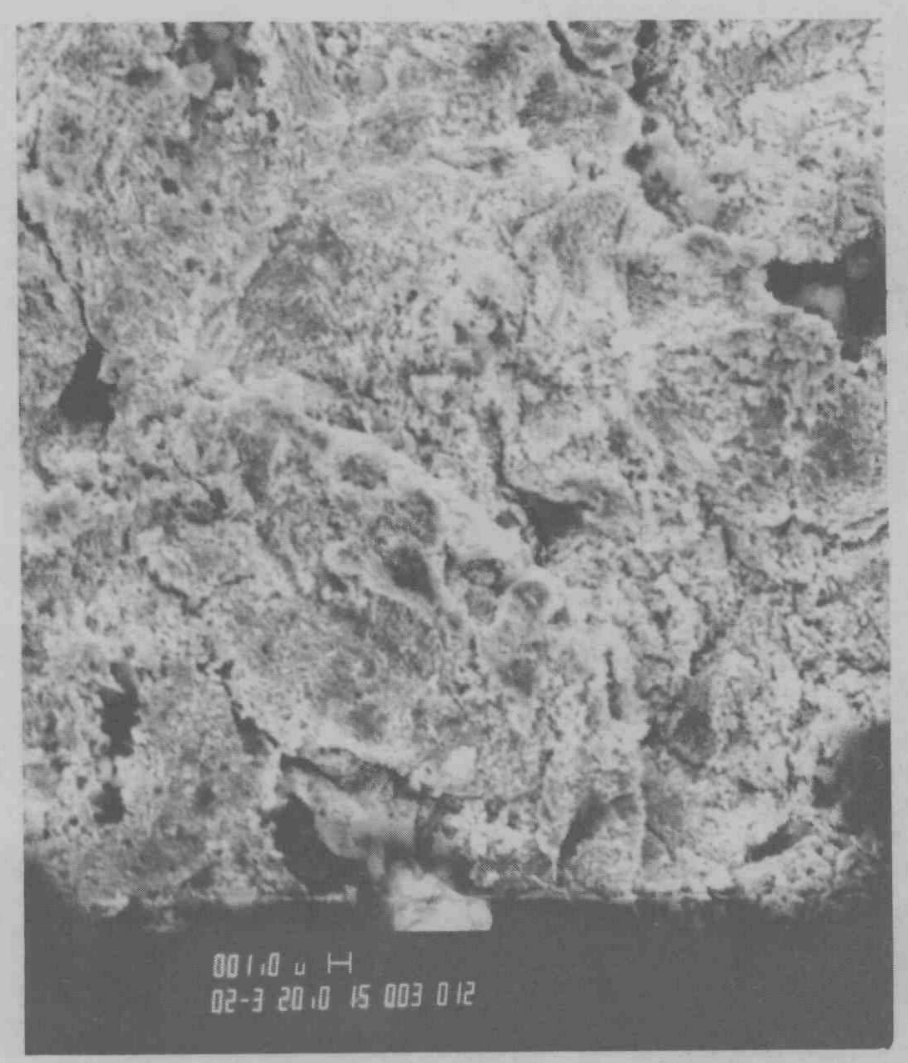

FIGURE 15: AREA OF THE SIDEWALL ज

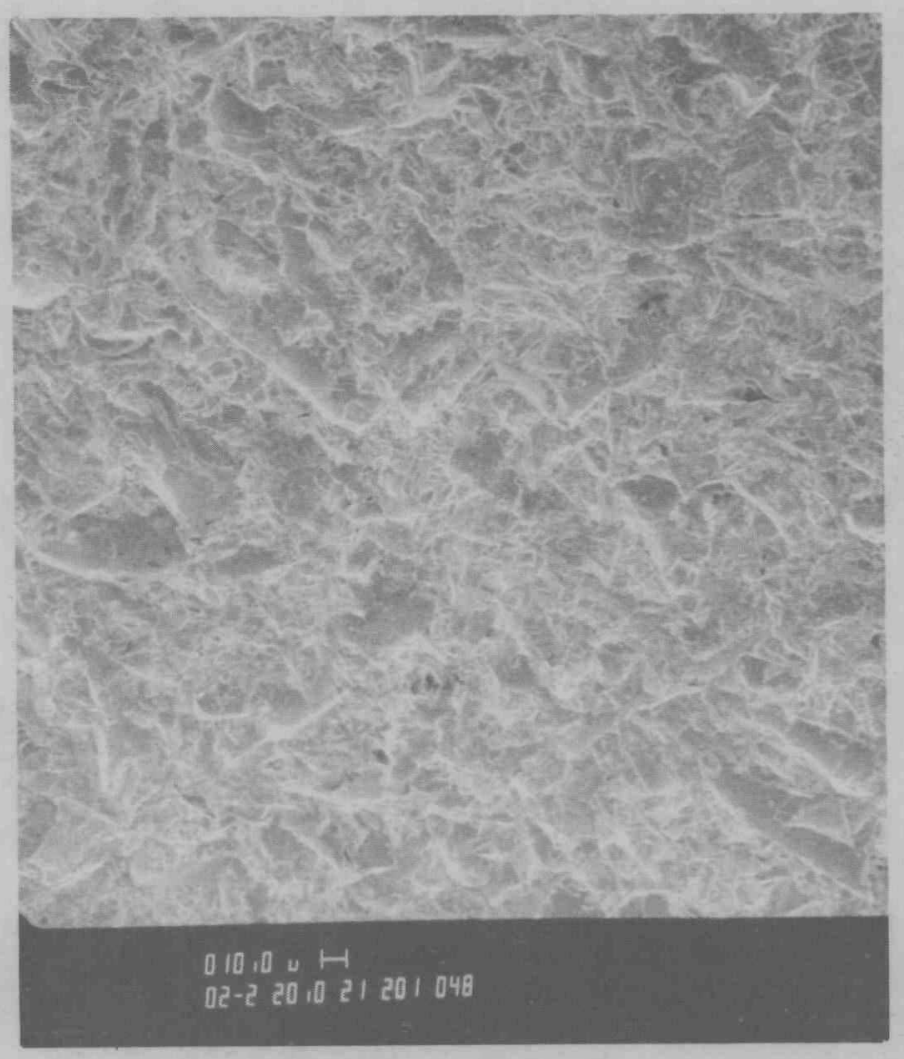

FIGURE 16: AS-GRIT-BLASTED SURFACE of A CONTROL SAMPLE OF PT-20 RH. 


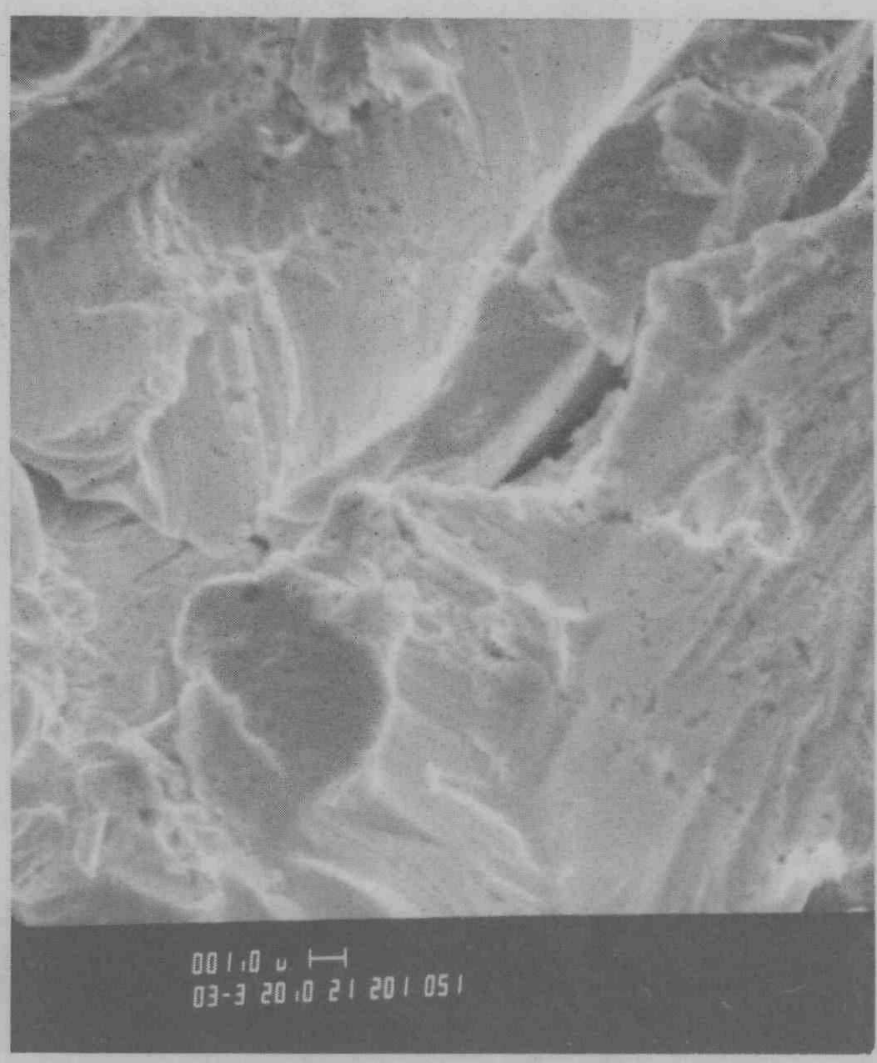

FIGURE 17: AS GRIT BLASTED SURFACE OF A CONTROL SAMPLE OF PT-2O RH.

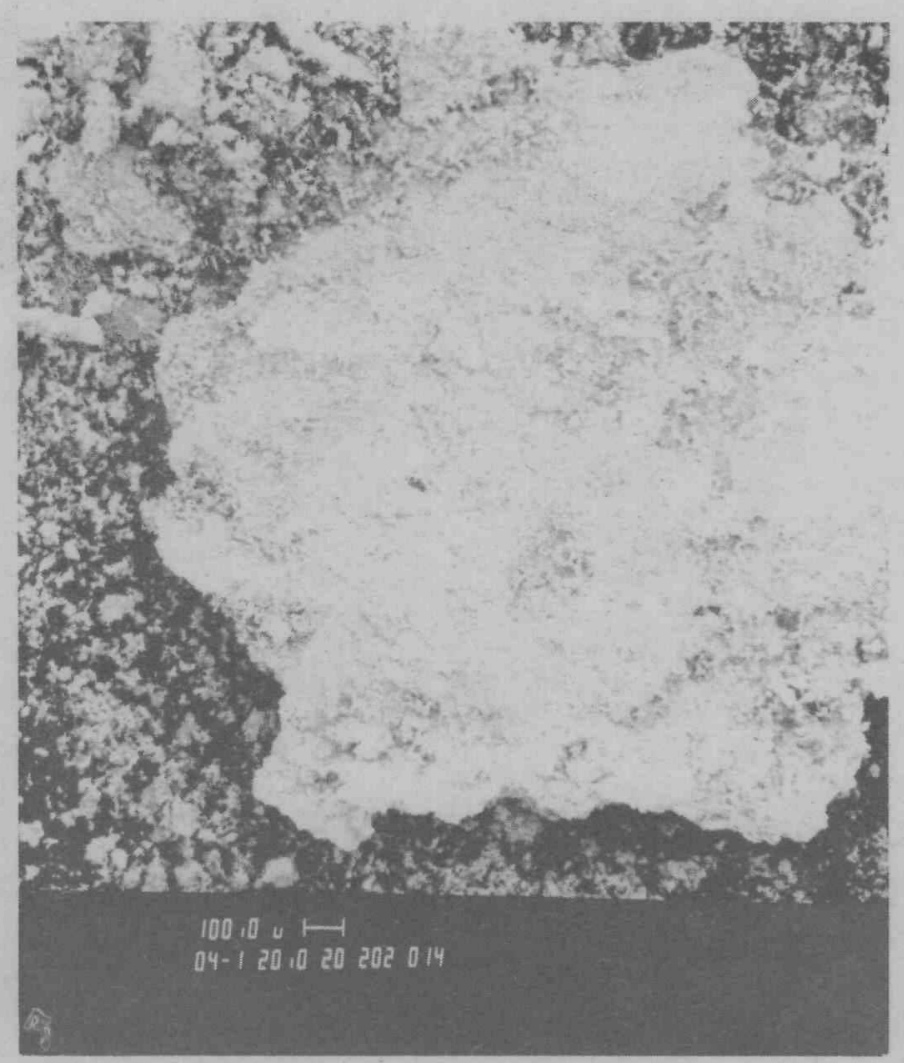

FIGURE 18: POWDER FOUND ON THE INSIDE OF THE VF-3 CLAD. 


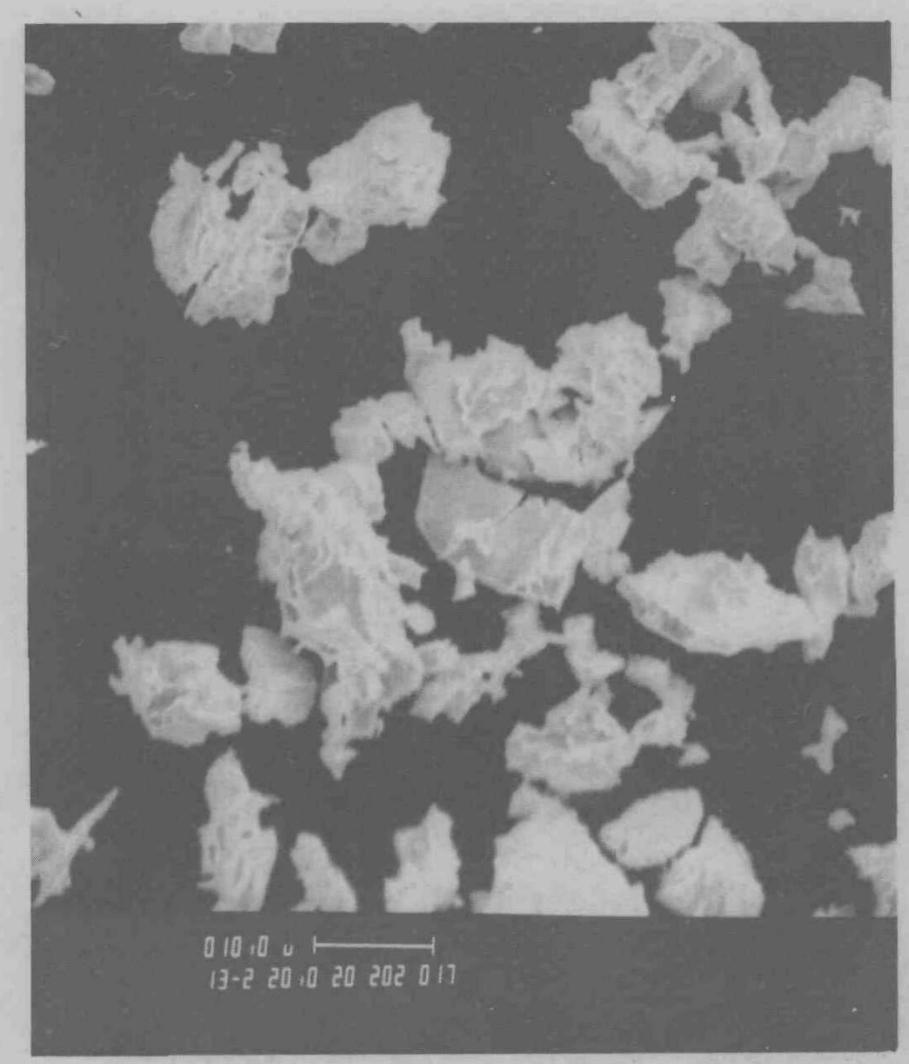

FIFURE 19: POWDER FOUND ON THE INSIDE OF THE VF-3 CLAD.

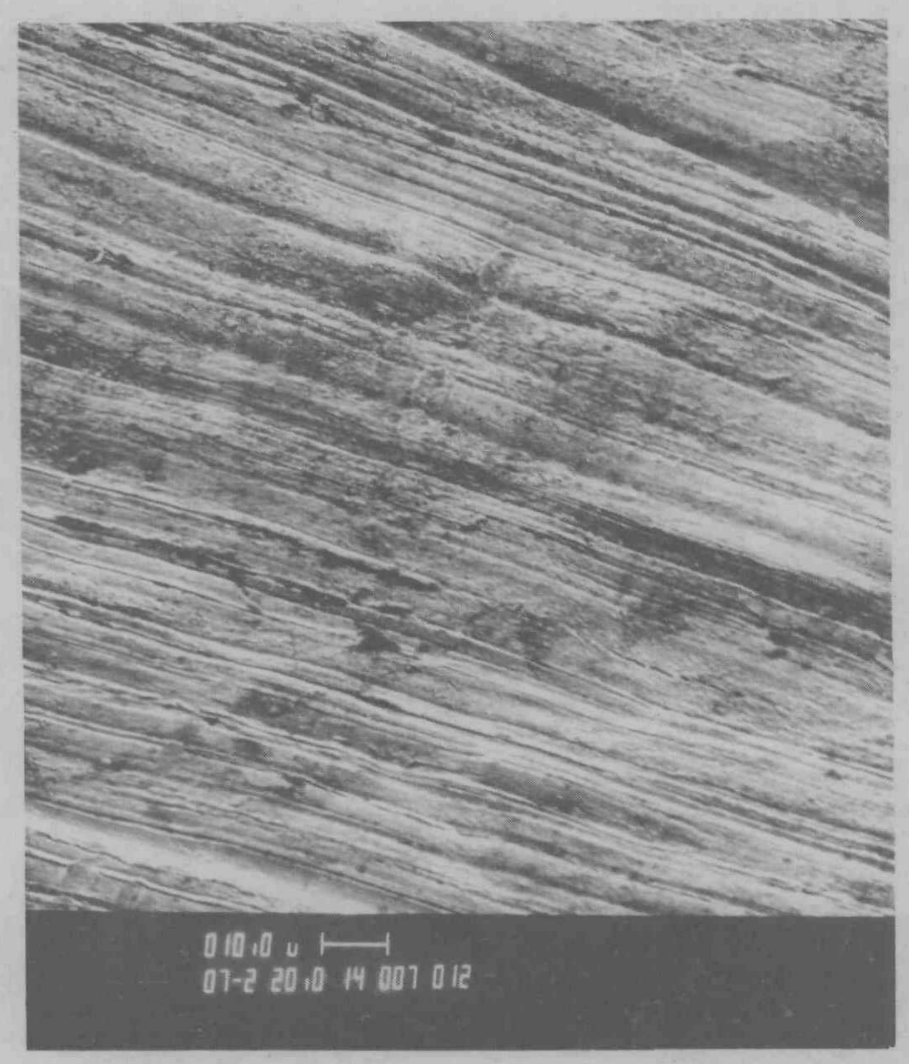

FIGURE 20: SURFACE OF THE VF-7 END CAP WHICH WAS IN CONTACT WITH THE GRAPHITE CRADLE. 


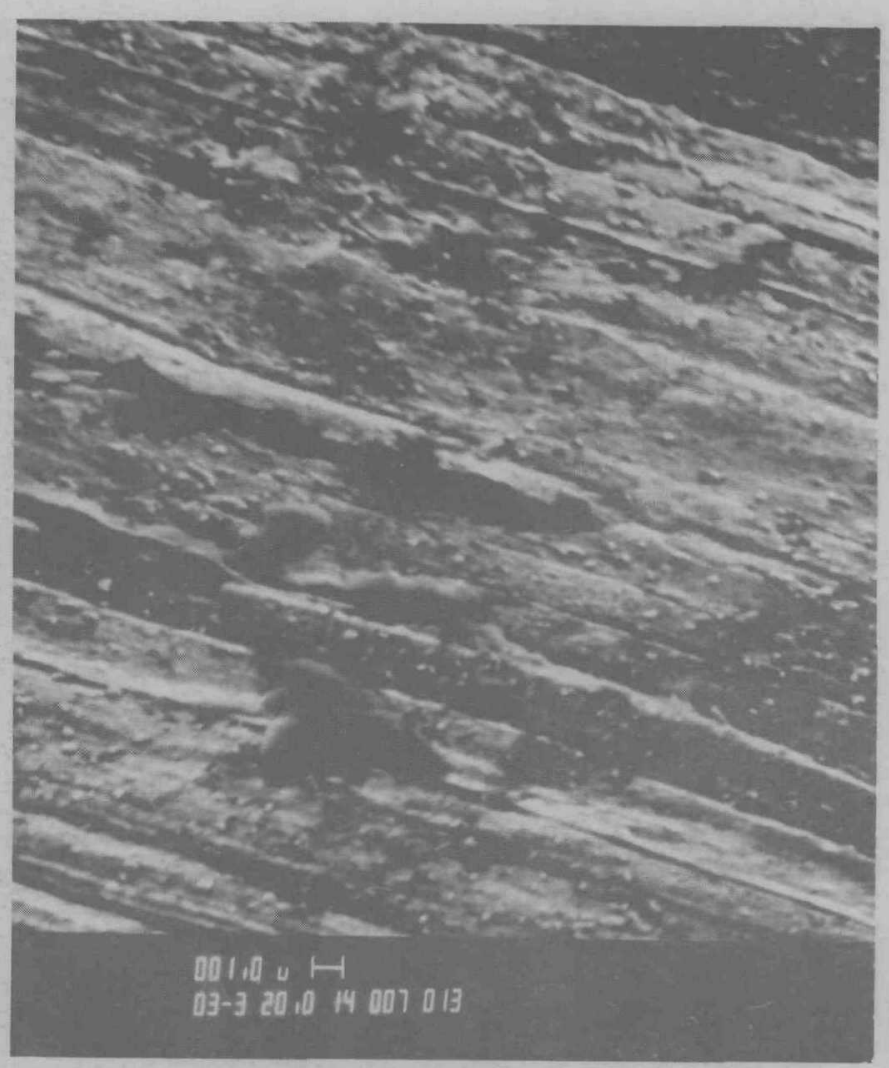

FIGURE 21: SURFACE OF THE VF-7 END CAP WHICH WAS IN CONTACT WITH THE GRAPHITE CRADLE.

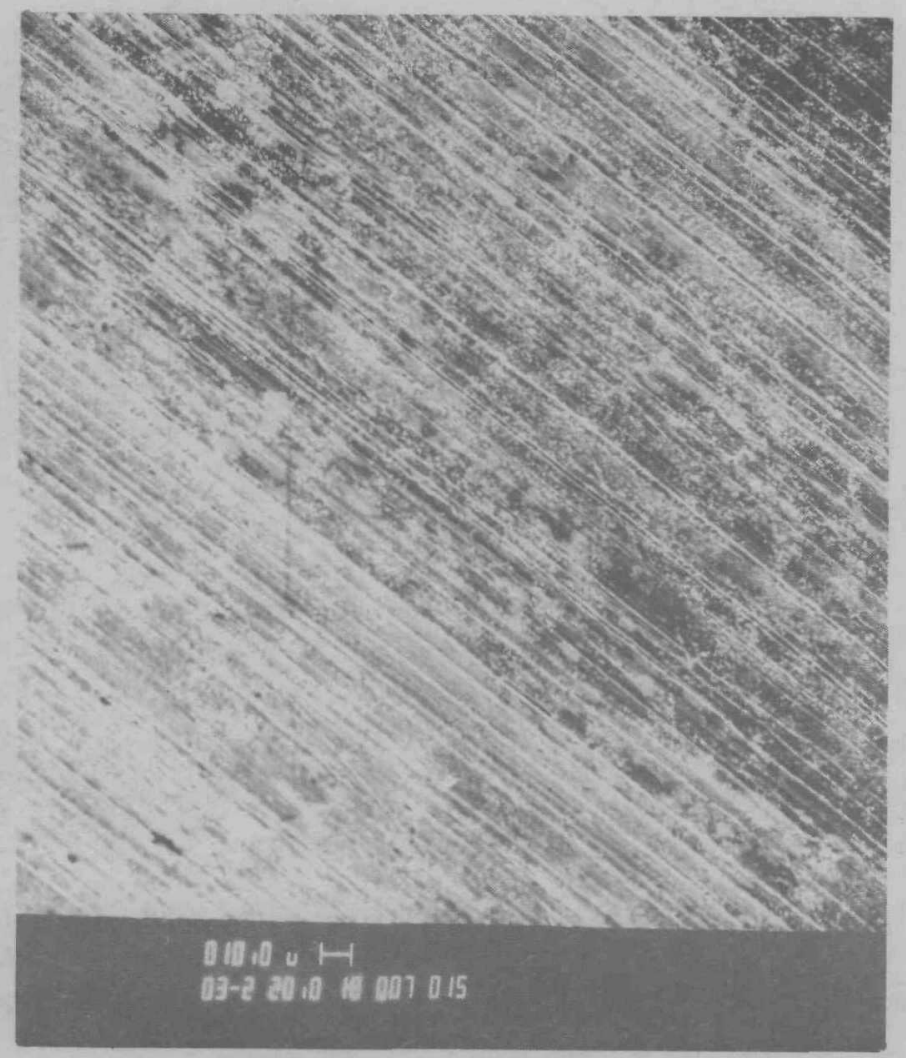

FIGURE 22: INTERFACE ON THE SURFACE OF THE VF-7 END CAP WHERE THE CONTACT LINE OF THE GRAPHITE CRADLE ENDED. 


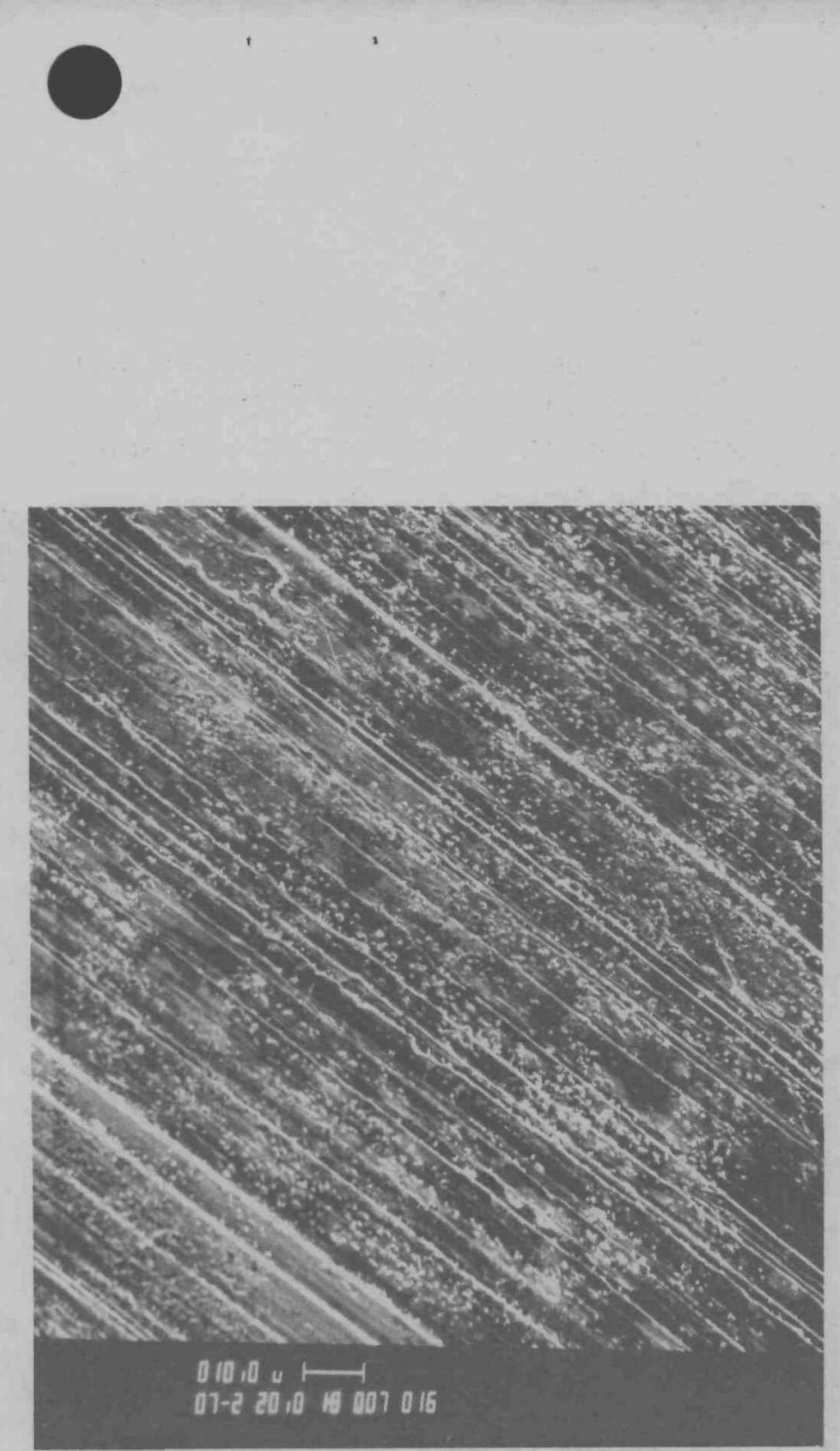

FIGURE 23: INTERFACE ON THE SURFACE. OF THE VF-7 END CAP WHERE

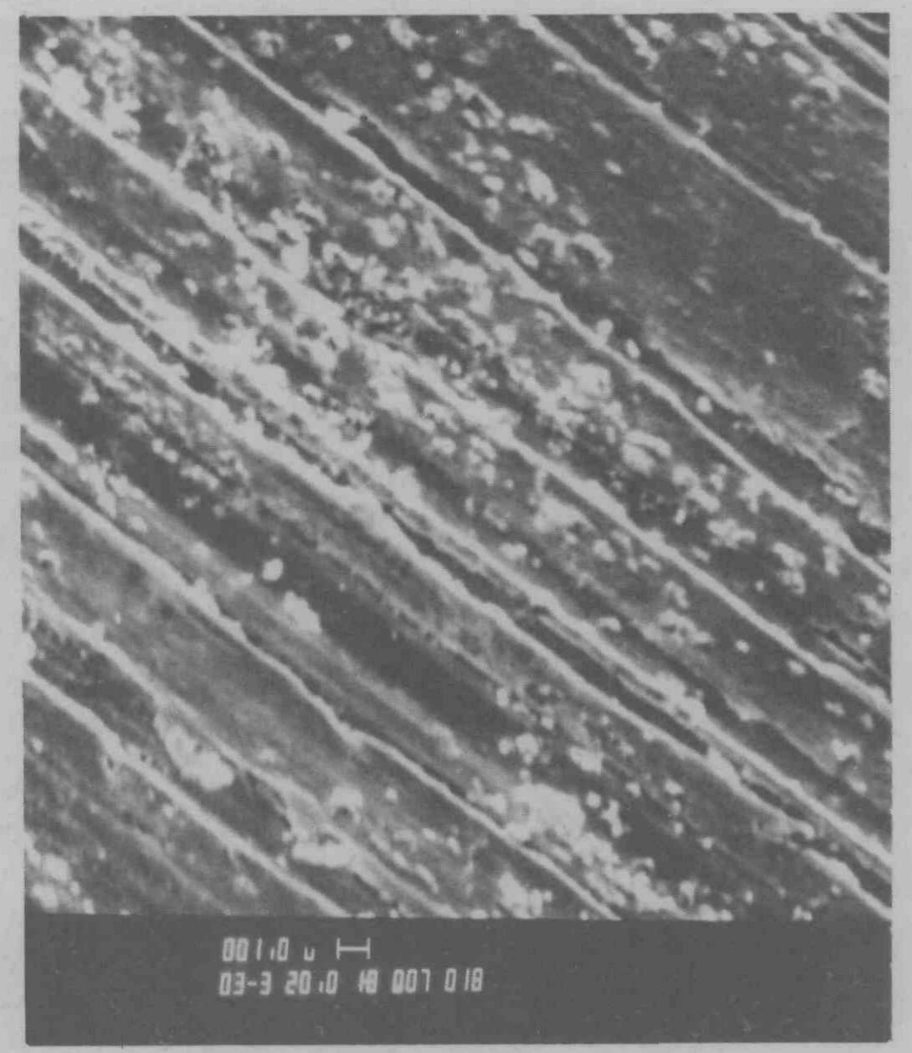

FIGURE 24: AREA OF THE SIDEWALL OF THE VF-7 END CAP BEYOND THE GRAPHITE CRADLE CONTACT LINE. CRADLE ENDED. 


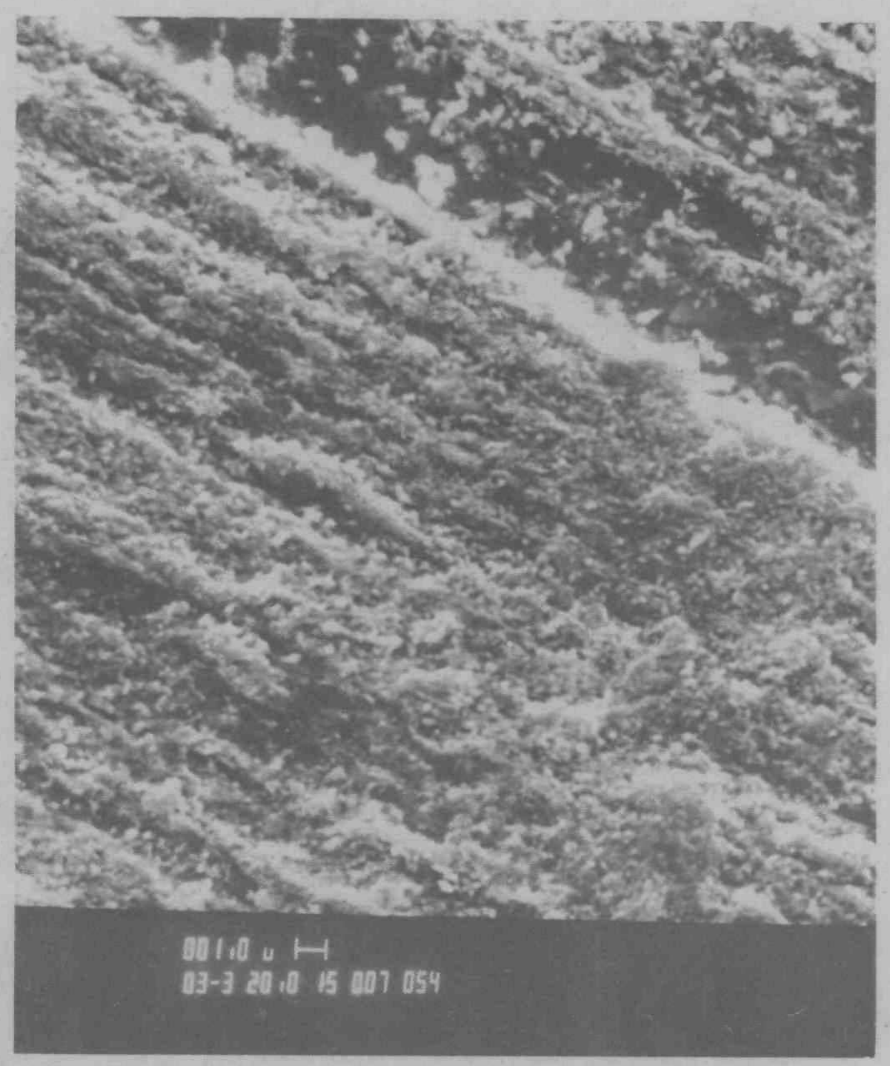

FIGURE 25: SIDEWALL SURFACE OF THE VF-7 CLAD END CAP LOCATED JUST ABOVE THE WELD ZONE.

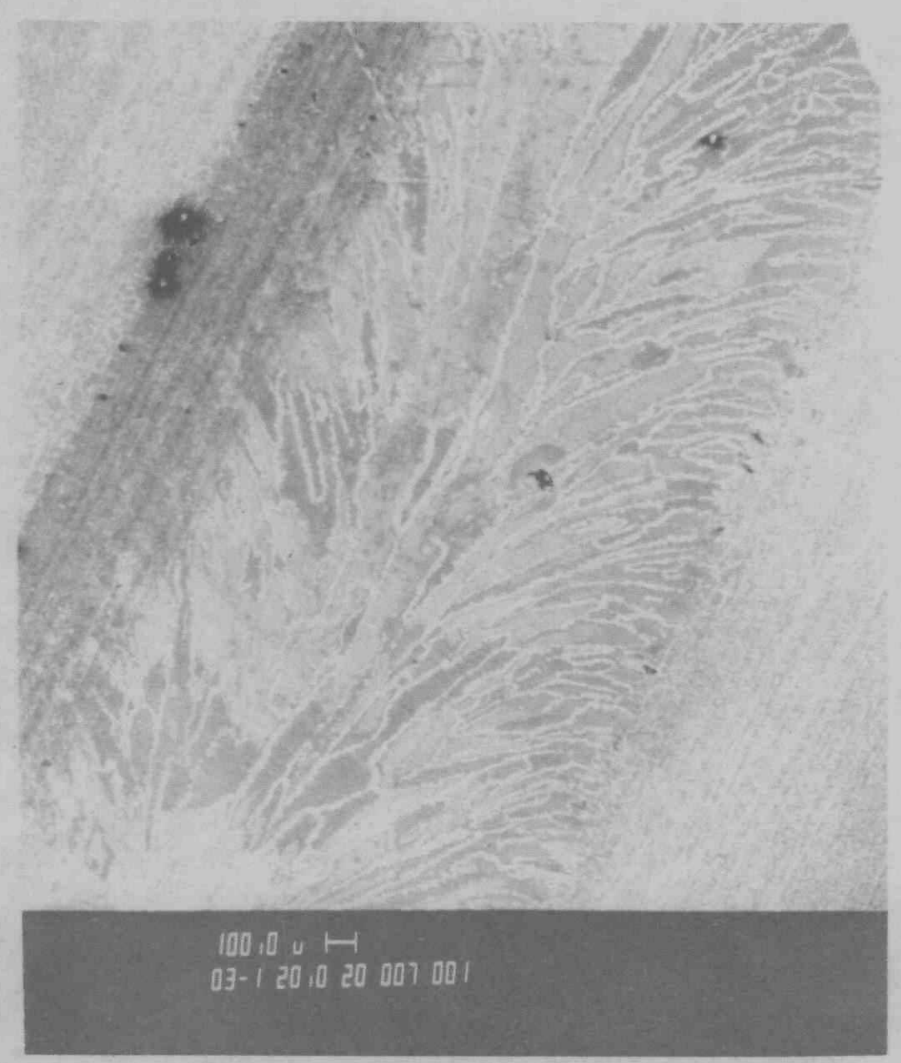

FIGURE 26: WELD ZONE OF THE VF-7 CLAD. 


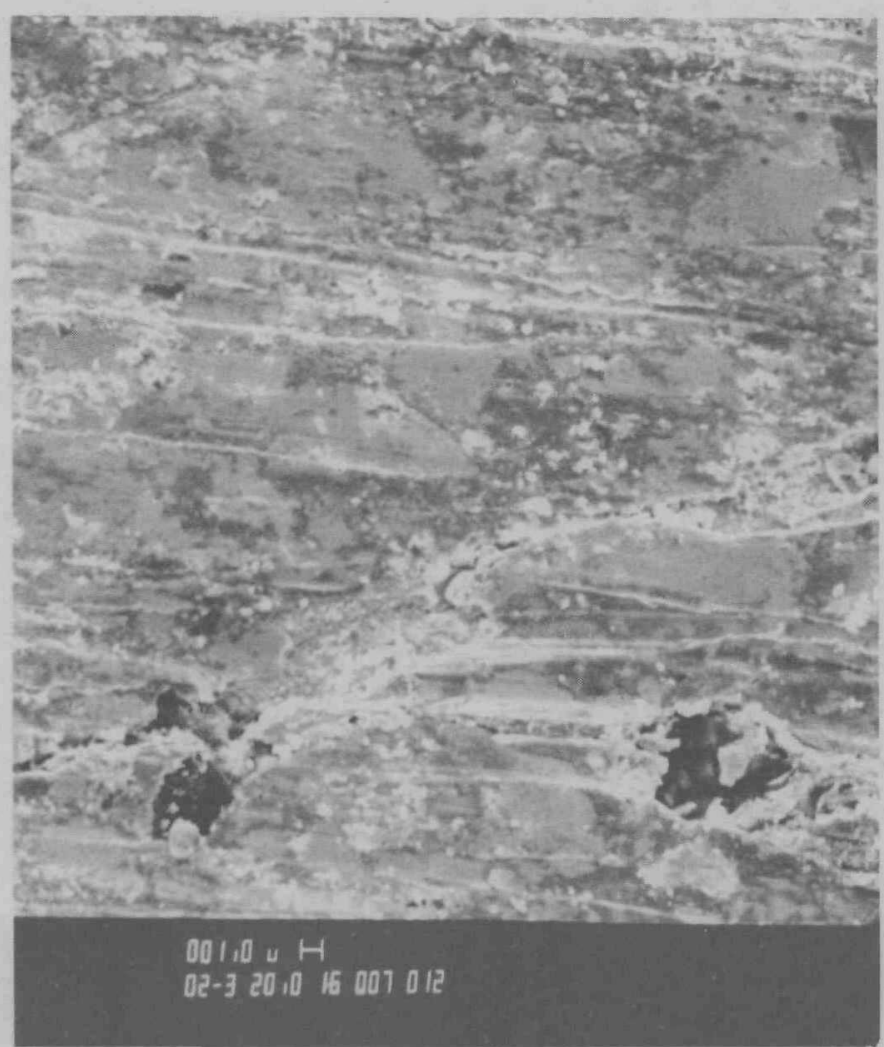

FIGURE 27: TRANSITION ZONE BETWEEN END CAP AND WELD ZONE OF THE VF-7 CLAD.

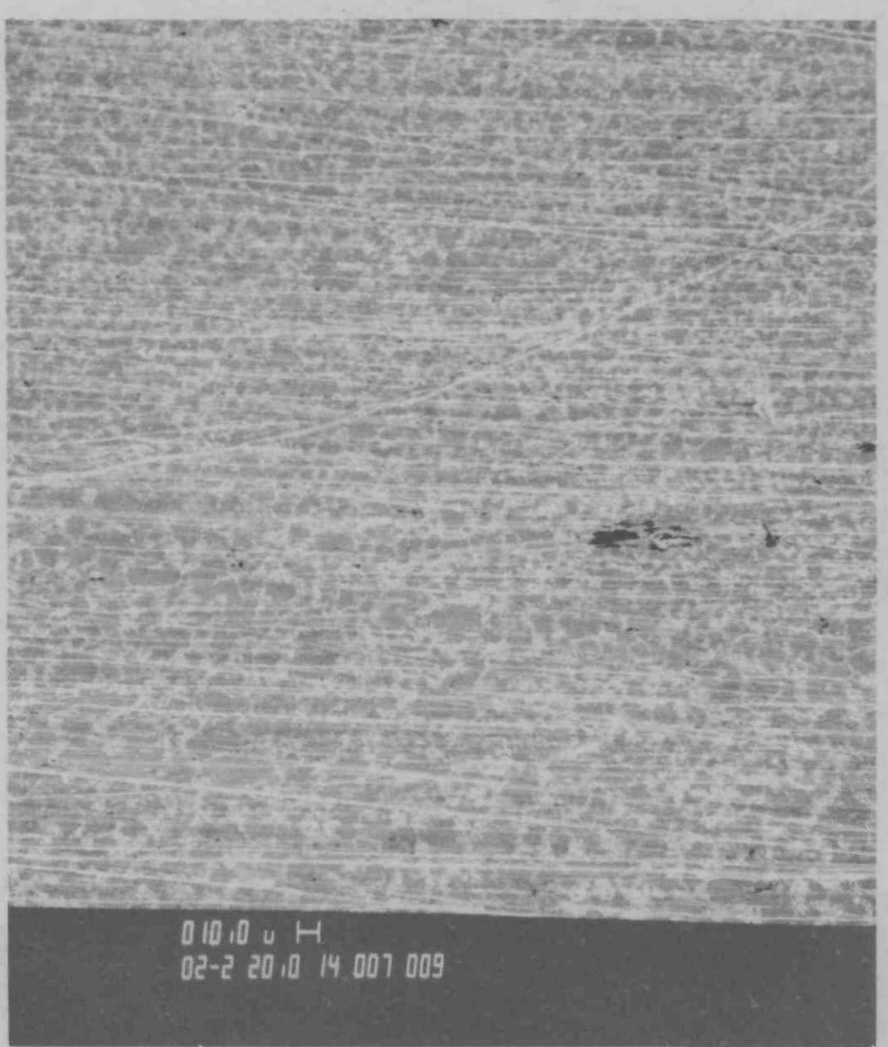

FIGURE 28: AREA IMMEDIATELY ABOVE THE WELD OF THE VF-7 CLAD. 


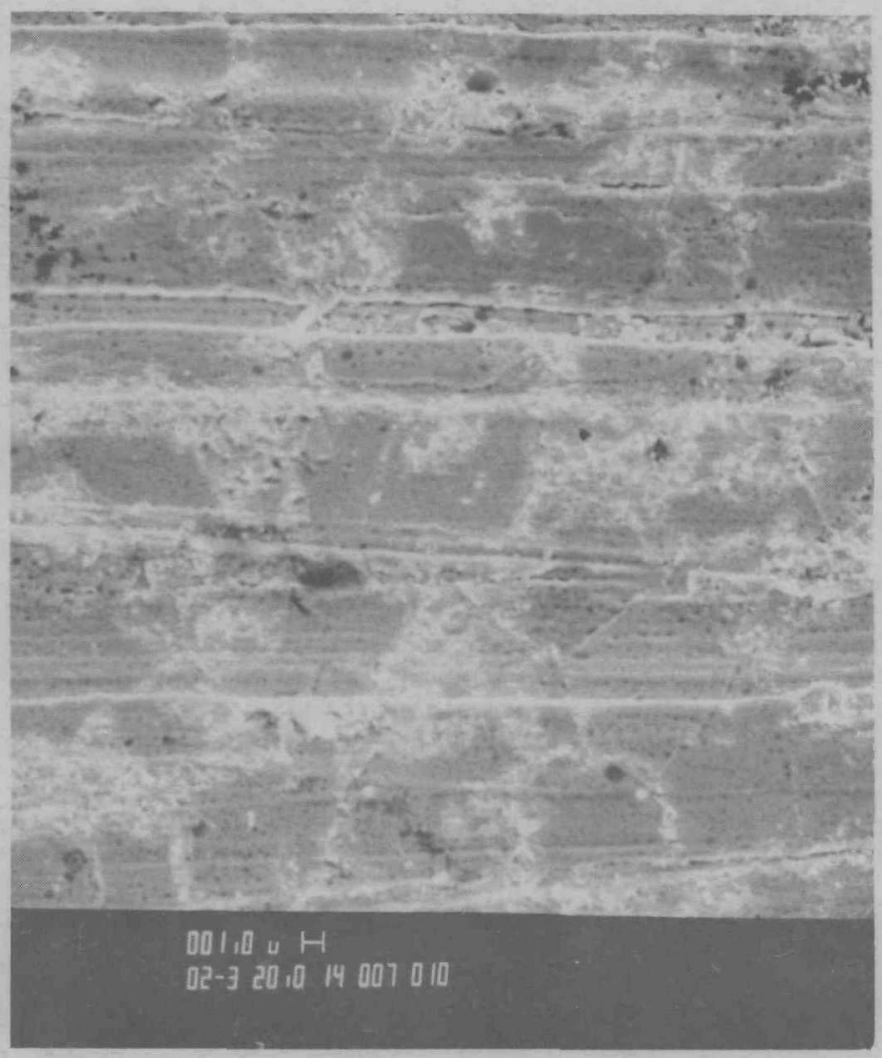

FIGURE 29: AREA IMMEDIATELY ABOVE THE WELD OF THE VF-7 CLAD.

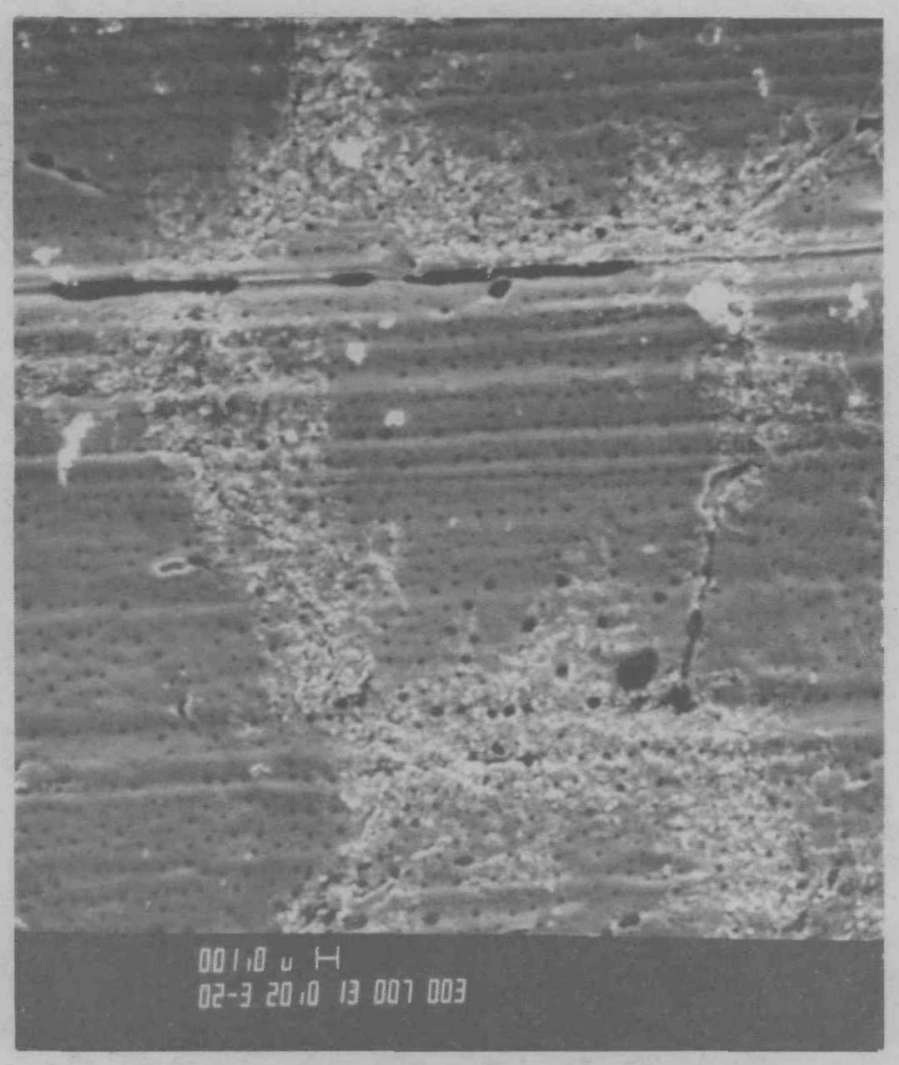

FIGURE 30: AREA IMMEDIATELY ABOVE THE WELD OF THE VF-7 CLAD. 


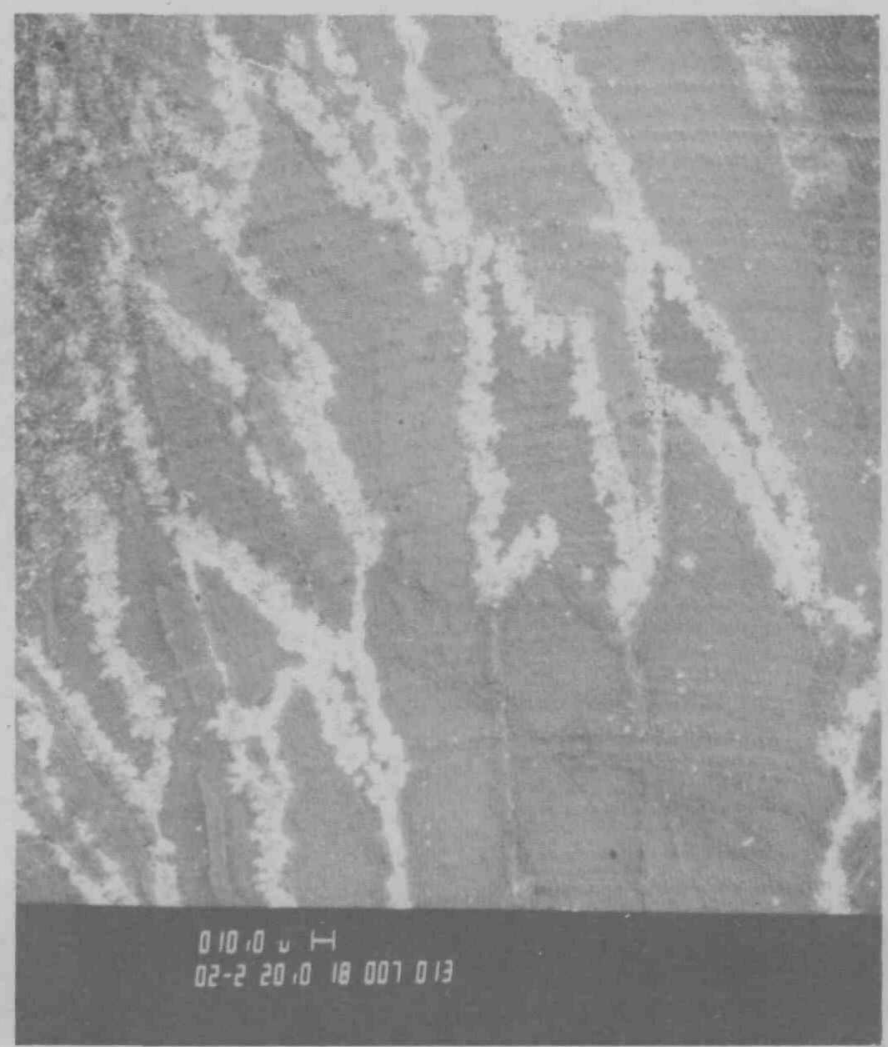

FIGURE 31: SURFACE OF THE WELD OF THE VF-7 CLAD.

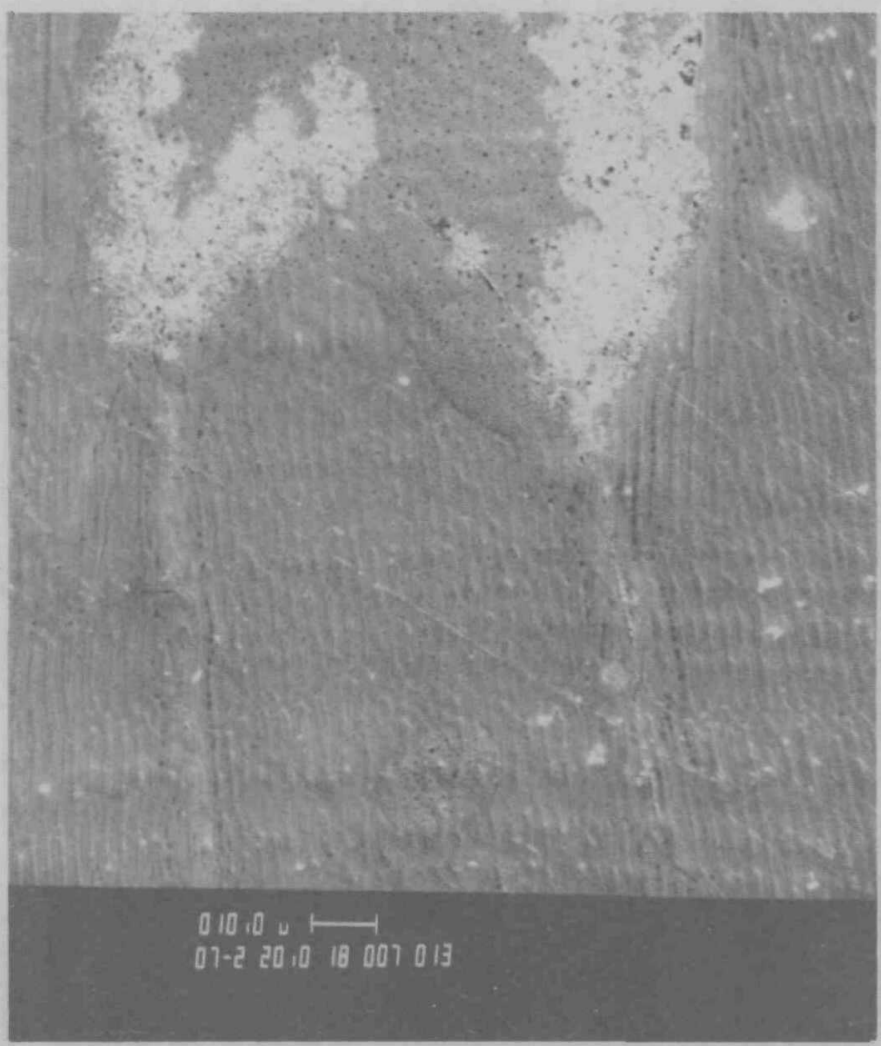

FIGURE 32: SURFACE OF THE WELD OF THE VF 7 CLAD. 


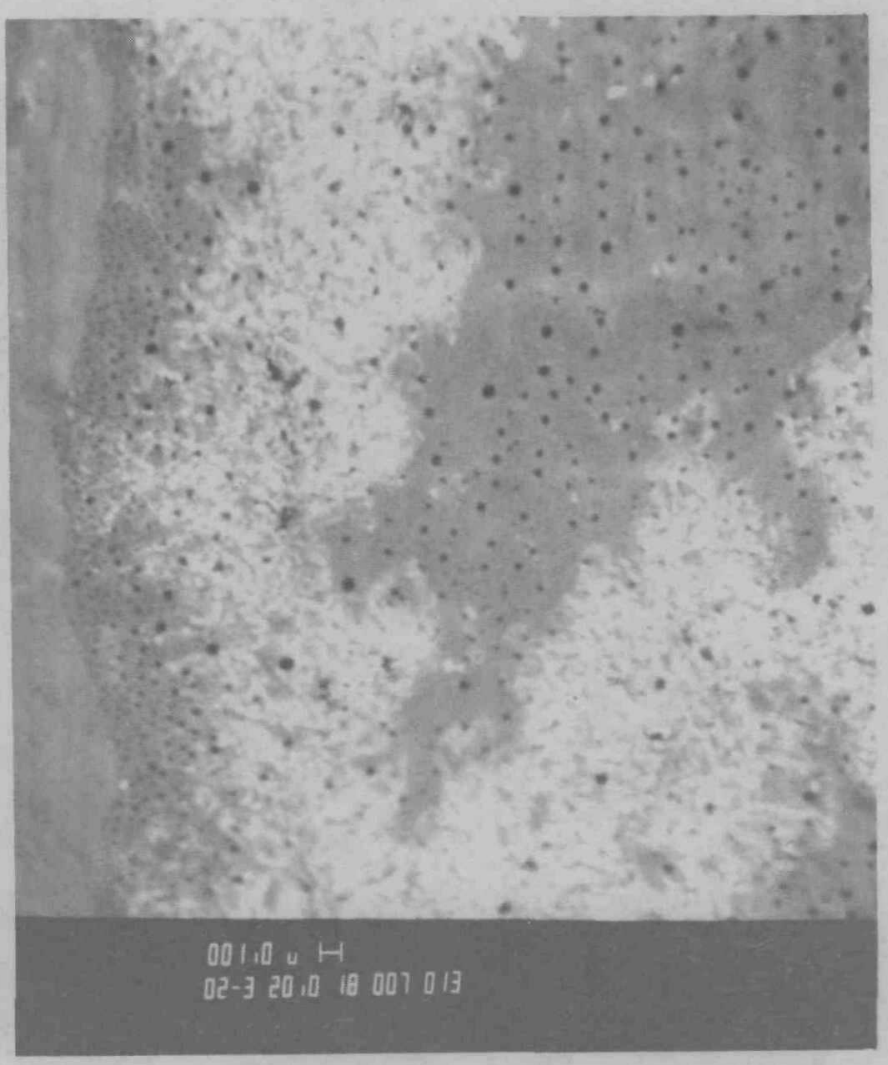

FIGURE 33: SURFACE OF THE WELD OF THE VF -7 CLAD.

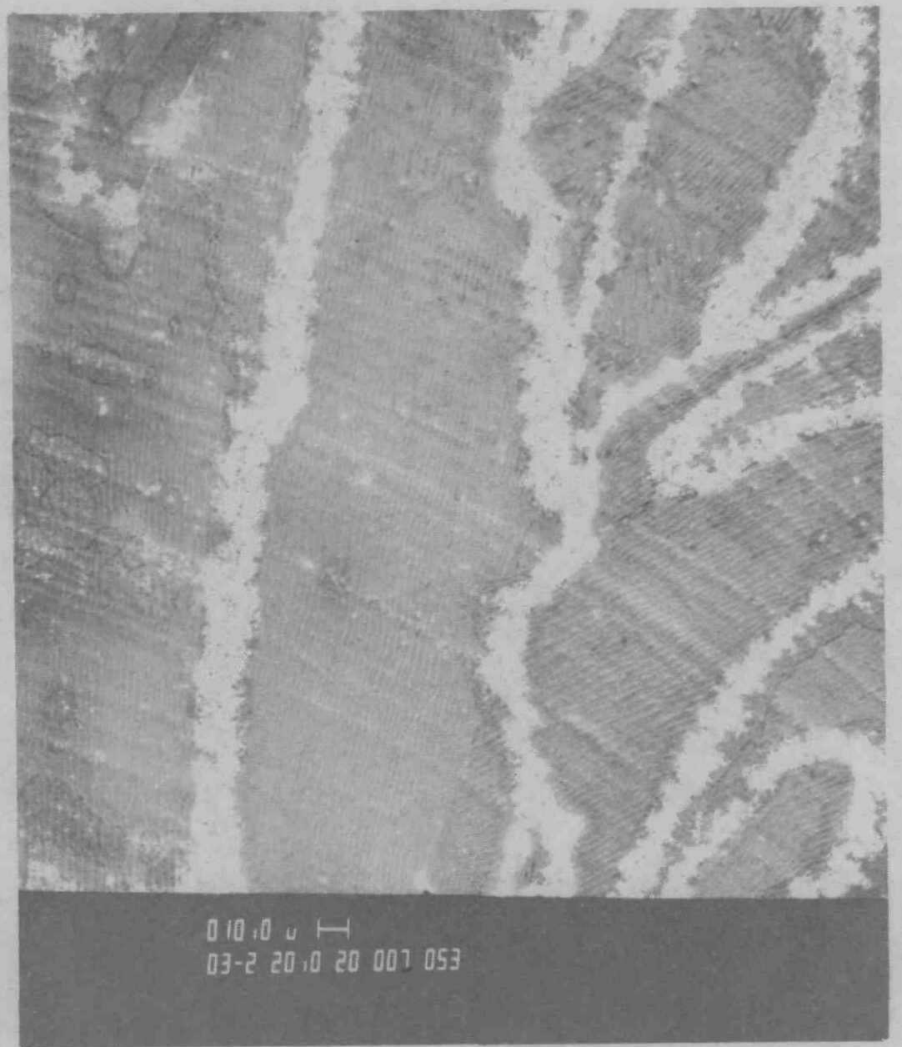

FIGURE 34: SURFACE OF THE WELD OF THE VF-7 CLAD. 


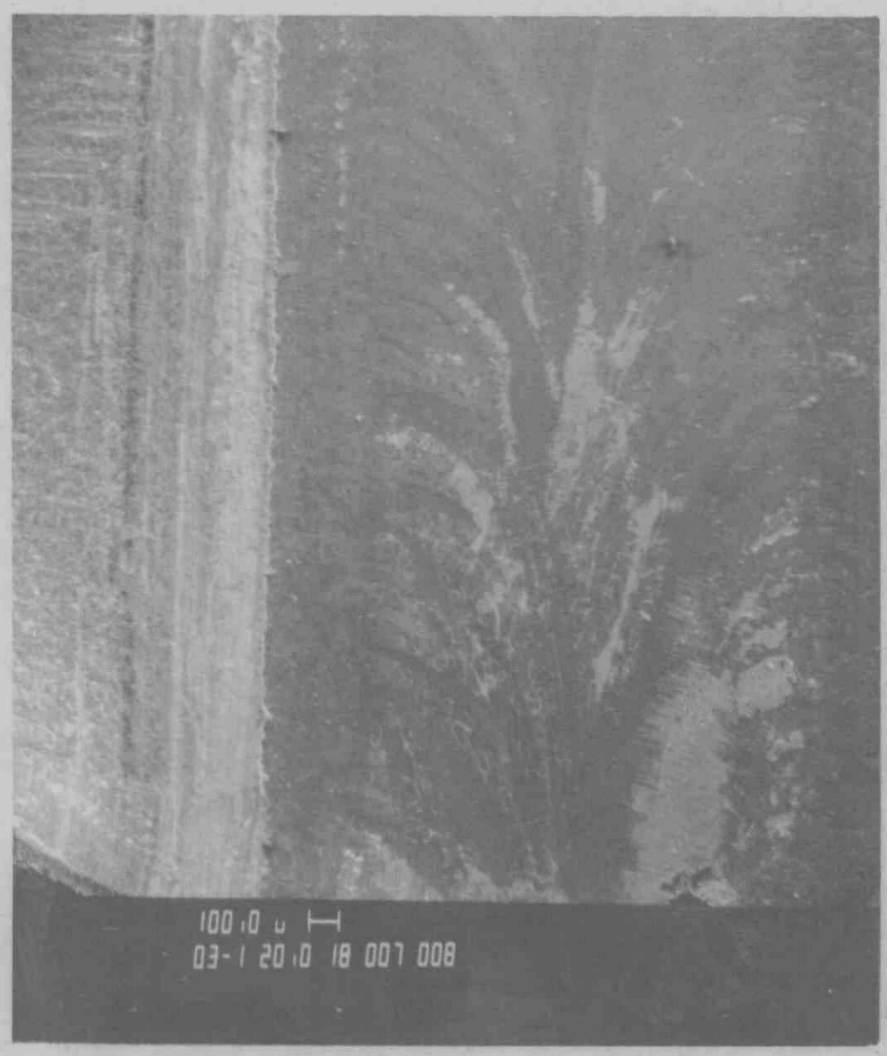
THE VF-7 CLAD WELD.

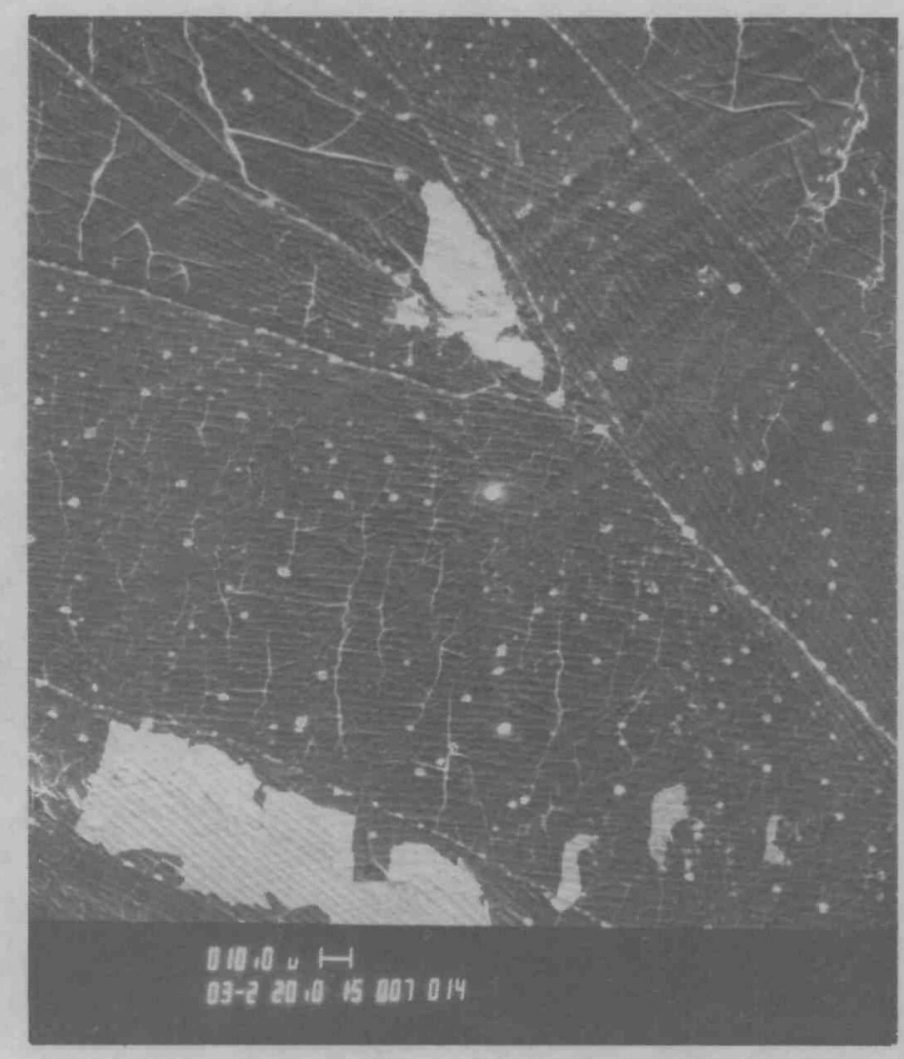

FIGURE 36: UNDERSIDE SURFACE OF THE VF-7 CLAD WELD. 


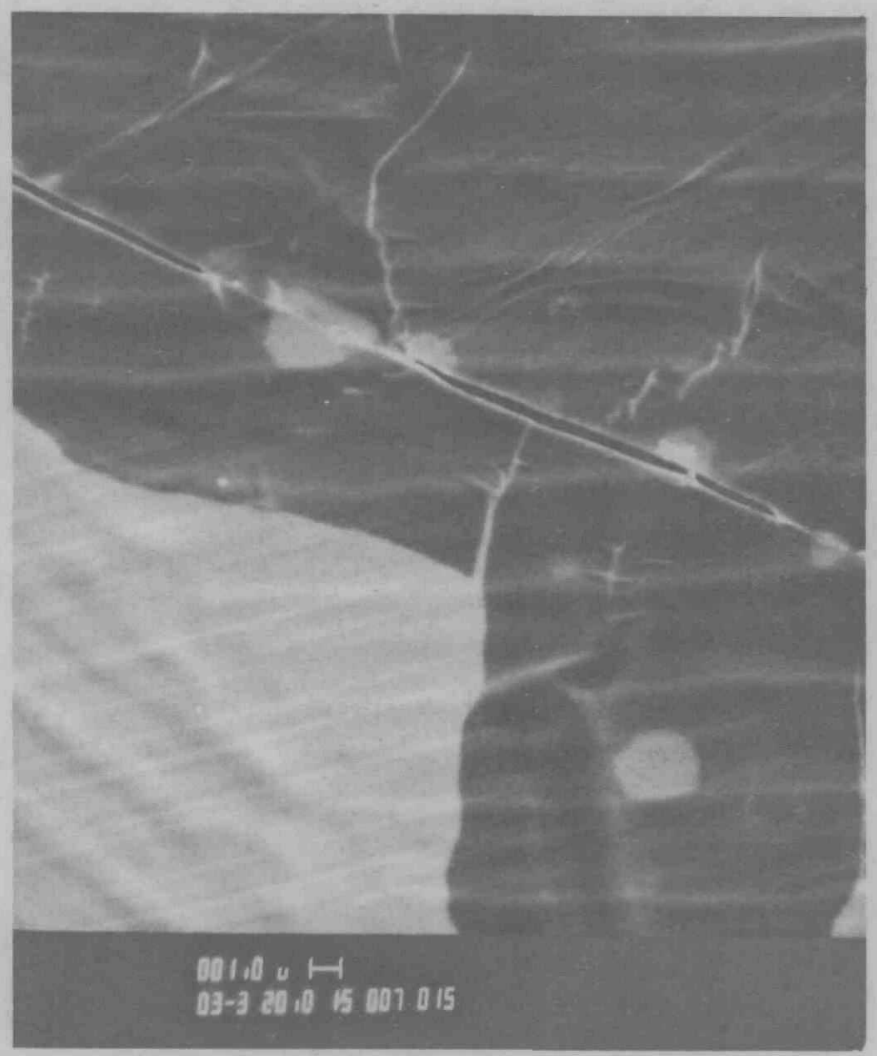

FIGURE 37: UNDERSIDE WELD SURFACE OF THE VF -7 CLAD.

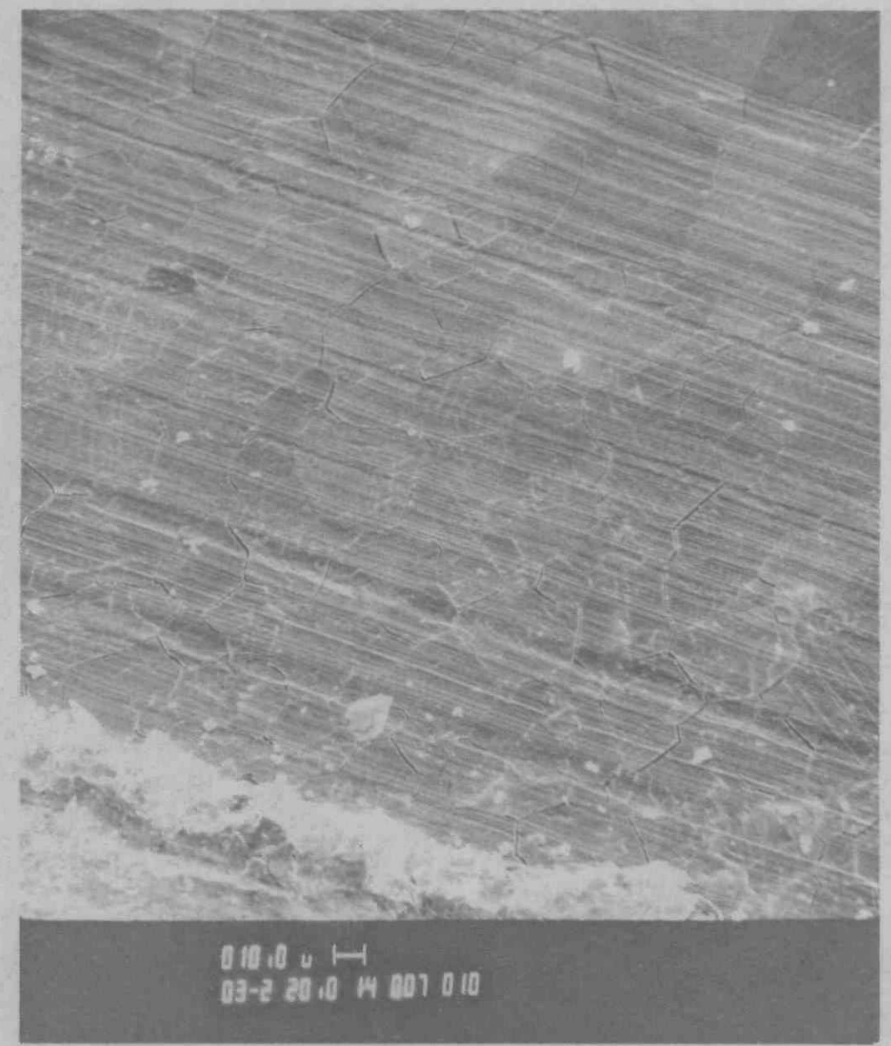

FIGURE 38: UNDERSIDE OF THE ELECTRICALLY ETCHED SURFACE OF THE VF-7 CLAD. 


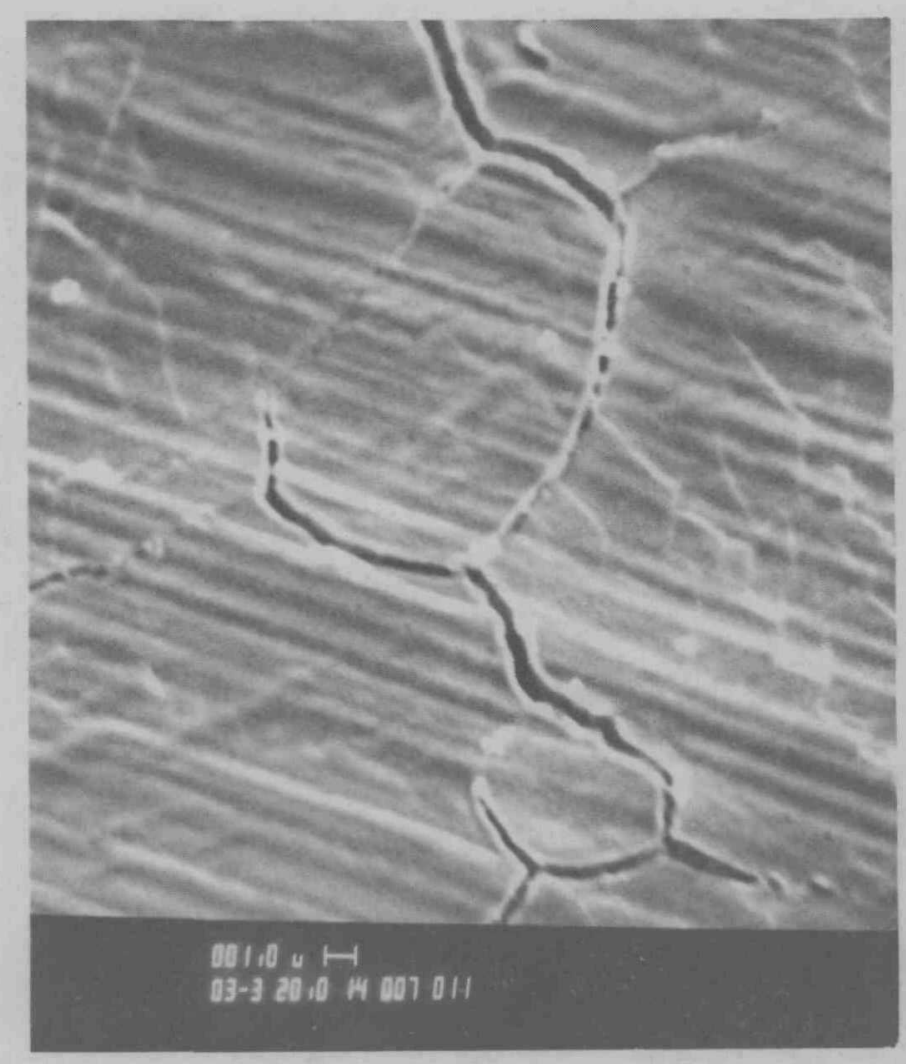

FIGURE 39: UNDERSIDE OF THE ELECTROLYTICALLY ETCHED SURFACE OF THE VF-7 CLAD.

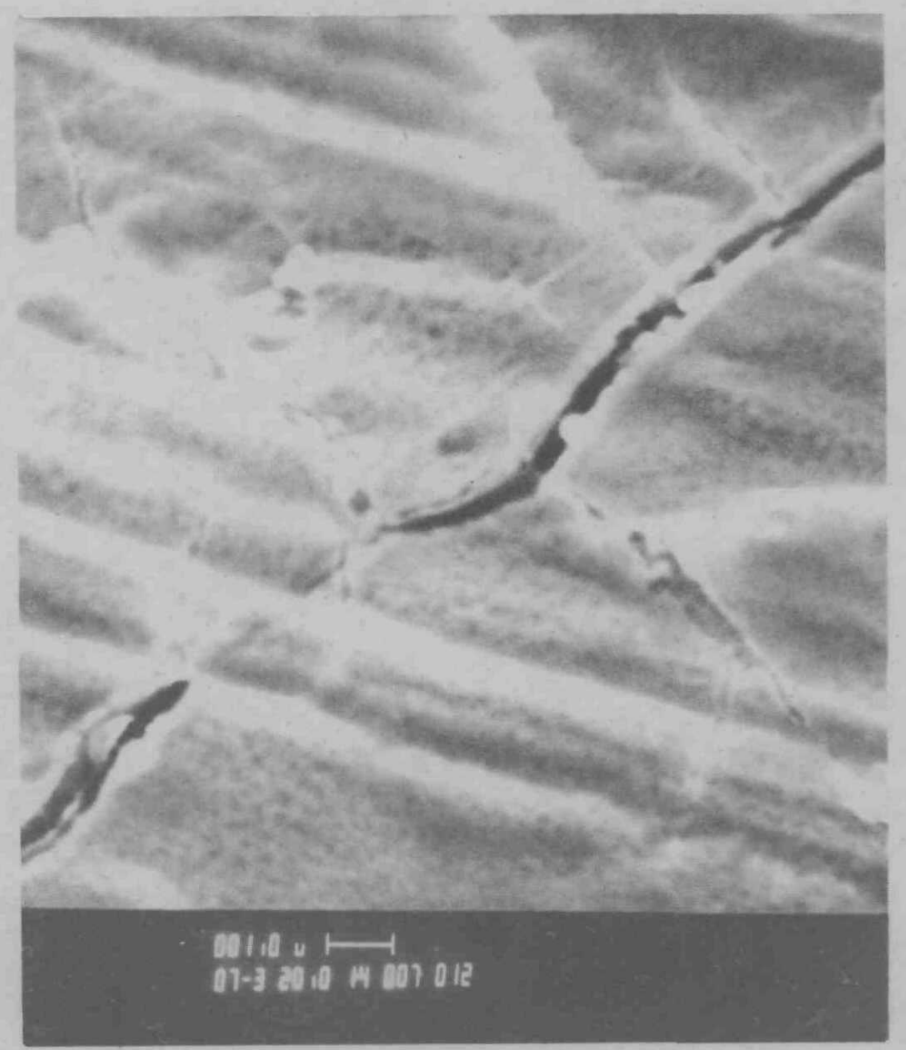

FIGURE 40: UNDERSIDE OF THE ELECTROLYTICALLY ETCHED SURFACE OF THE VF -7 CLAD. 


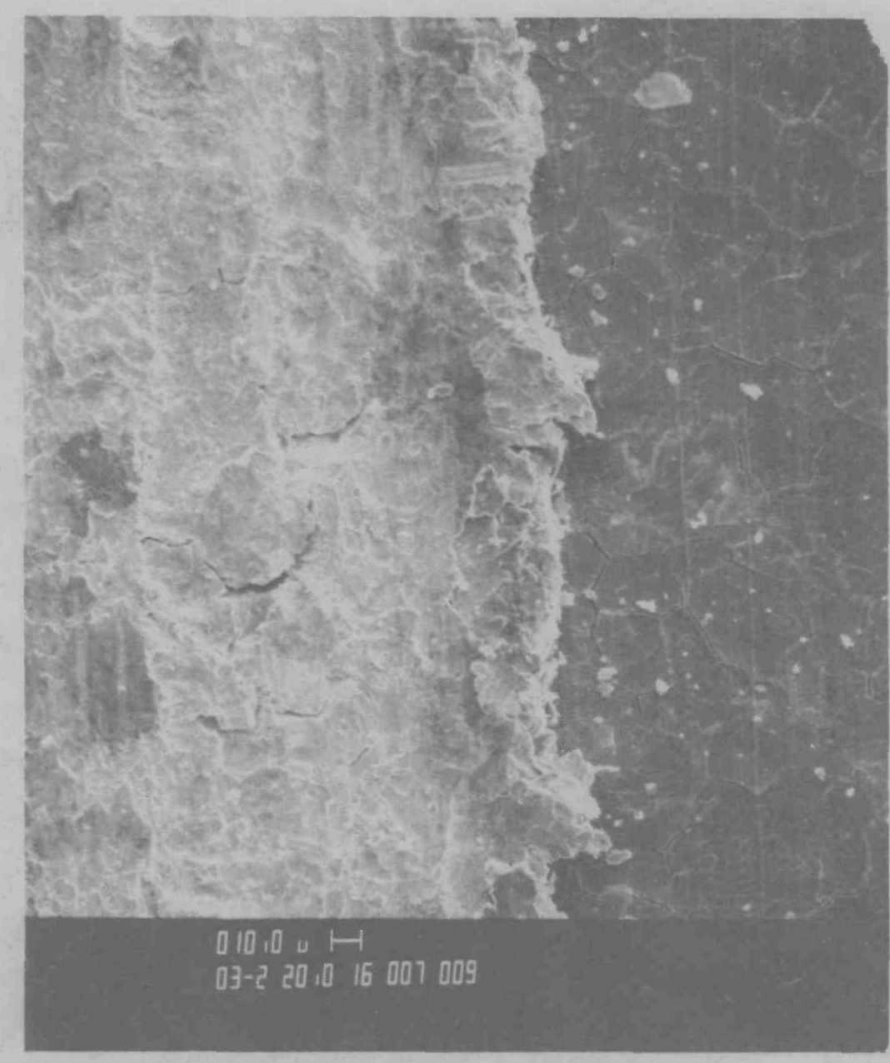

FIGURE 41: UNDERSIDE OF THE VF $\rightarrow 7$ CLAD BODY WHERE THE MACHINE DRESSING WAS MADE.

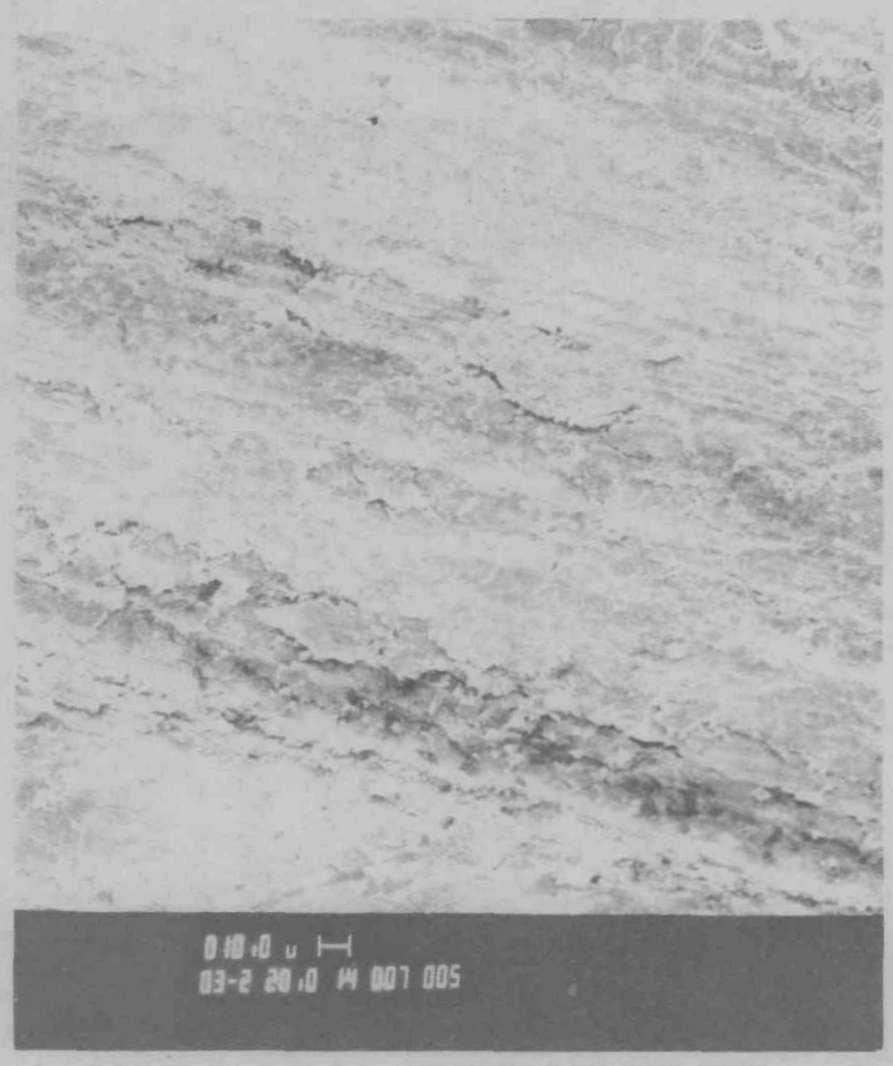

FIGURE 42: UNDERSIDE OF THE VF-7 CLAD BODY WHERE THE MACHINE DRESSING WAS MADE. 


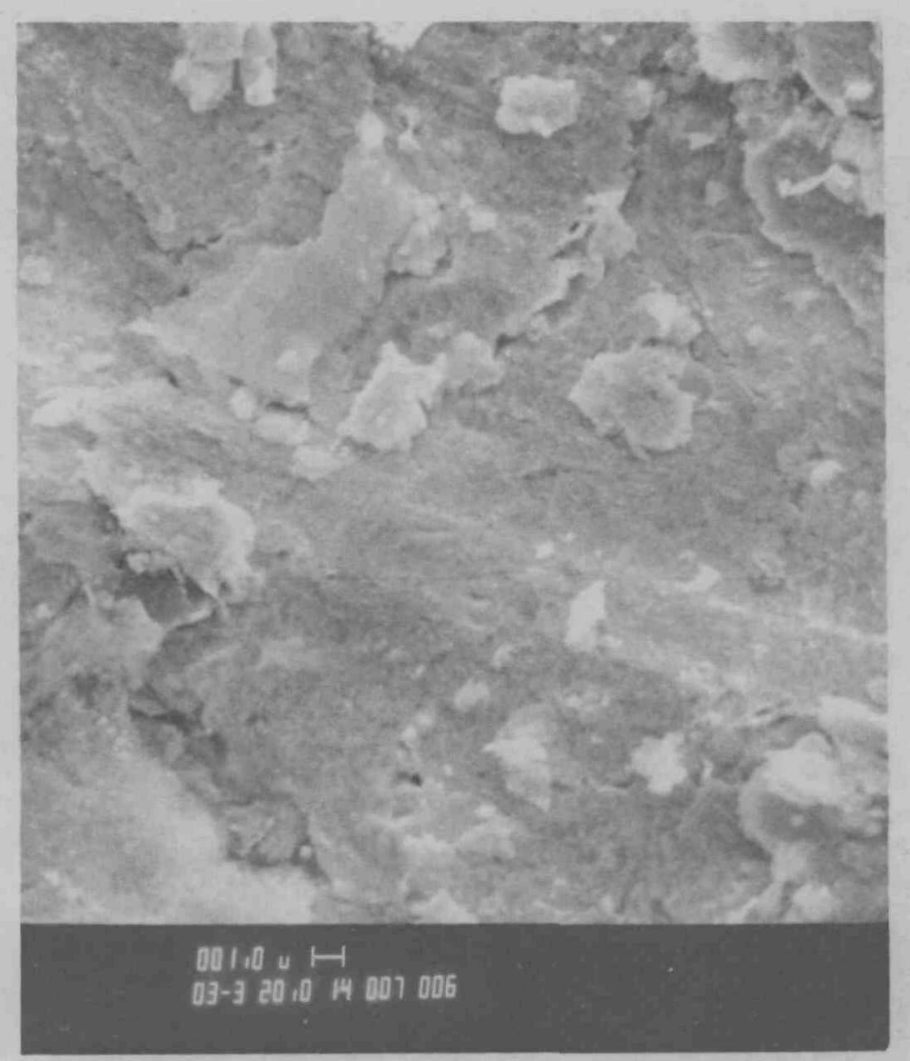

FIGURE 43: UNDERSIDE OF THE VF-7 CLAD BODY WHERE THE MACHINE DRESSING G WAS MADE.

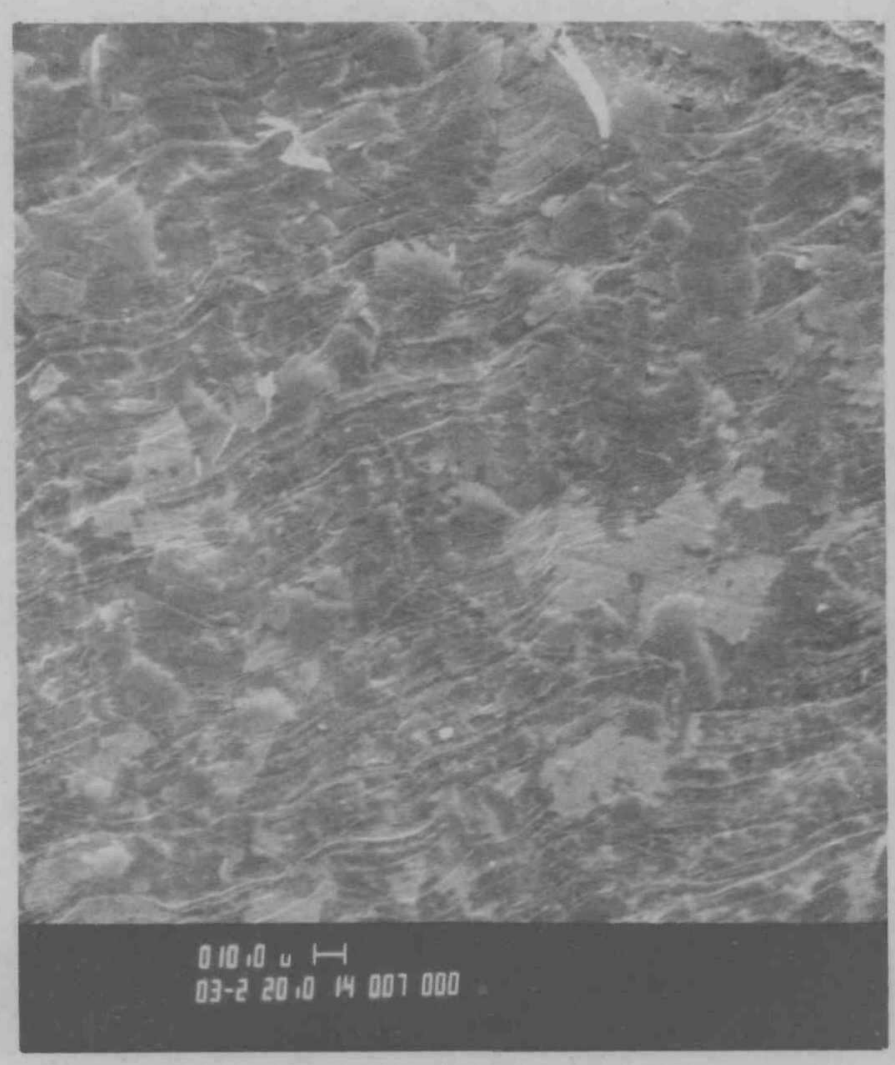

FIGURE 44: INTERIOR SIDEWALL OF THE VF -7 CLAD BODY. 


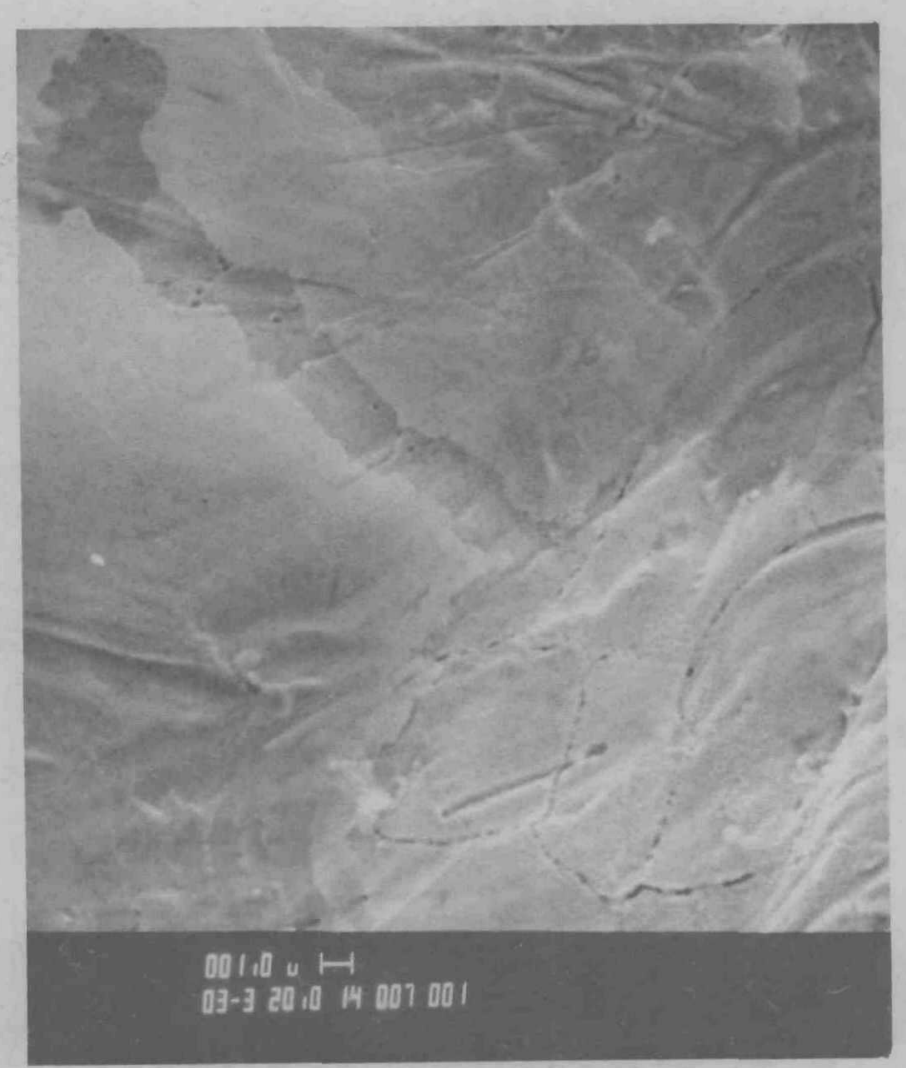

FIGURE 45: INTERIOR SIDEWALL OF THE VF-7 CLAD BODY.

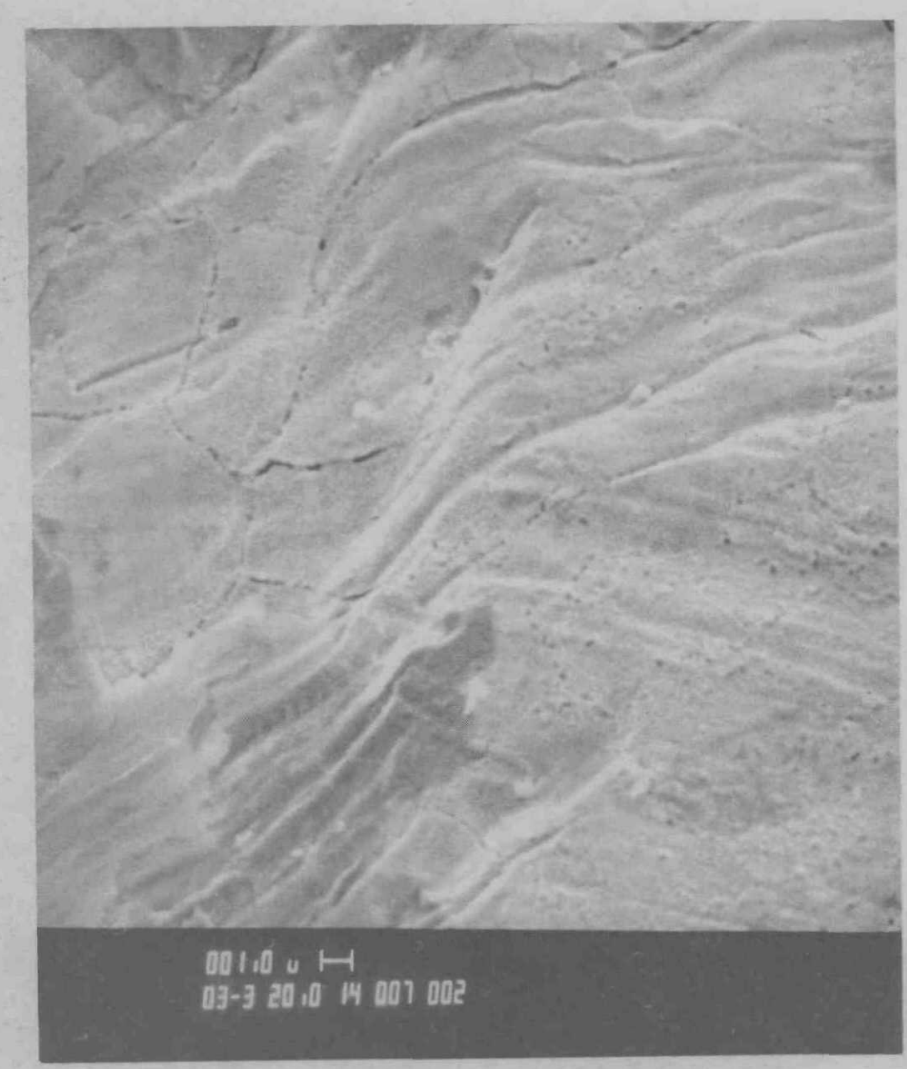

FIGURE 46: INTERIOR SIDEWALL OF THE VF -7 CLAD BODY. 


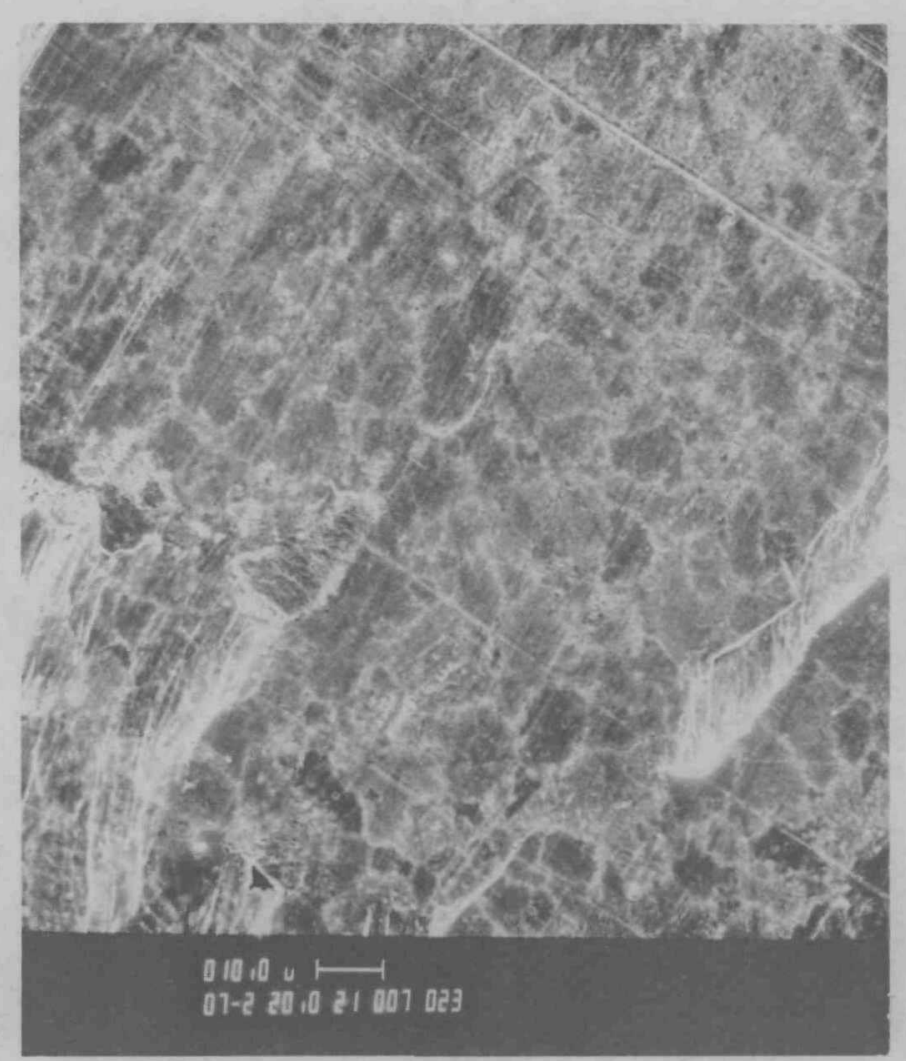

FIGURE 47: INTERIOR SURFACE OF THE VF-7 CLAD END CAP. 


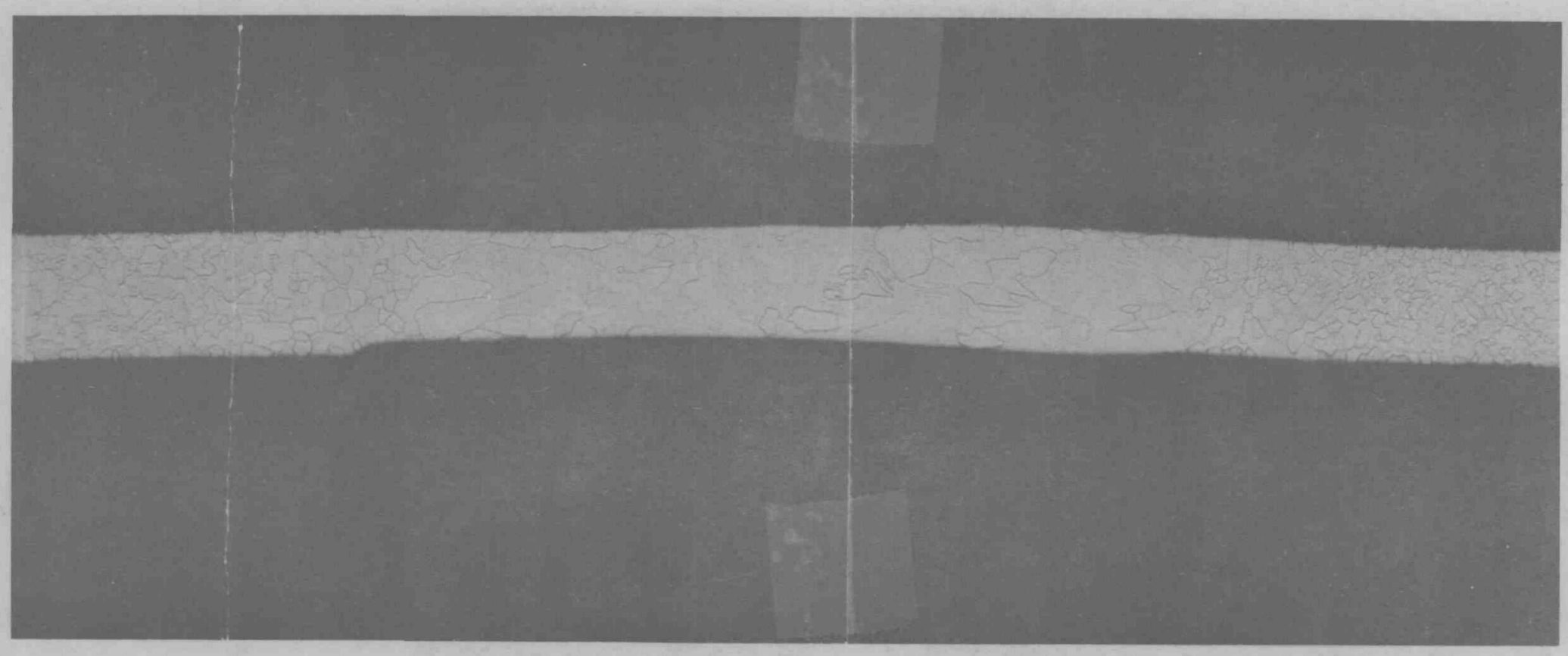

FIGURE 48: CROSS-SECTION OF THE VF-7 CLAD WELD (40X), 


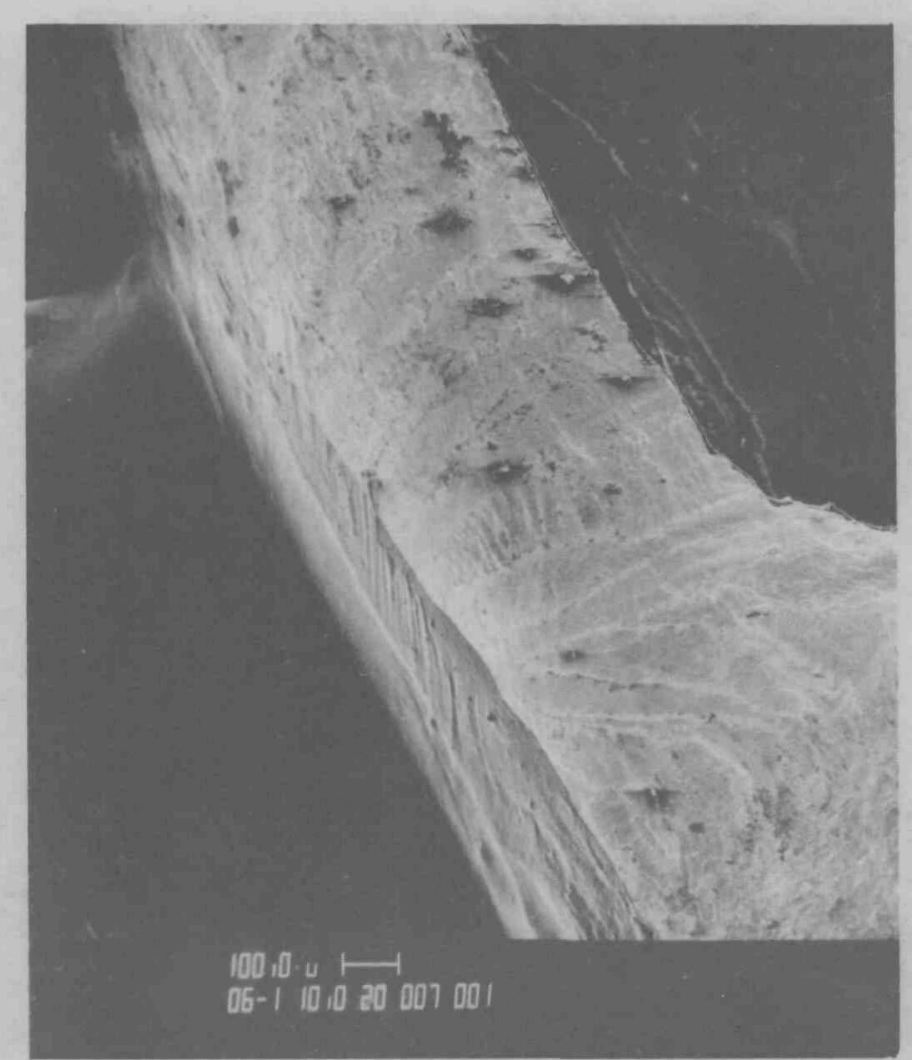

a)
FIGURE 49: FRACTURE CROSS-SECTION OF THE VF-7 CLAD WELD.

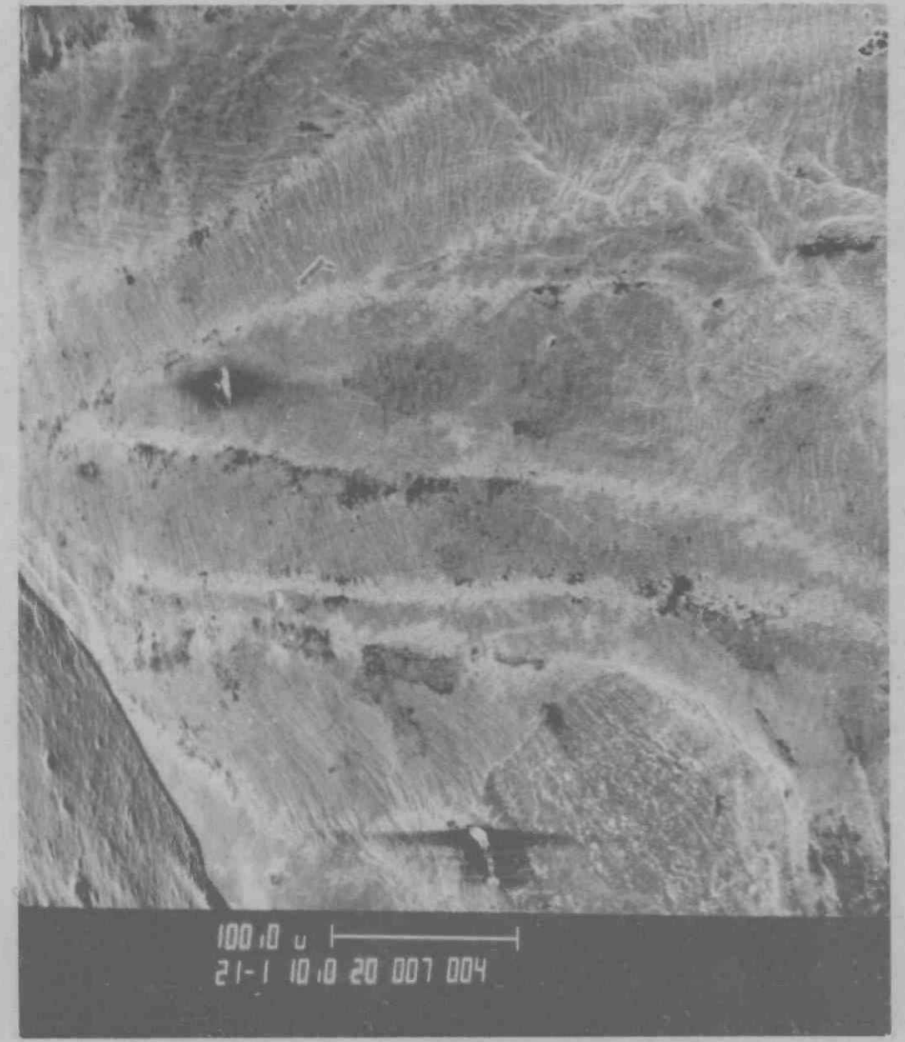

FIGURE 50: FRACTURE CROSS-SECTION OF THE VF-7 CLAD WELD. 


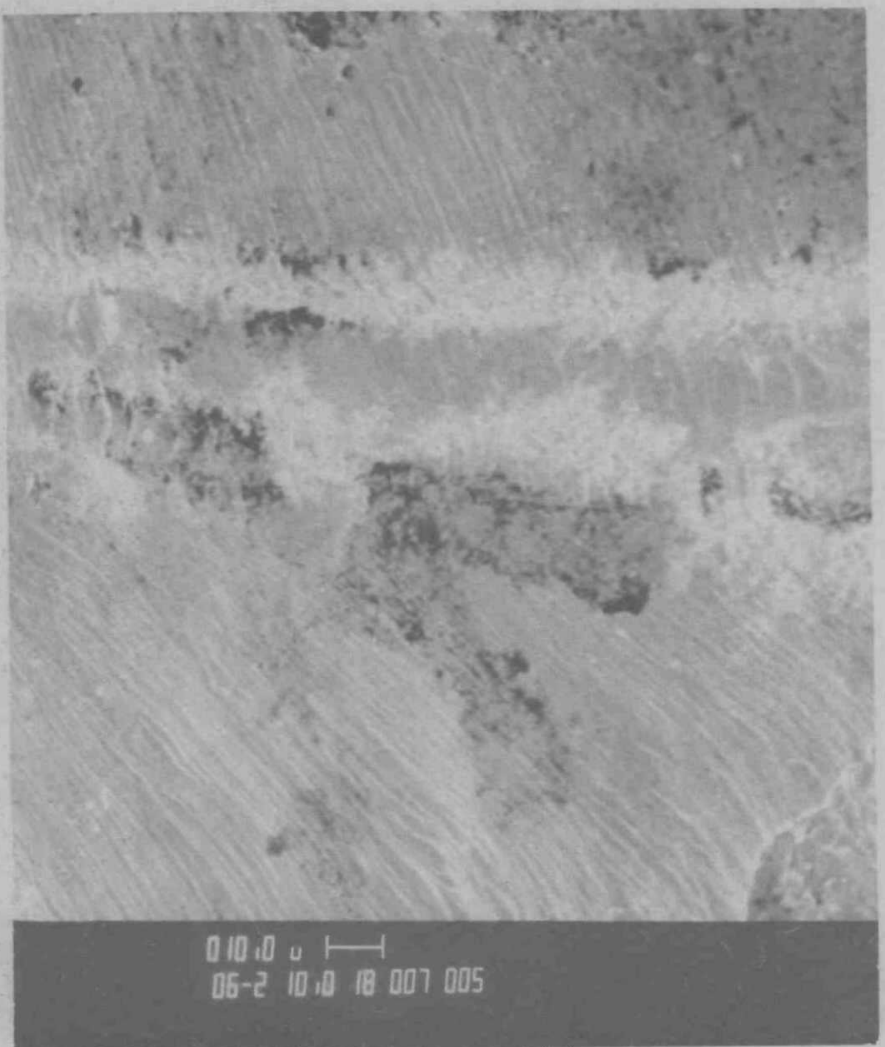

FIGURE 51: FRACTURE CROSS-SECTION OF THE VF-7 CLAD WELD.

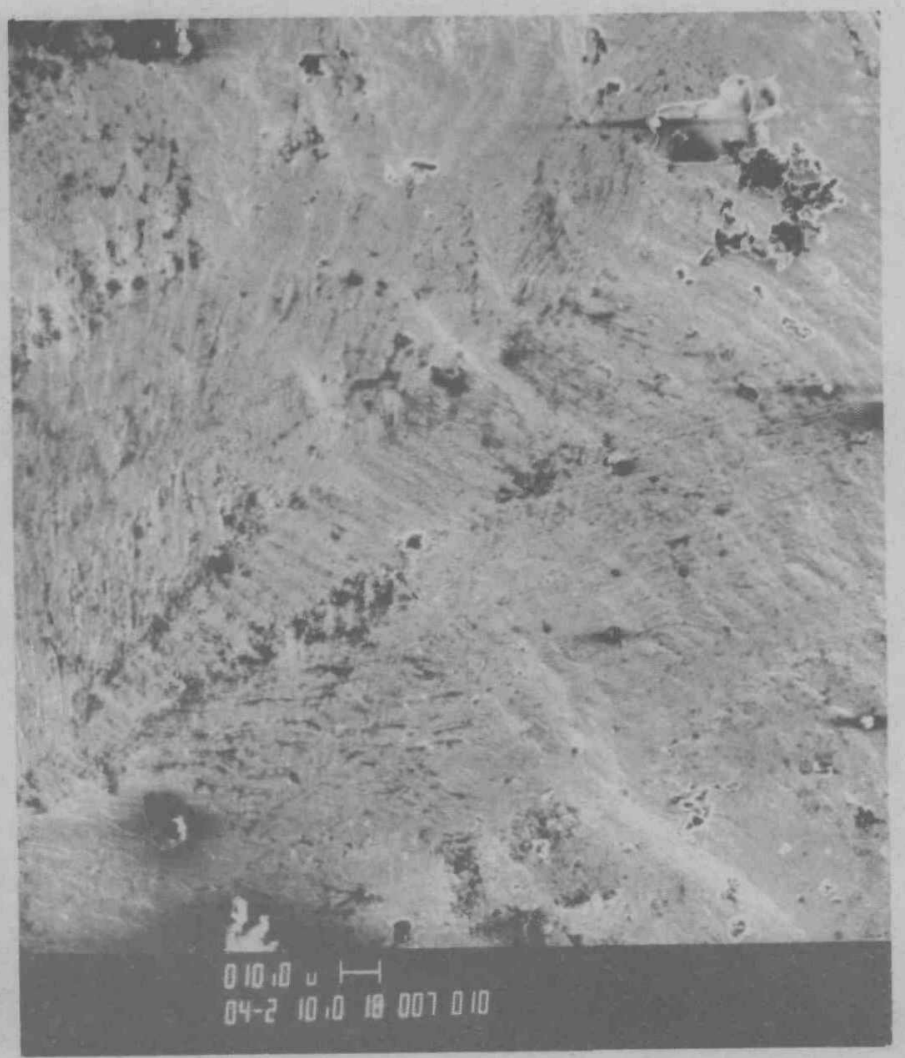

FIGURE 52: FRACTURE CROSS-SECTION OF THE VF-7 CLAD WELD. 


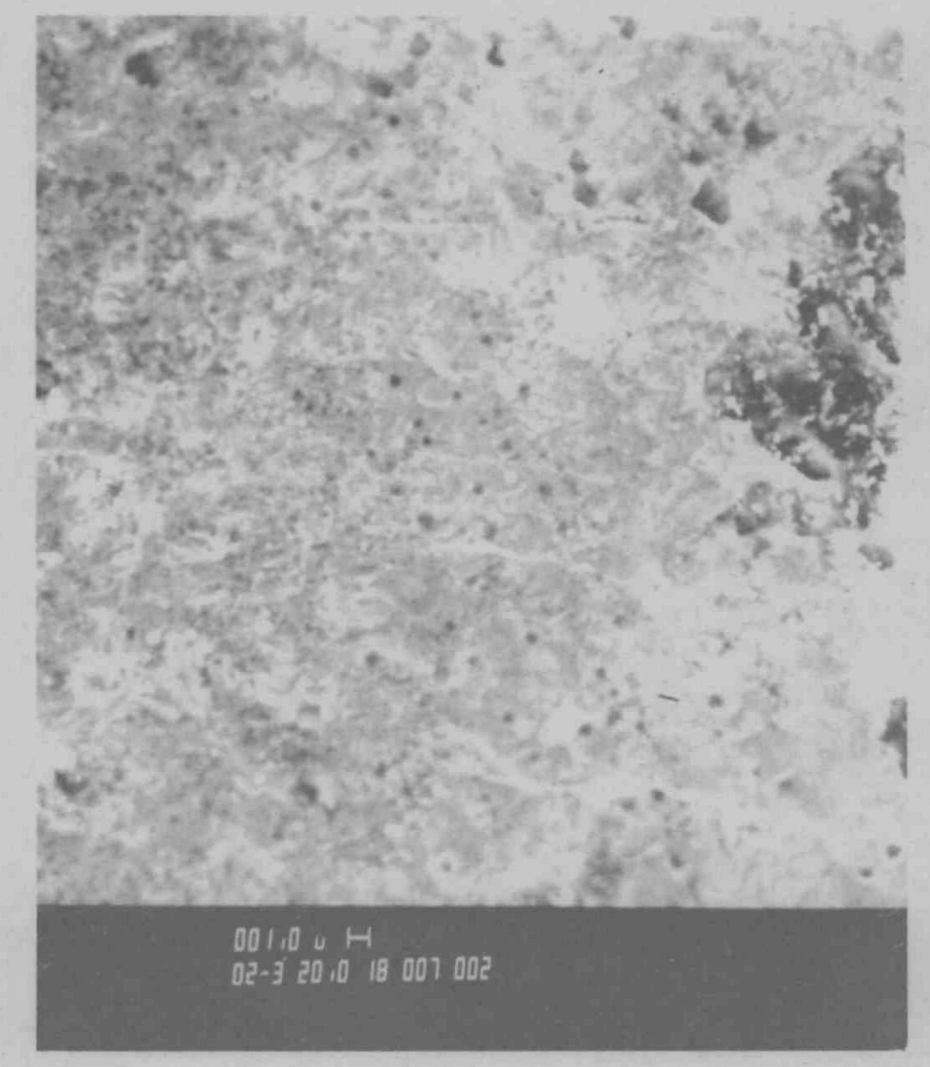

FIGURE 53: UNCOATED SURFACE OF or THE VF-7 CLAD BODY - JUST BELOW THE WELD.

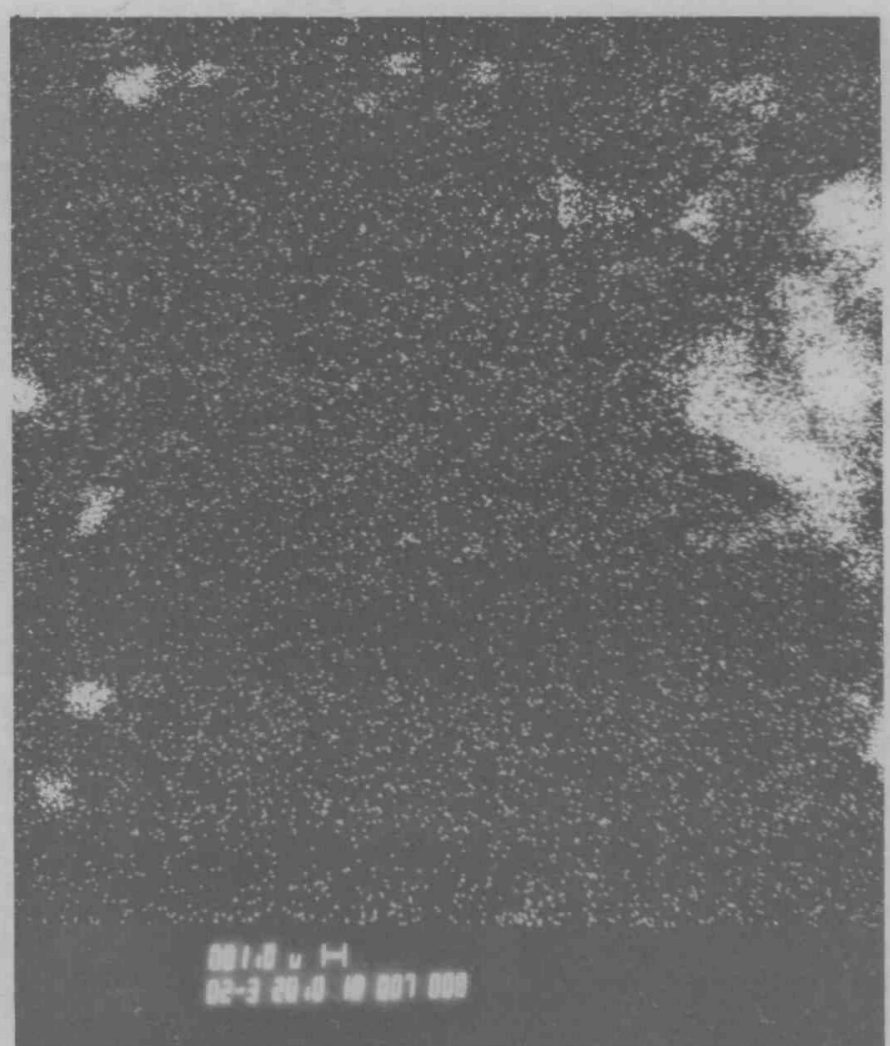

FIGURE 54: ELEMENTAL X-RAY MAP DF ALUMINUM MADE FROM THE SURFACE OF the SAMPLe Shown in the previous F I GURE. 


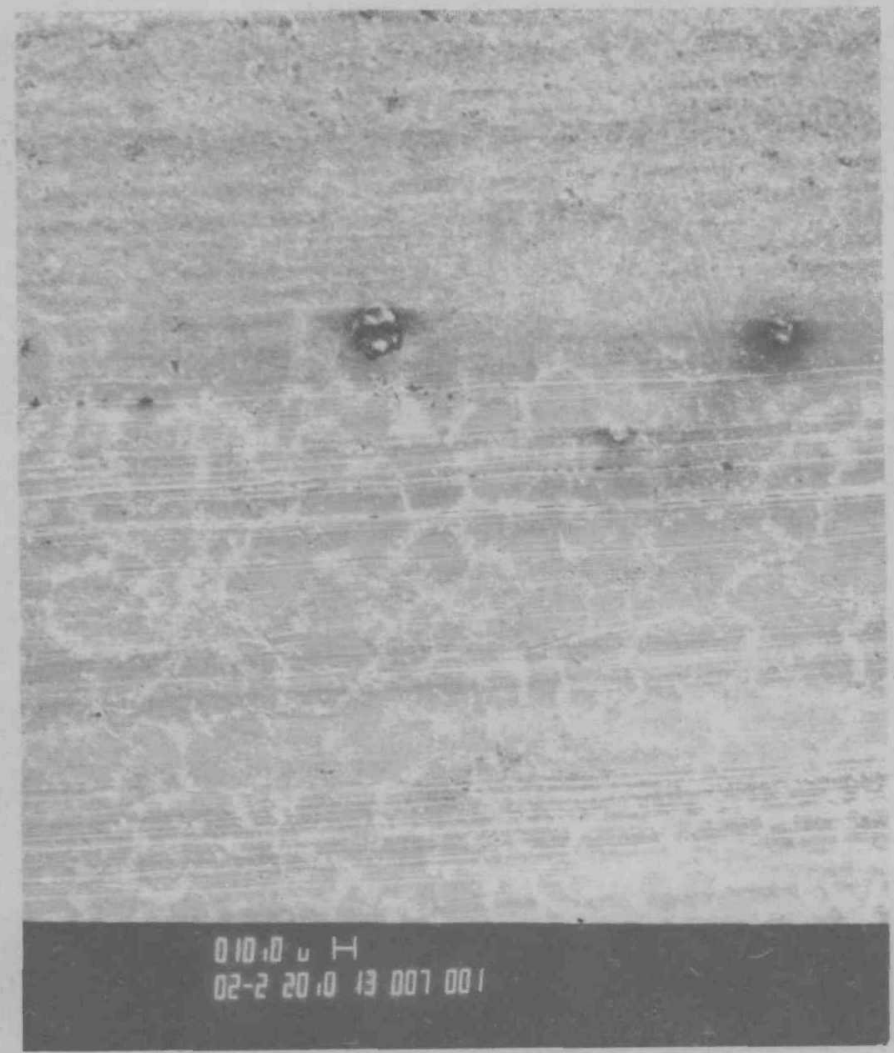

FIGURE 55: UNCOATED AREA OF THE VF -7 CLAD SIDEWALL.

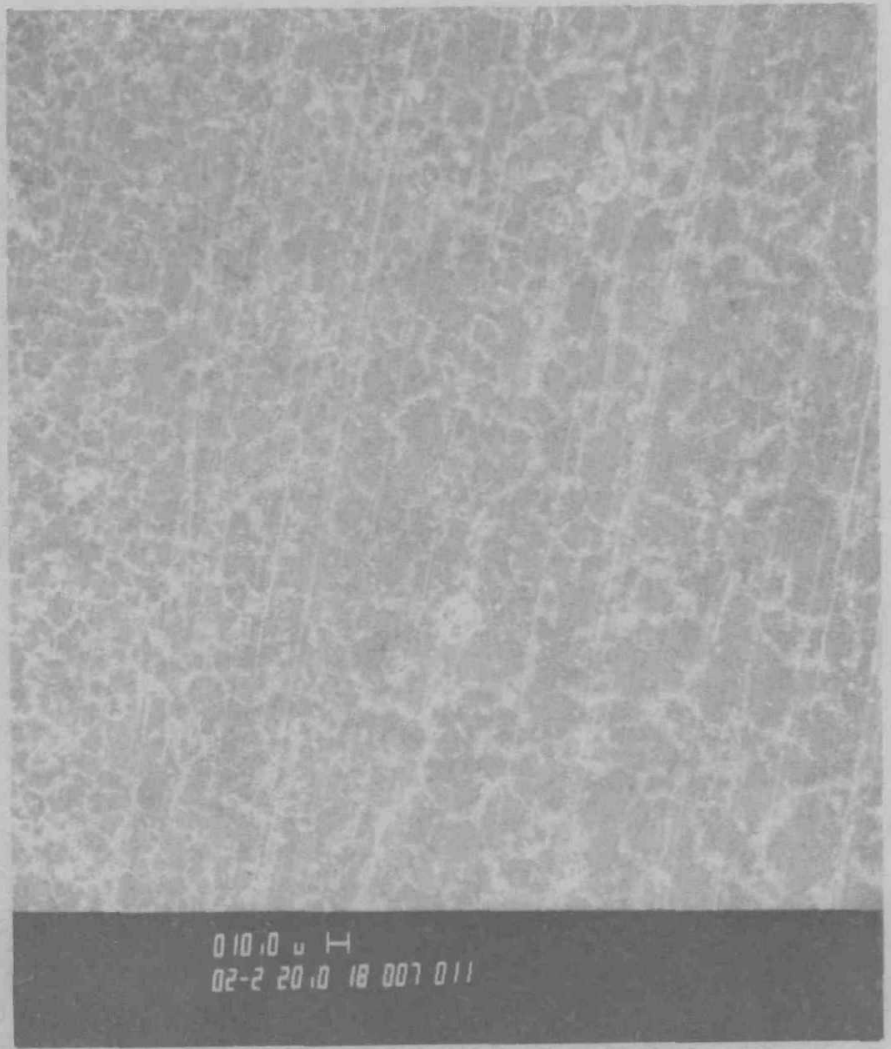

FIGURE 56: UNCOATED AREA OF THE VF -7 CLAD SIDEWALL. 


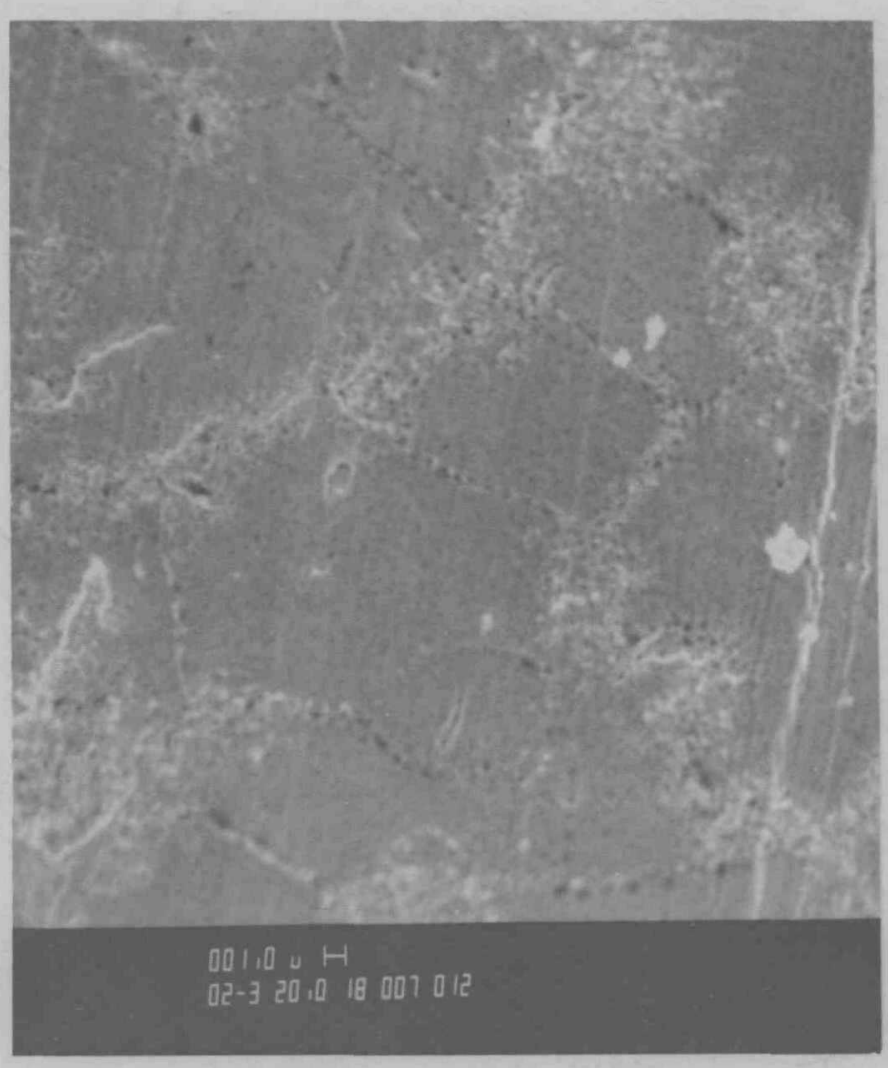

FIGURE 57: UNCOATED AREA OF THE

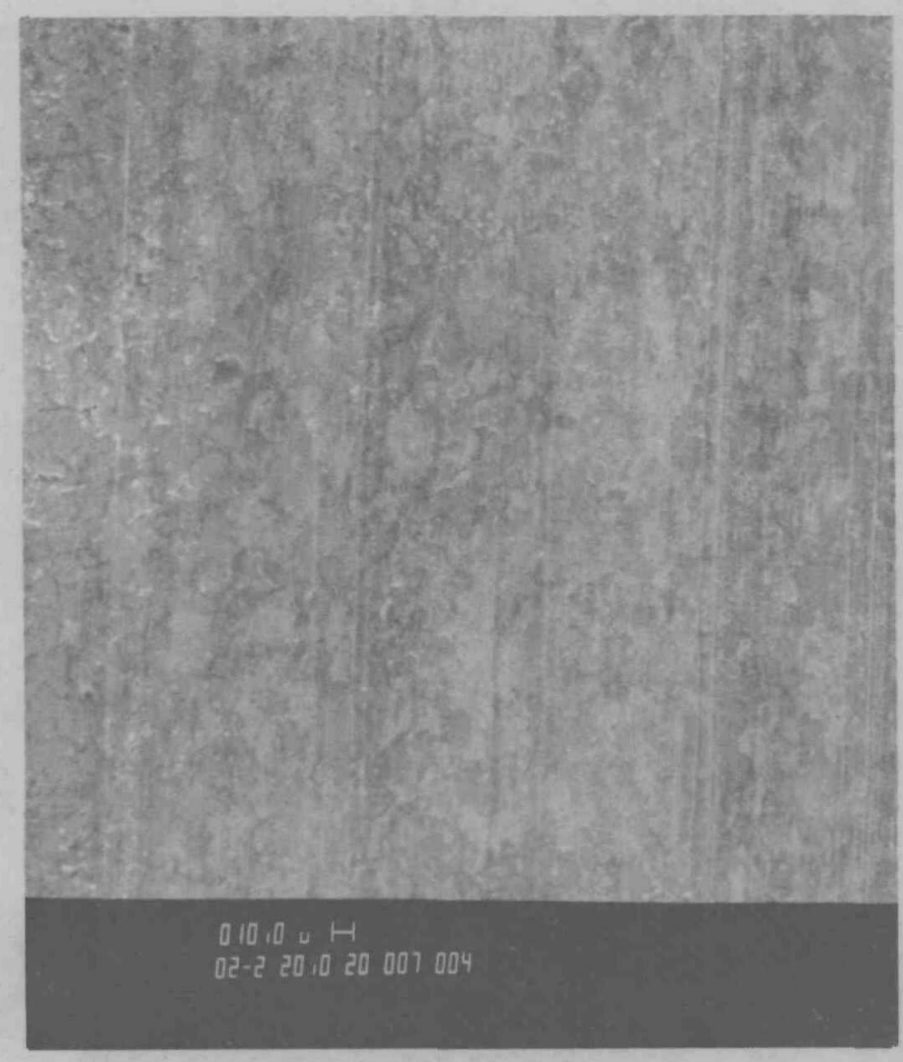

FIGURE 58: UNCOATED AREA OF THE VF -7 CLAD BODY SIDEWALL IMMEDIATELY ABOVE THE COATED AREA. 


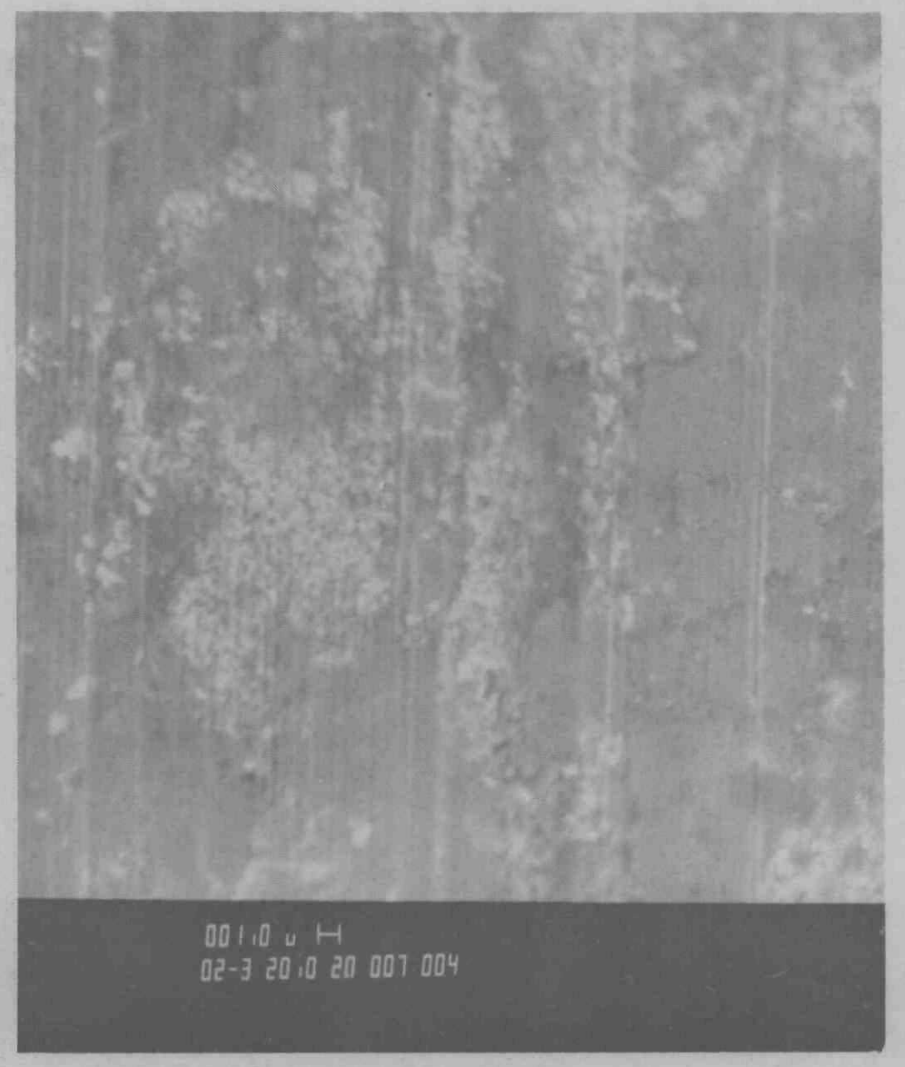

FIGURE 59: UNCOATED AREA OF THE VF-7 CLAD BODY SIDEWALL.

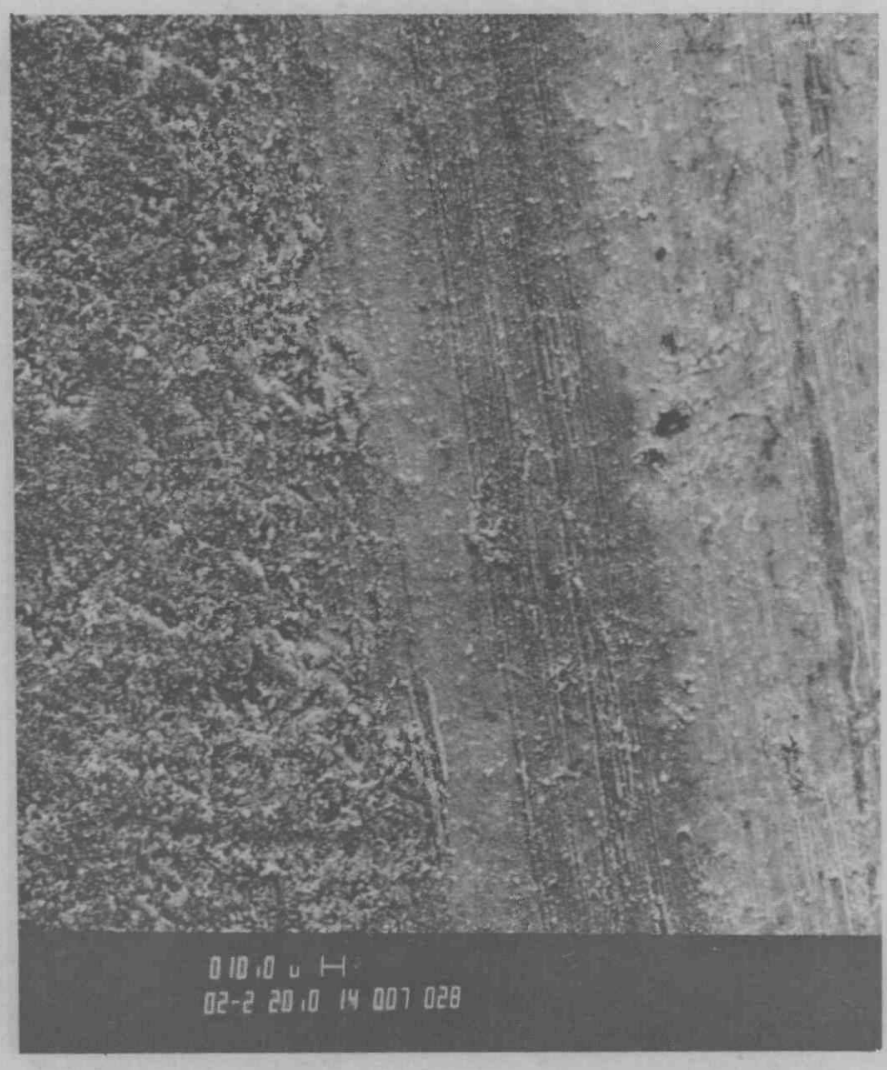

FIGURE 60: UNCOATED AREA OF THE VF $\rightarrow$ CLAD BODY SIDEWALL JUST ABOVE WHERE IT WAS COATED. 


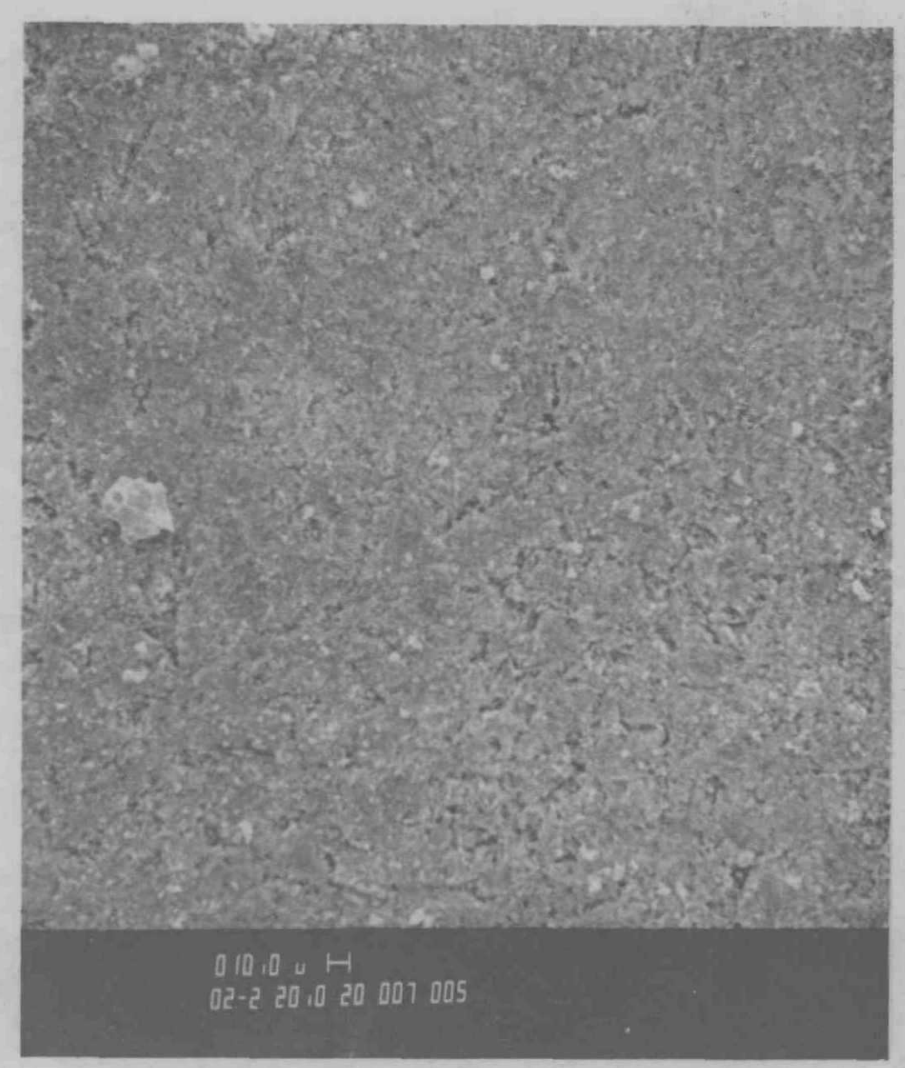

FIGURE 61: SURFACE OF THE VF-7 ติ FLAKED OFF.

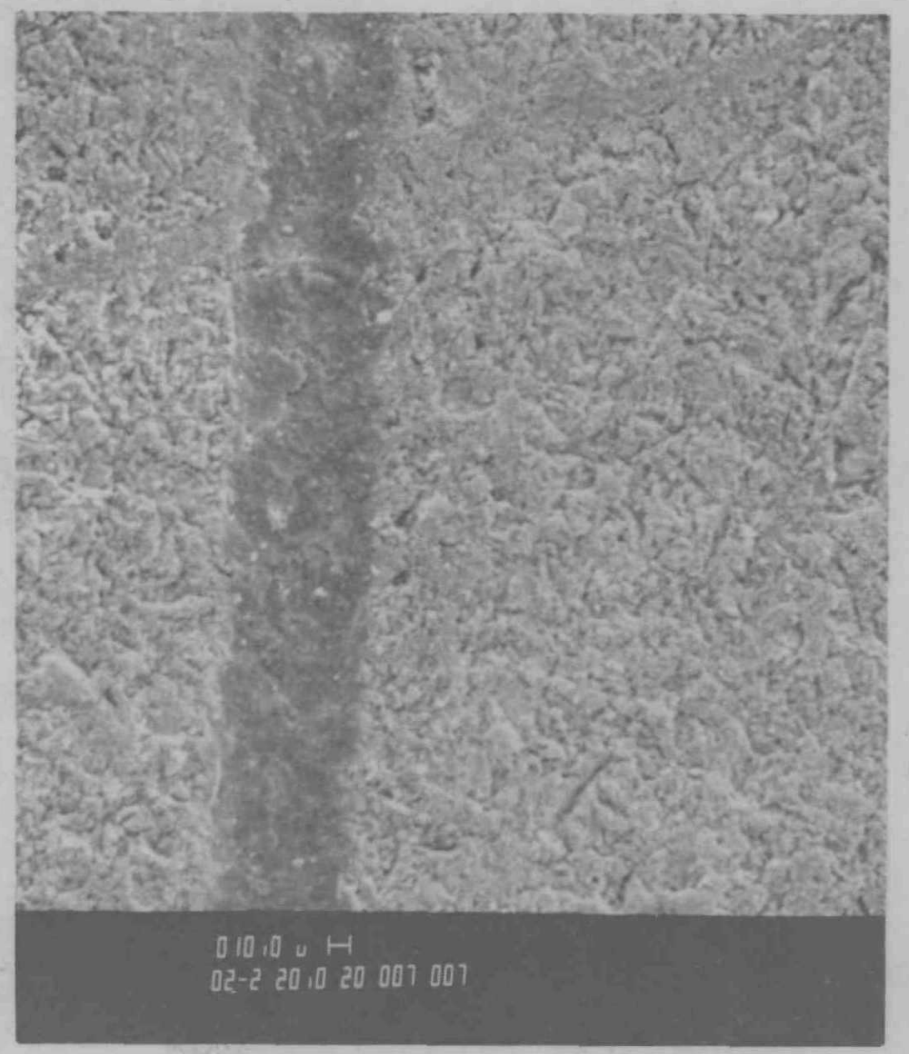

FIGURE 62: SCRATCH ON THE SURFACE OF THE VF $\rightarrow 7$ CLAD BODY WHERE THE COATING HAD FLAKED OFF. 


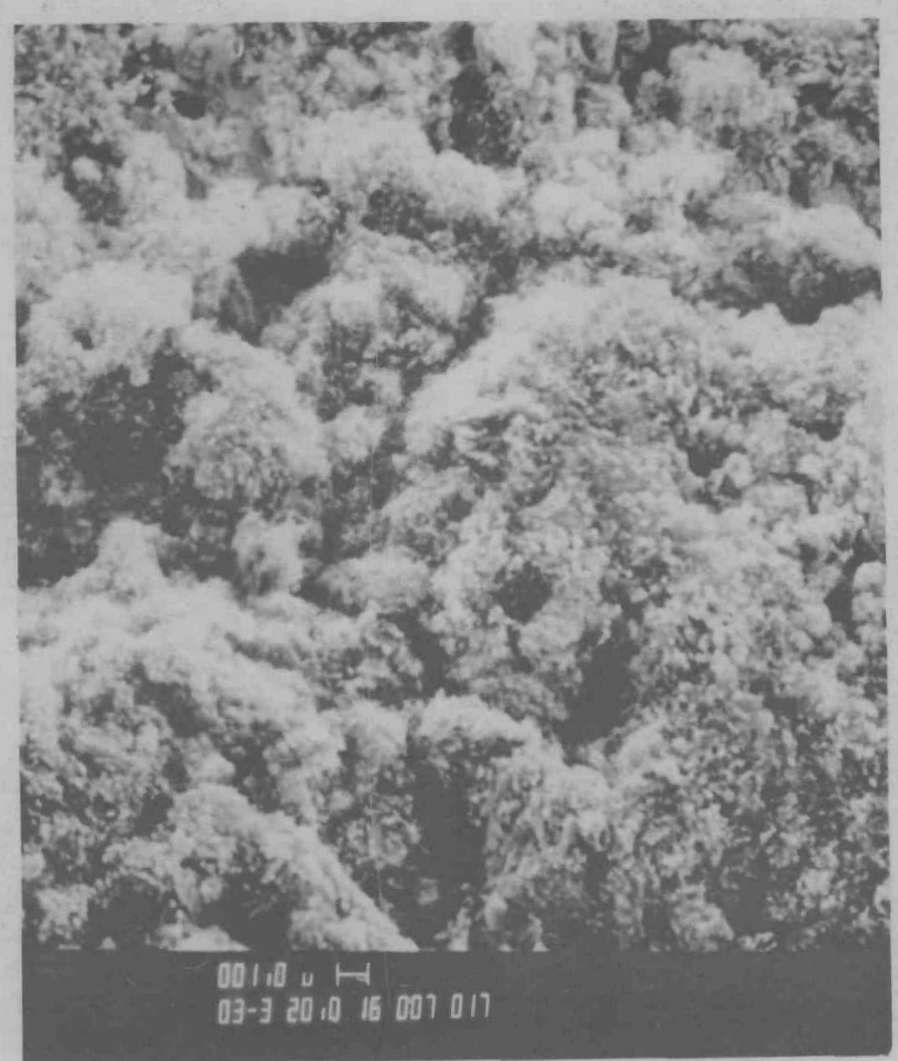

FIGURE 63: SURFACE OF THE VF-7 CLAD BODY WHERE THE COATING HAD FLAKED OFF. 


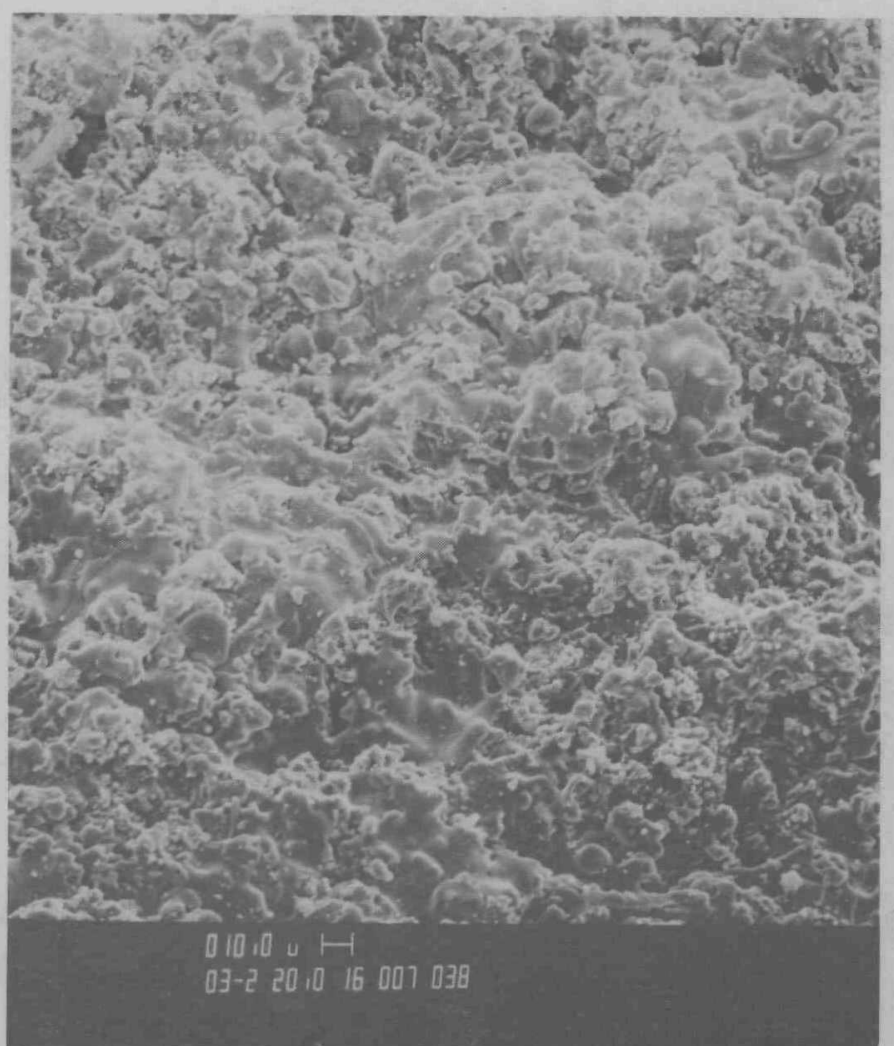

FIGURE 64A: DUTSIDE SURFACE OF
THE EMISSIVE COATING FROM THE $V F-7$ CLAD BODY.

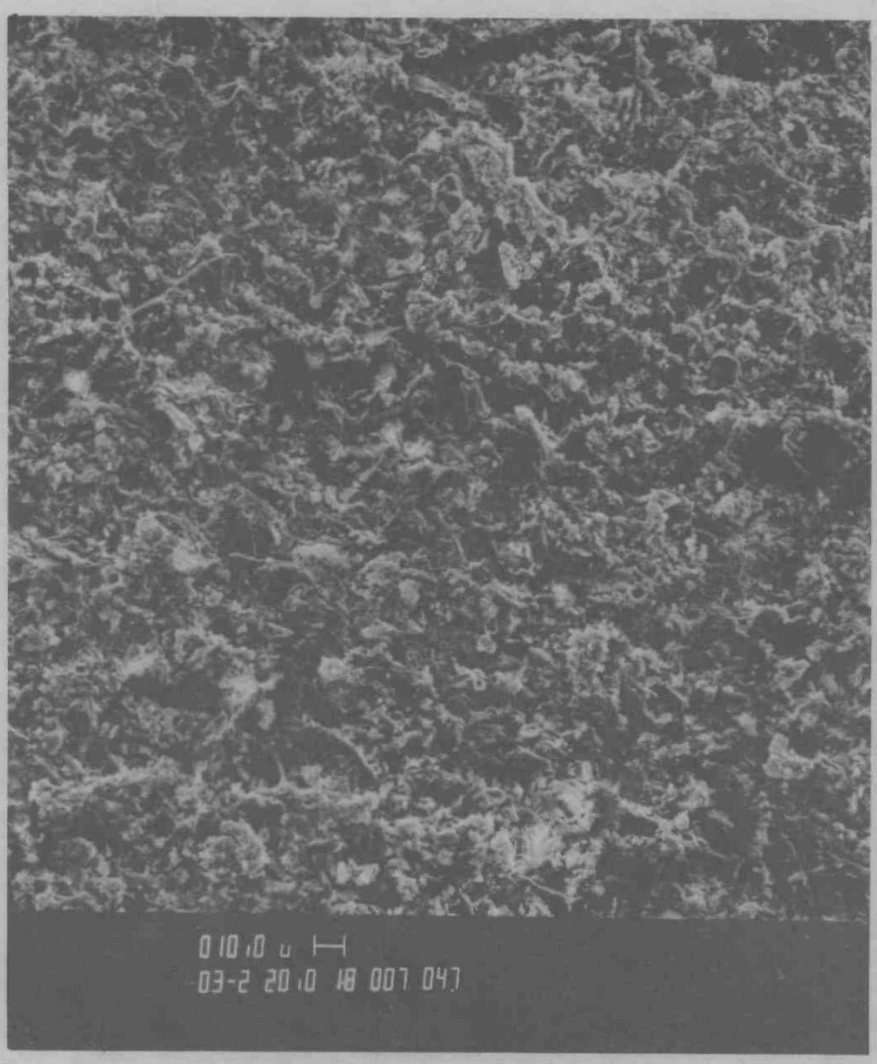

FIGURE 64B: INSIDE SURFACE OF THE EMISSIVE COATING FROM THE VF-7 CLAD BODY. 


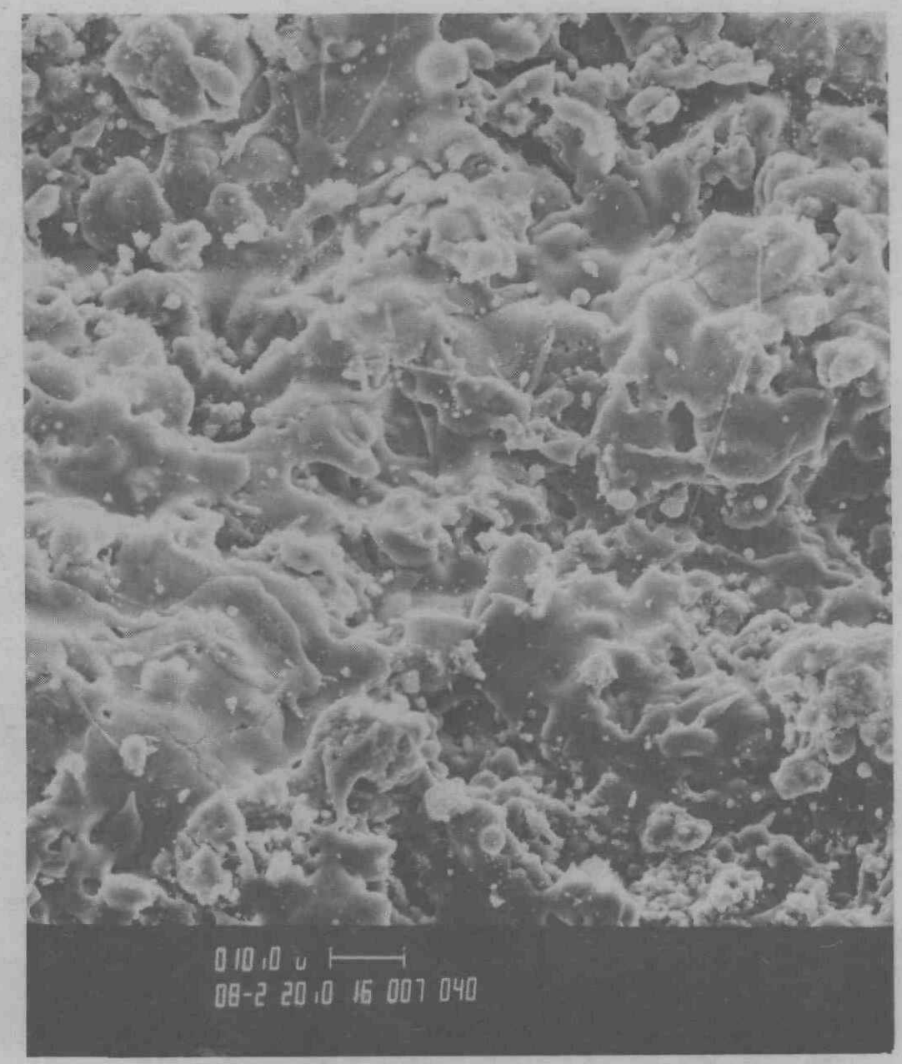

FIGURE 65A: OUTSIDE SURFACE OF THE EMISSIVE COATING FROM THE VF-7 CLAD BODY.

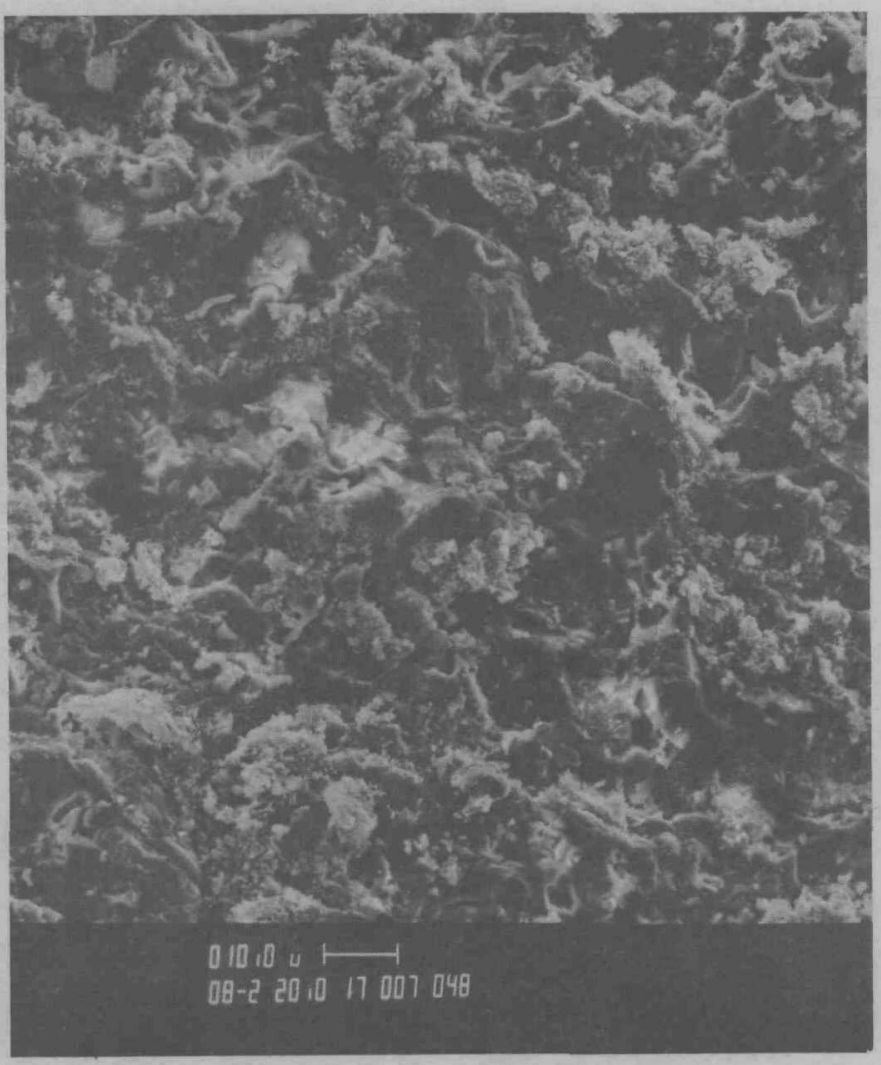

FIGURE 65B: INSIDE SURFACE OF THE EMISSIVE COATING FROM THE VF-7 CLAD BODY. 


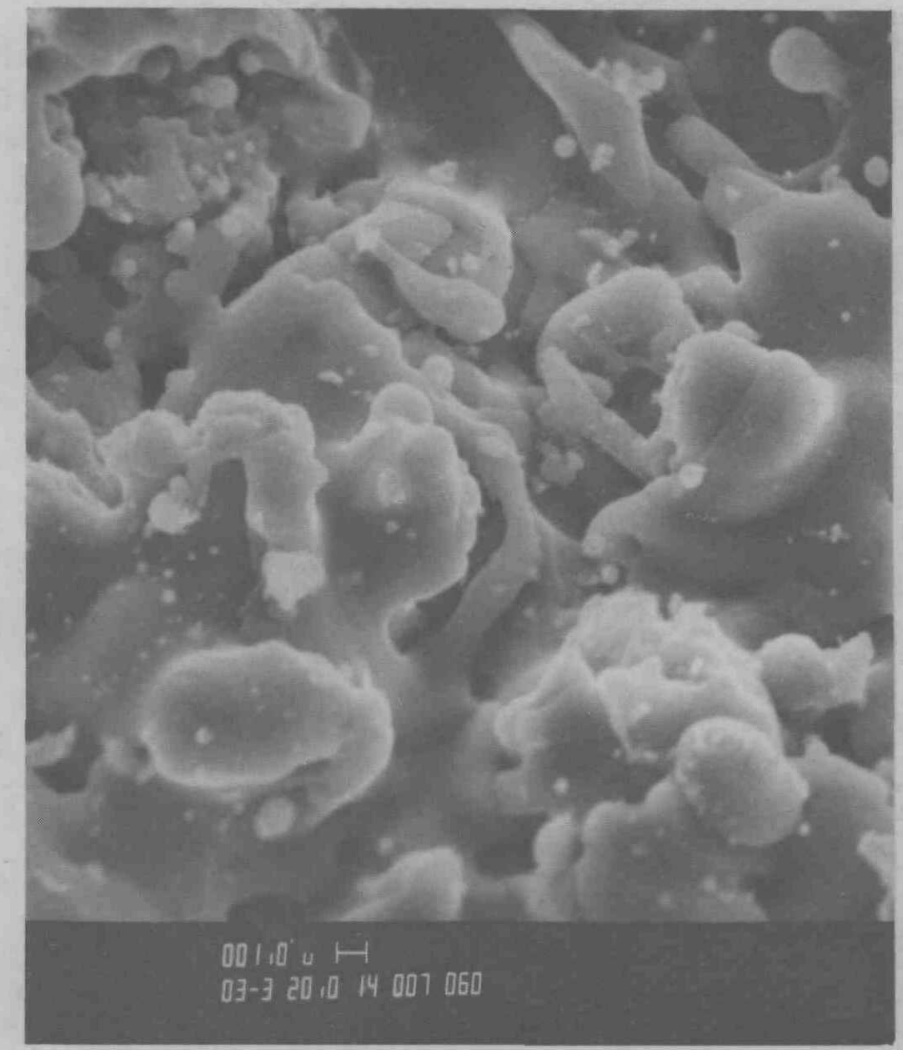

FIGURE 66A: DUTSIDE SURFACE OF THE BODY.

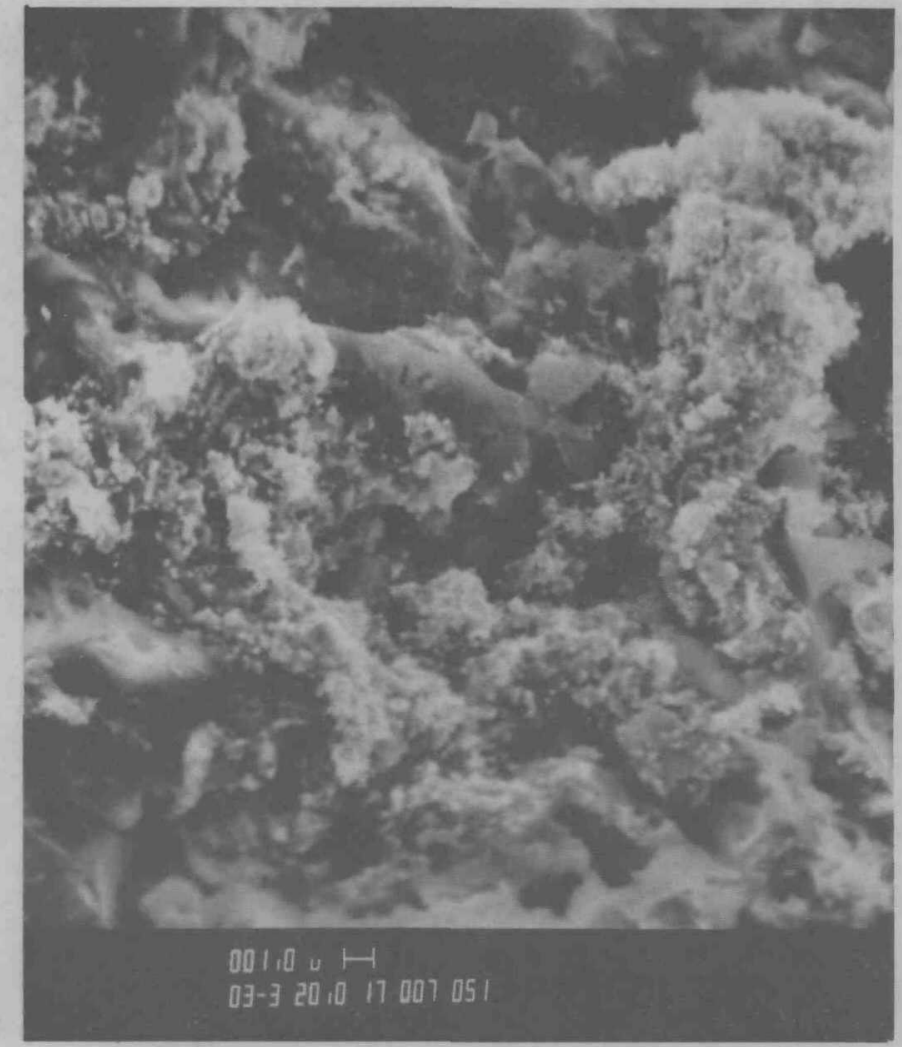

FIGURE 66B: INSIDE SURFACE OF THE EMISSIVE COATING FROM THE VF-7 CLAD BODY. 


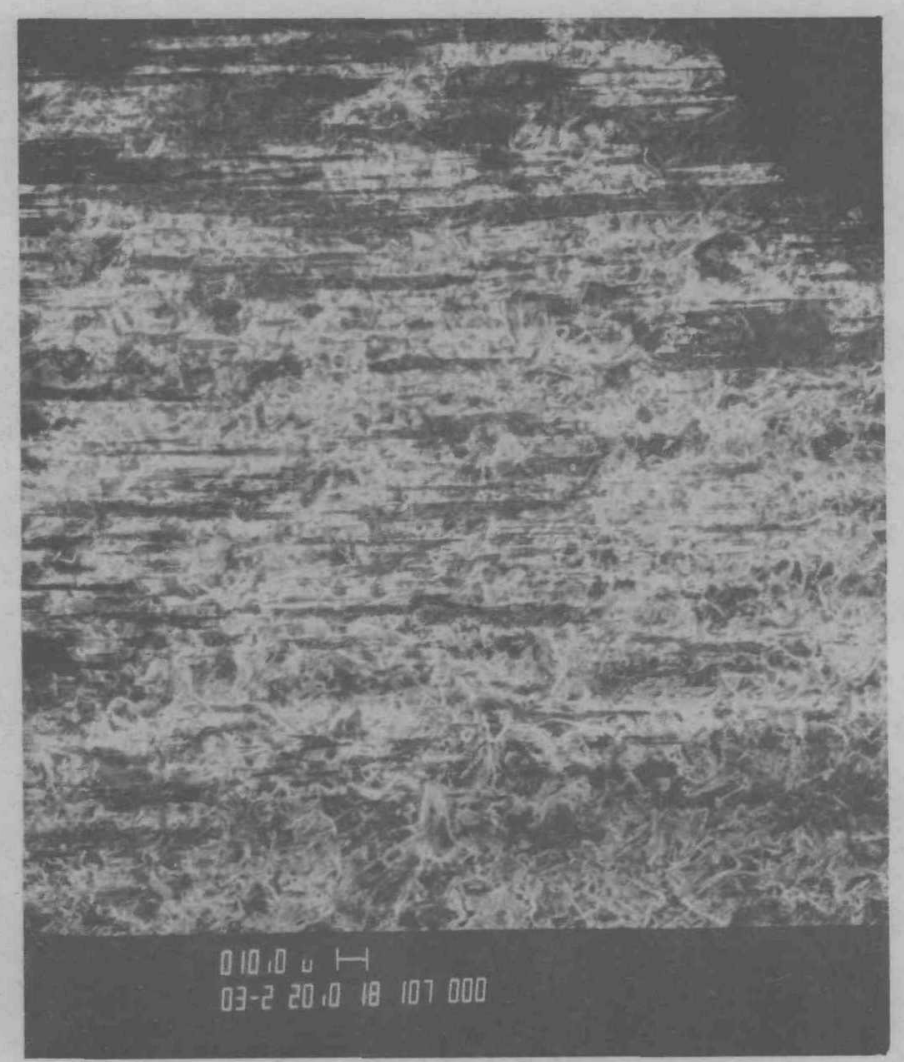

FIGURE 67: DUTSIDE SURFACE OF THE EMISSIVE COATING FROM THE VF-3 CLAD BODY BEFORE CARBON COATING.

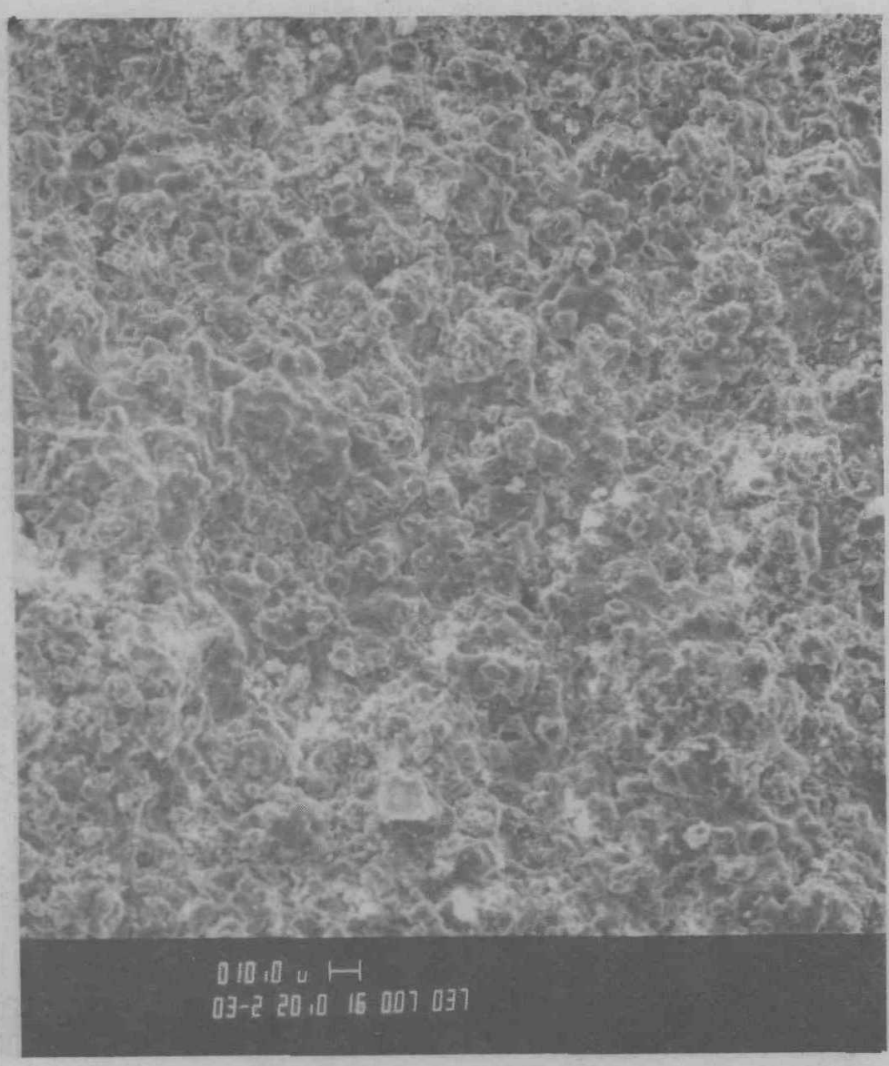

FIGURE 68: DUTSIDE SURFACE OF THE EMISSIVE COATING FROM THE VF-3 CLAD BODY AFTER CARBON COATING. 


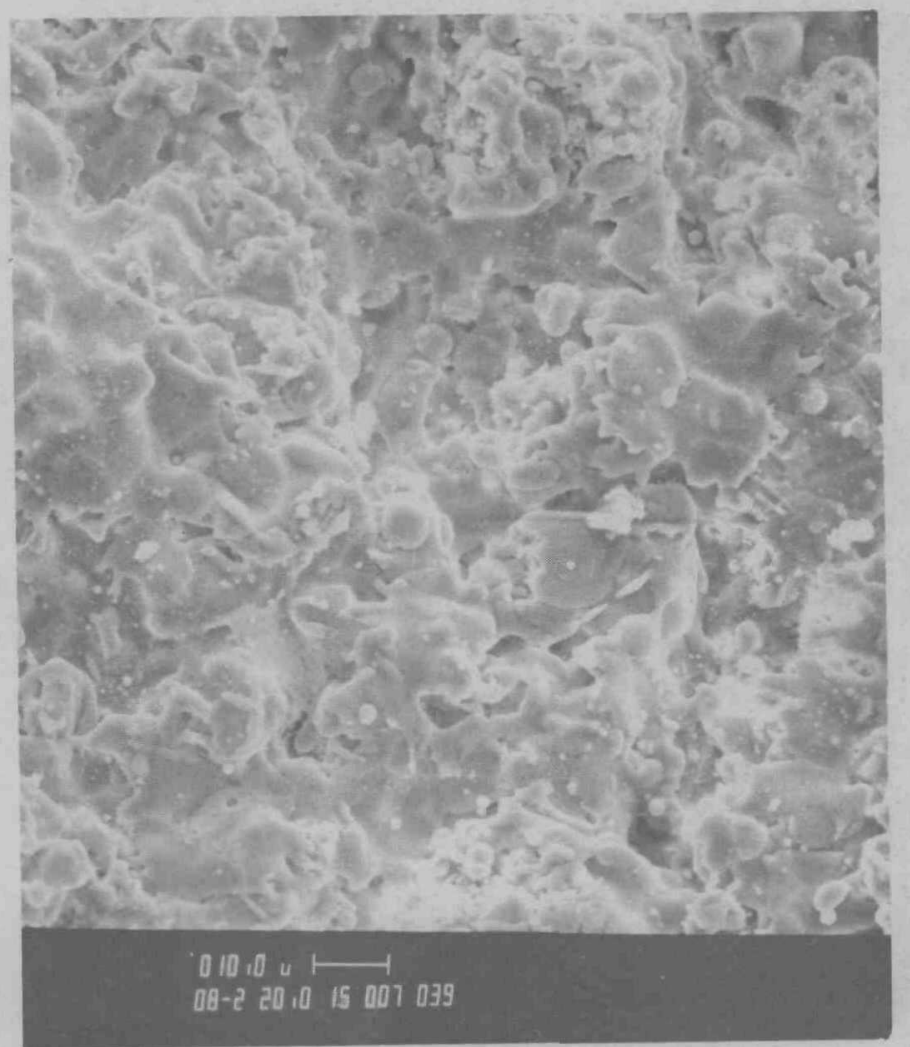

FIGURE 69: OUTSIDE SURFACE OF THE
EMISSIVE COATING FROM THE VF-3 CLAD BODY AFTER CARBON COATING.

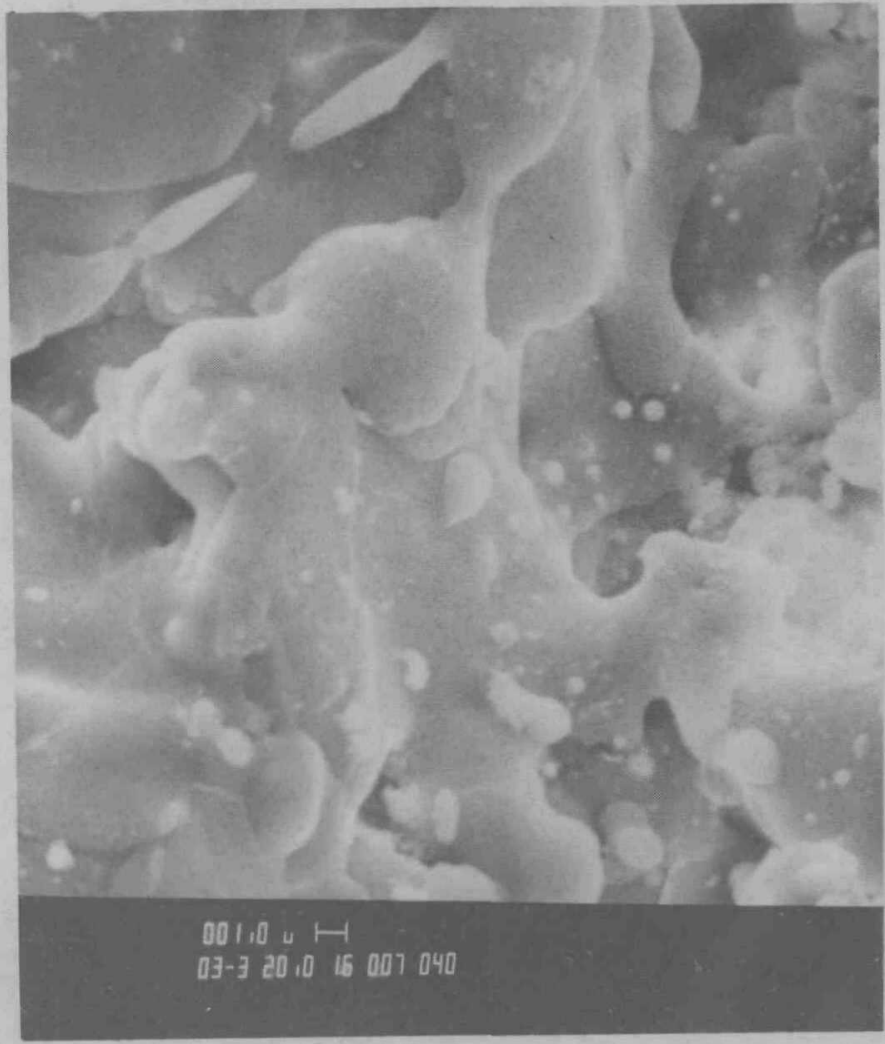

FIGURE 70: DUTSIDE SURFACE OF THE EMISSIVE COATING FROM THE VF-3 CLAD BODY AFTER CARBON COATING. 


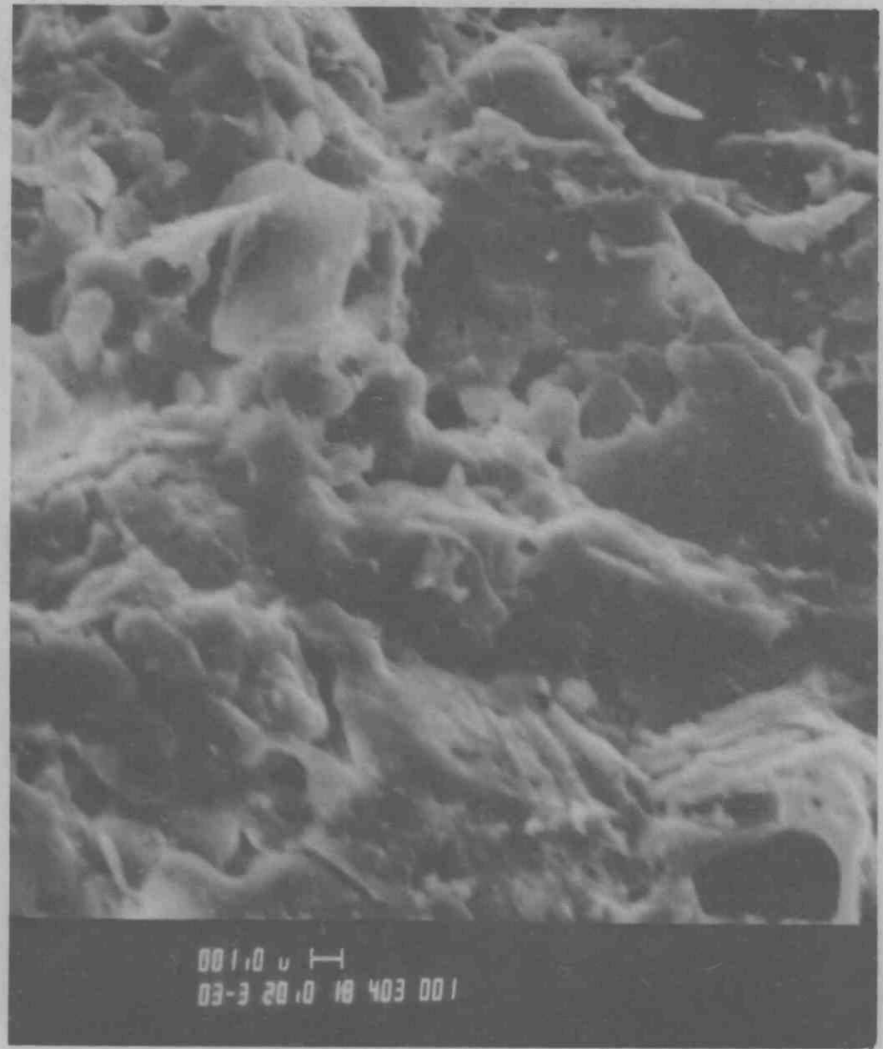

FIGURE 71: INSIDE SURFACE OF THE EMISSIVE COATING FROM THE VF-3 CLAD BODY AFTER CARBON COATING.

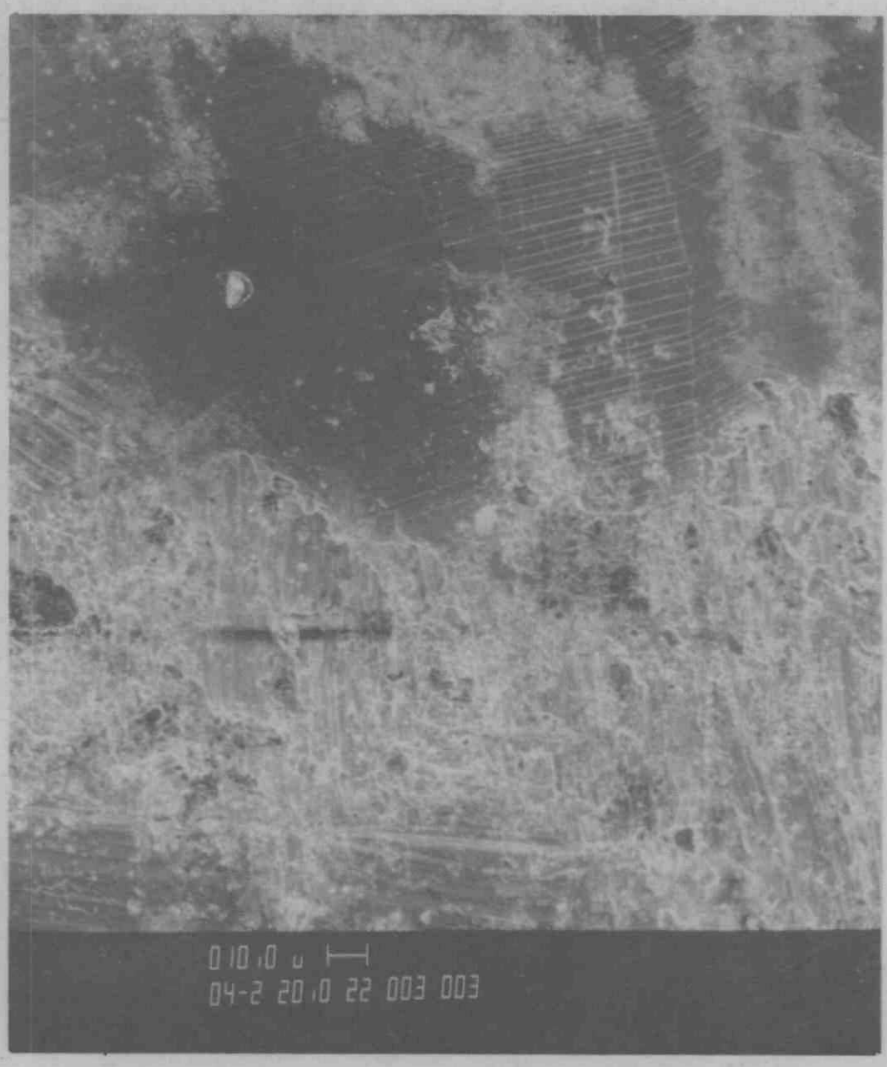

FIGURE 72: BASE OF THE WELD OF THE VF -3 CLAD. 


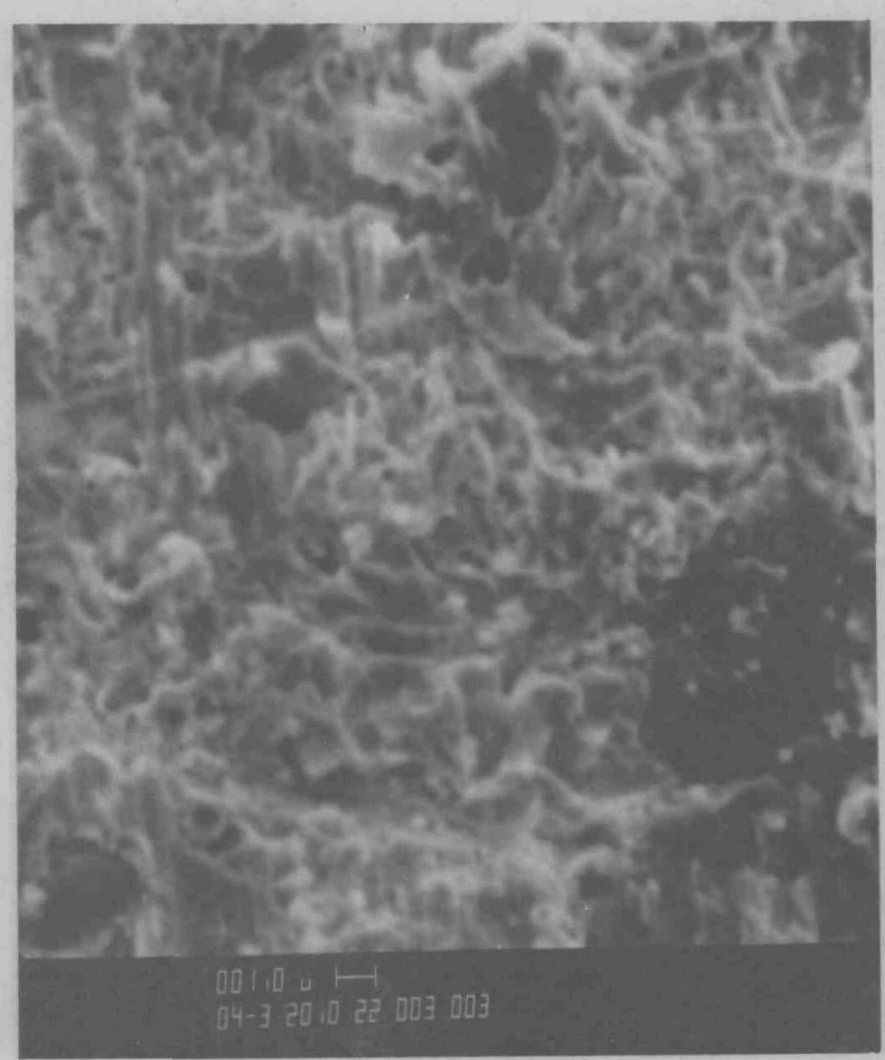

ป

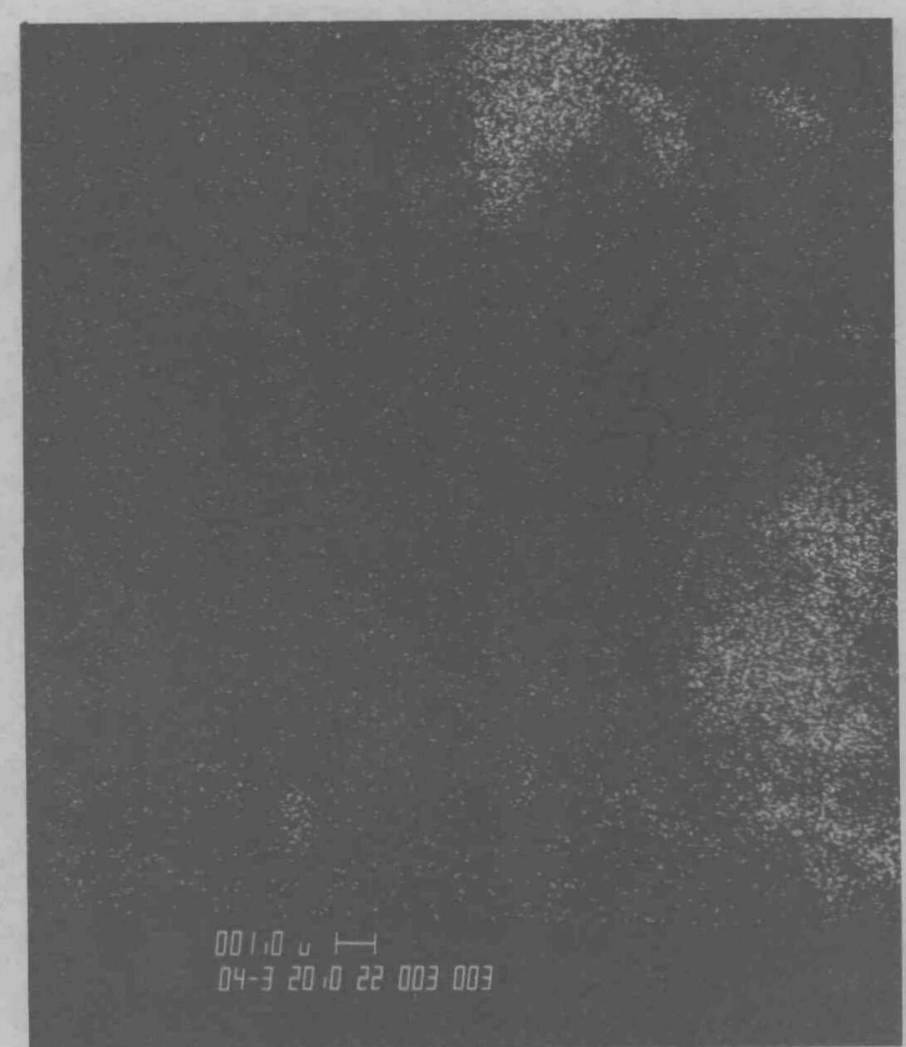

FIGURE 74: ELEMENTAL X-RAY MAP FOR IRON IN THE AREA SHOWN IN FIGURE 73. 


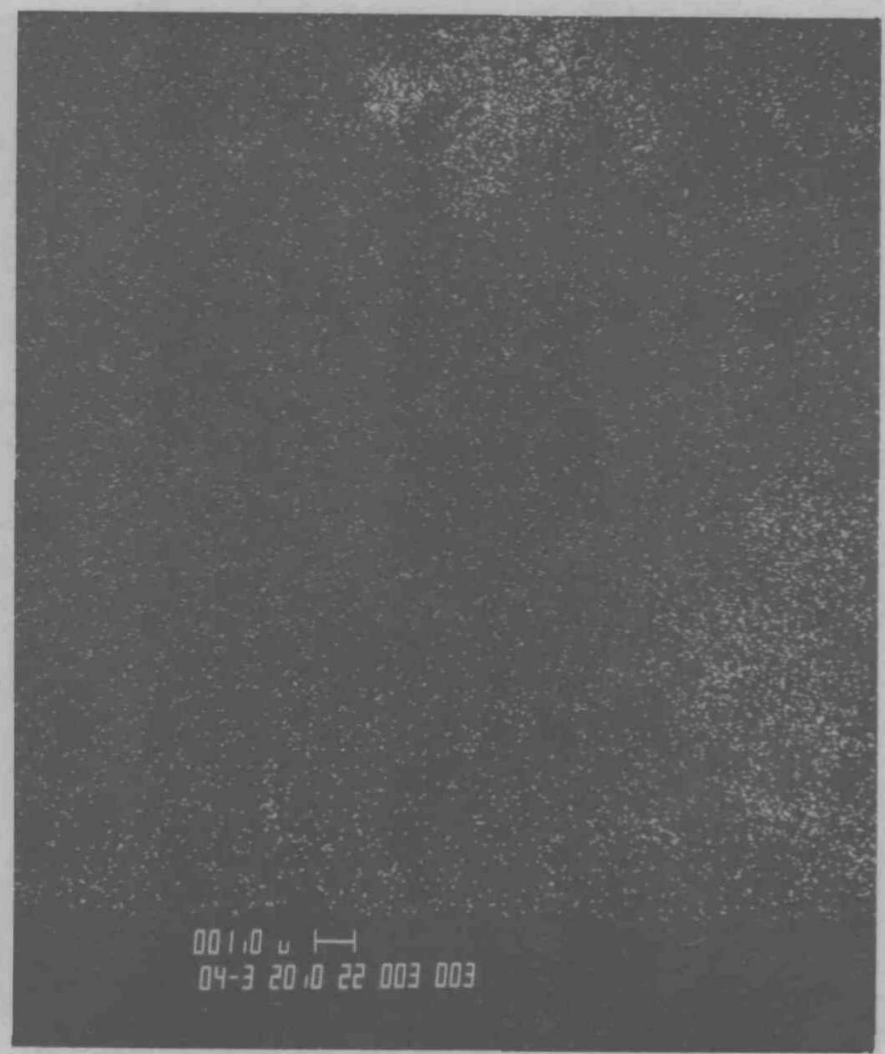

FIGURE 75: ELEMENTAL X-RAY MAP FOR CHROMIUM IN THE AREA SHOWN IN FIGURE 73.

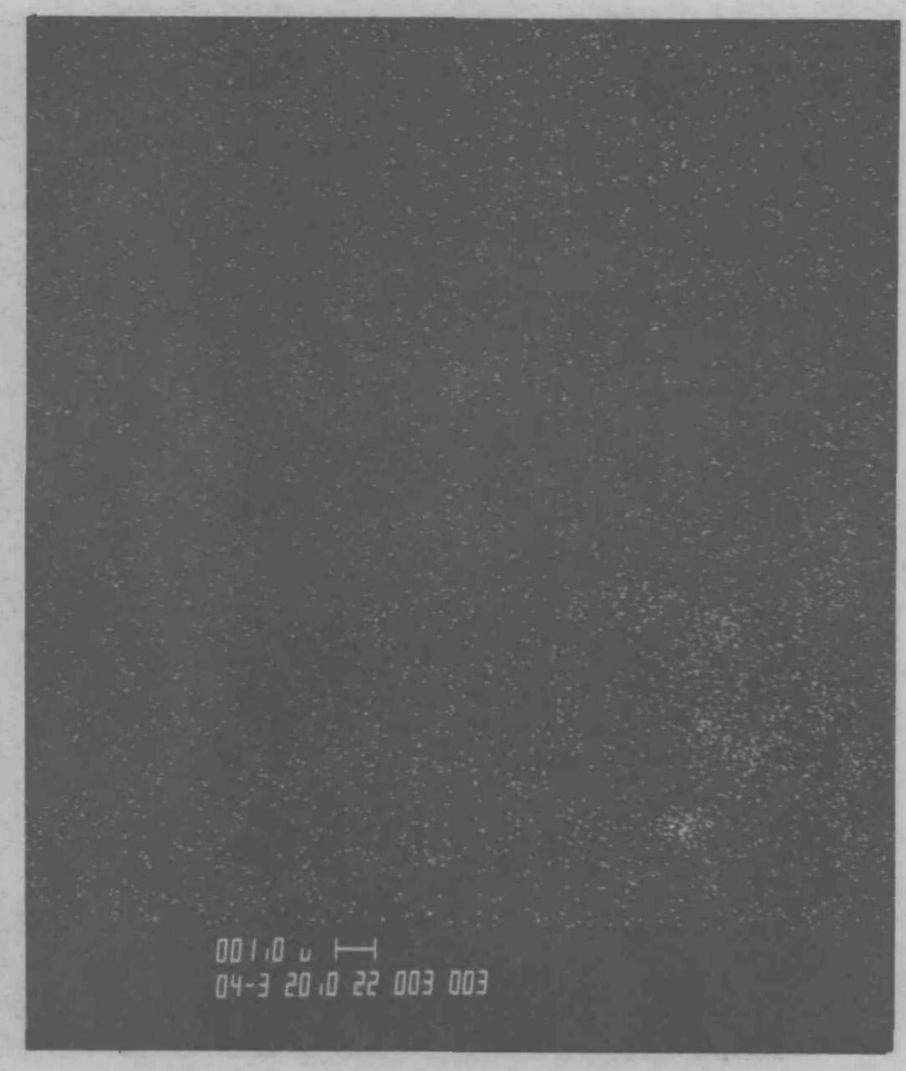

FIGURE 76: ELEMENTAL X-RAY MAP FOR NICKEL IN THE AREA SHOWN IN FIGURE 73 . 


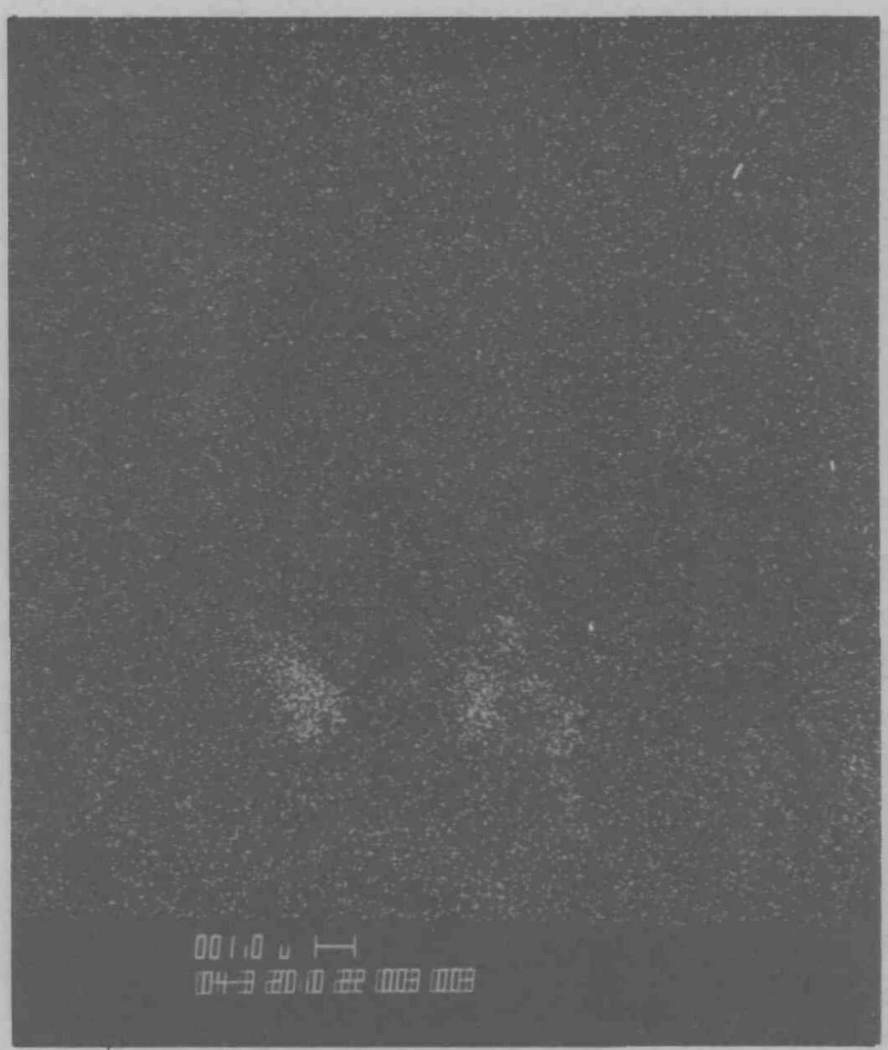

FIGURE 77: ELEMENTAL X-RAY MAP For MANGANESE IN THE AREA SHOWN IN FIGURE 73.

FIGURE 78: ELEMENTAL X-RAY MAP FOR TANTALUM IN THE AREA SHOWN IN F IGURE 73. 


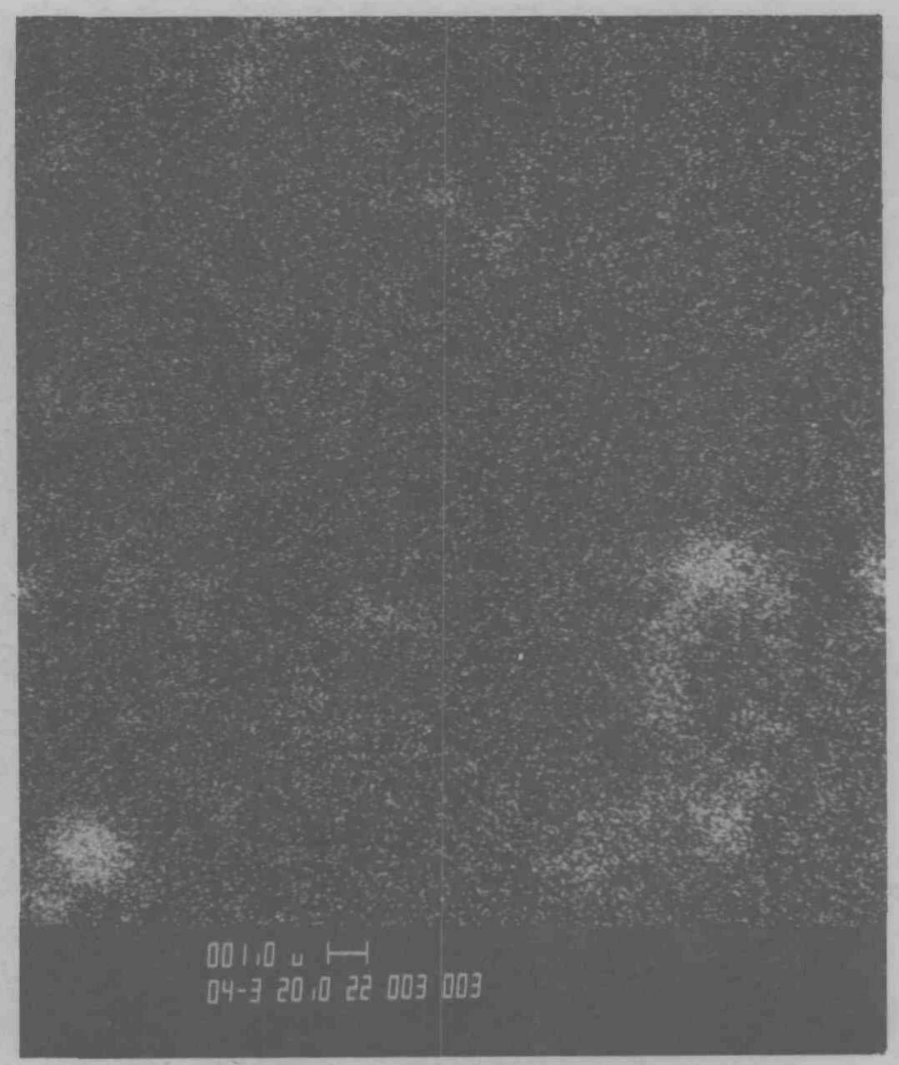

FIGURE 79: ELEMENTAL X-RAY MAP FOR ALUMINUM IN THE AREA SHOWN IN FIGURE 73.

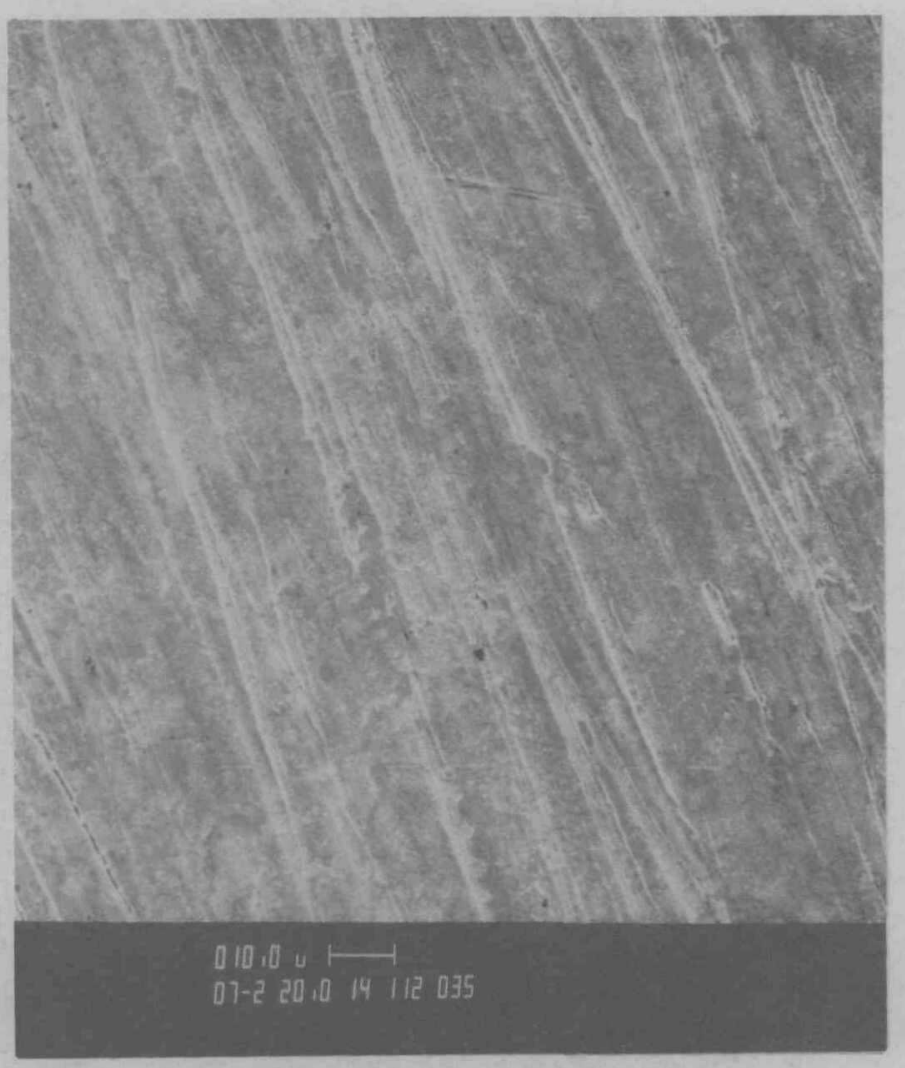

FIGURE 80: SURFACE OF THE DOMED END of THE VF -7 ReMAKE EXAMPLE WELD CLAD BODY. 


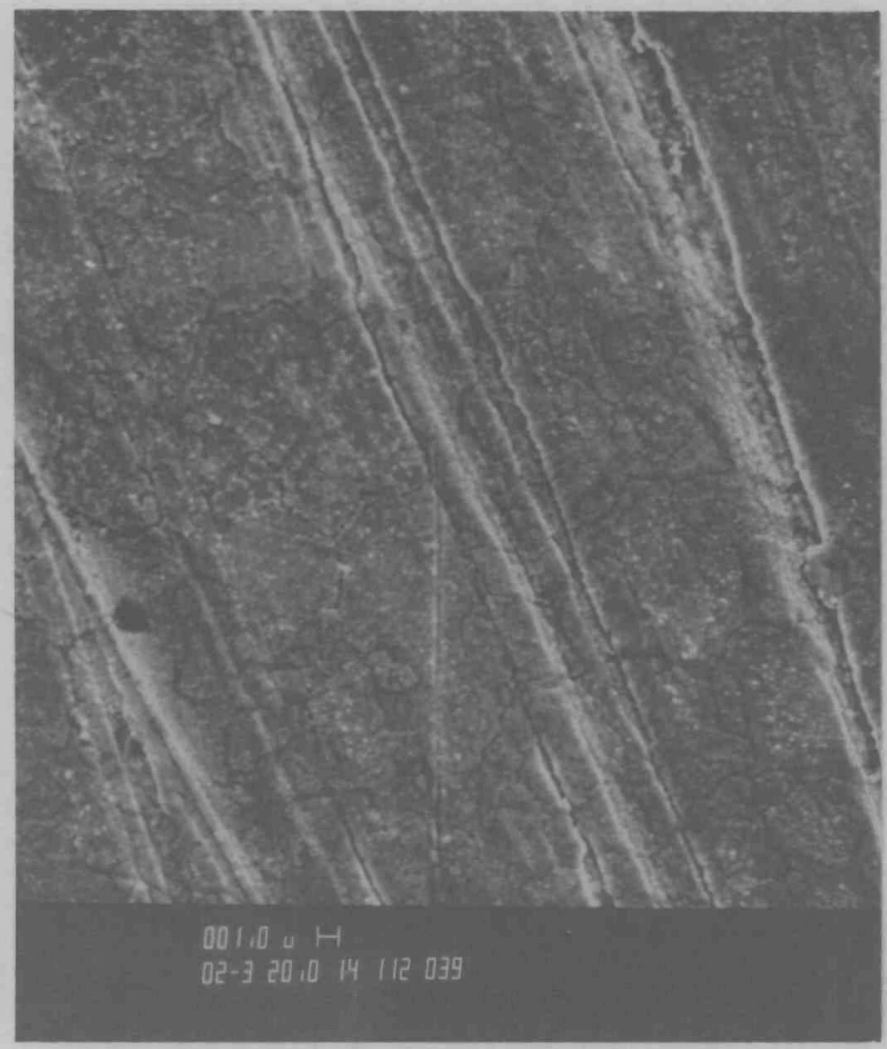

FIGURE 81: SURFACE OF THE DOMED END OF THE VF-7 REMAKE EXAMPLE WELD CLAD BODY.

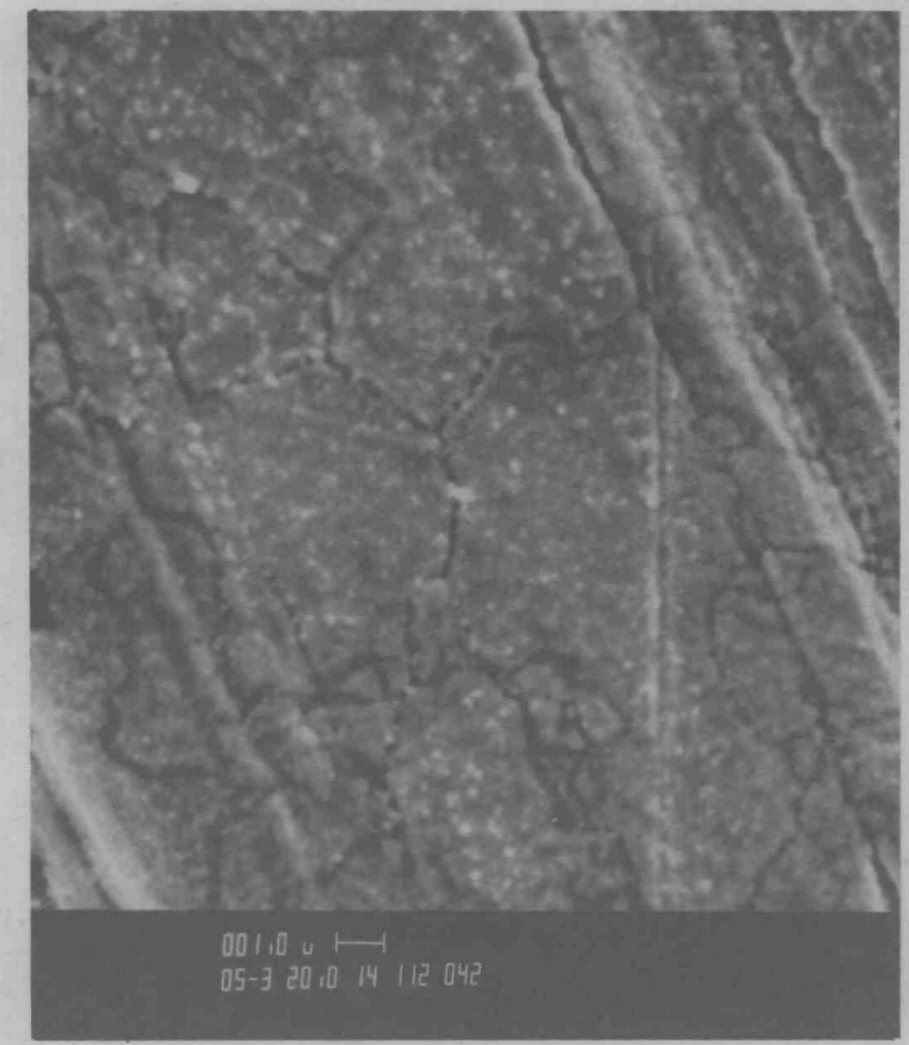

FIGURE 82: SURFACE OF THE DOMED END OF THE VF-7 REMAKE EXAMPLE WELD CLAD BODY. 


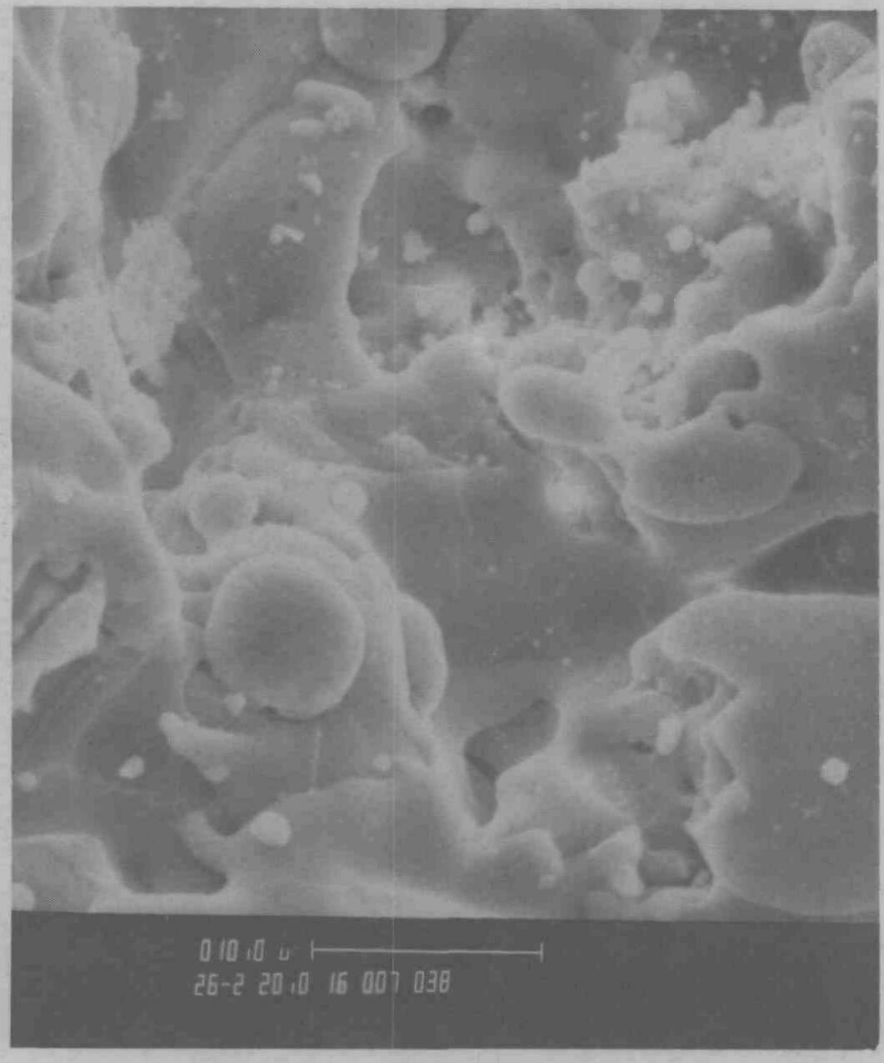

FIGURE 83: OUTSIDE SURFACE OF THE EMISSIVE COATING FROM THE VF-7 REMAKE WELD CLAD BODY - AFTER CARBON COATING.

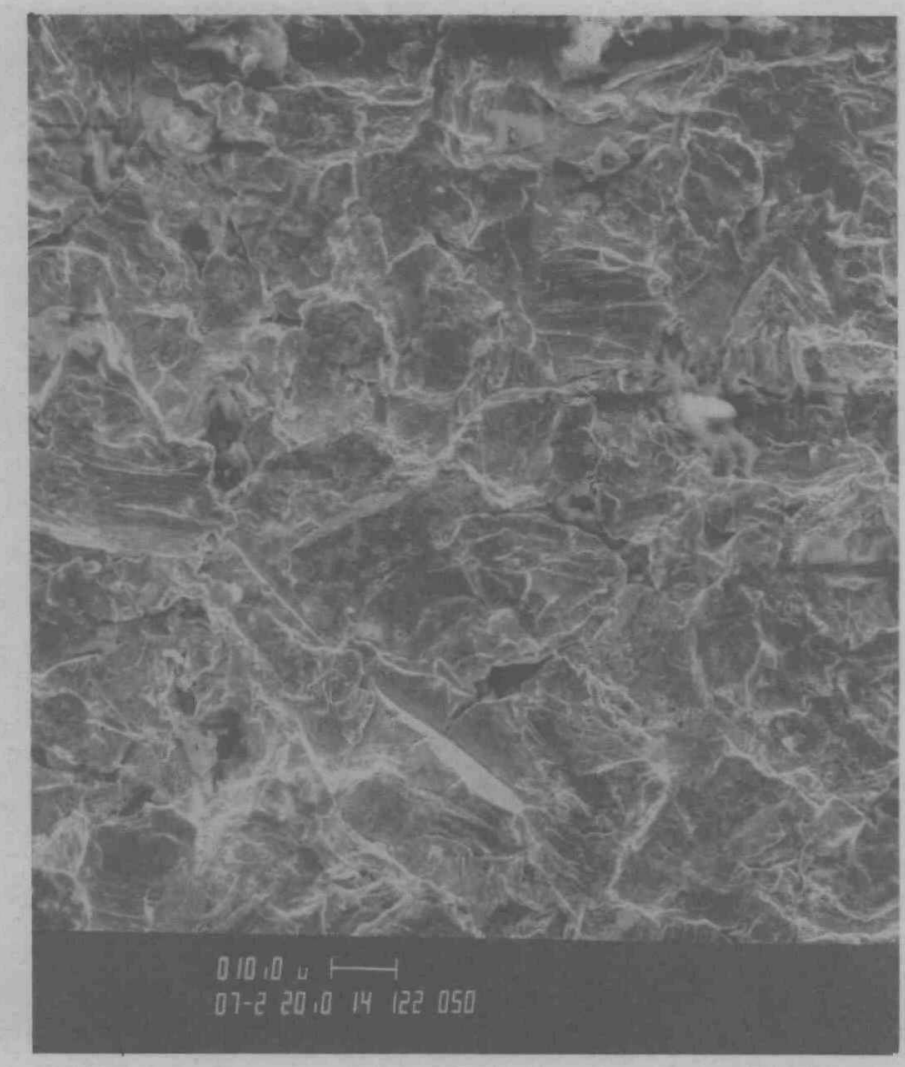

FIGURE 84: SURFACE OF THE VF-7 REMAKE EXAMPLE WeLd CLÁD BODY WHERE THE EMISSIVE COATING HAD FLAKED OFF. 


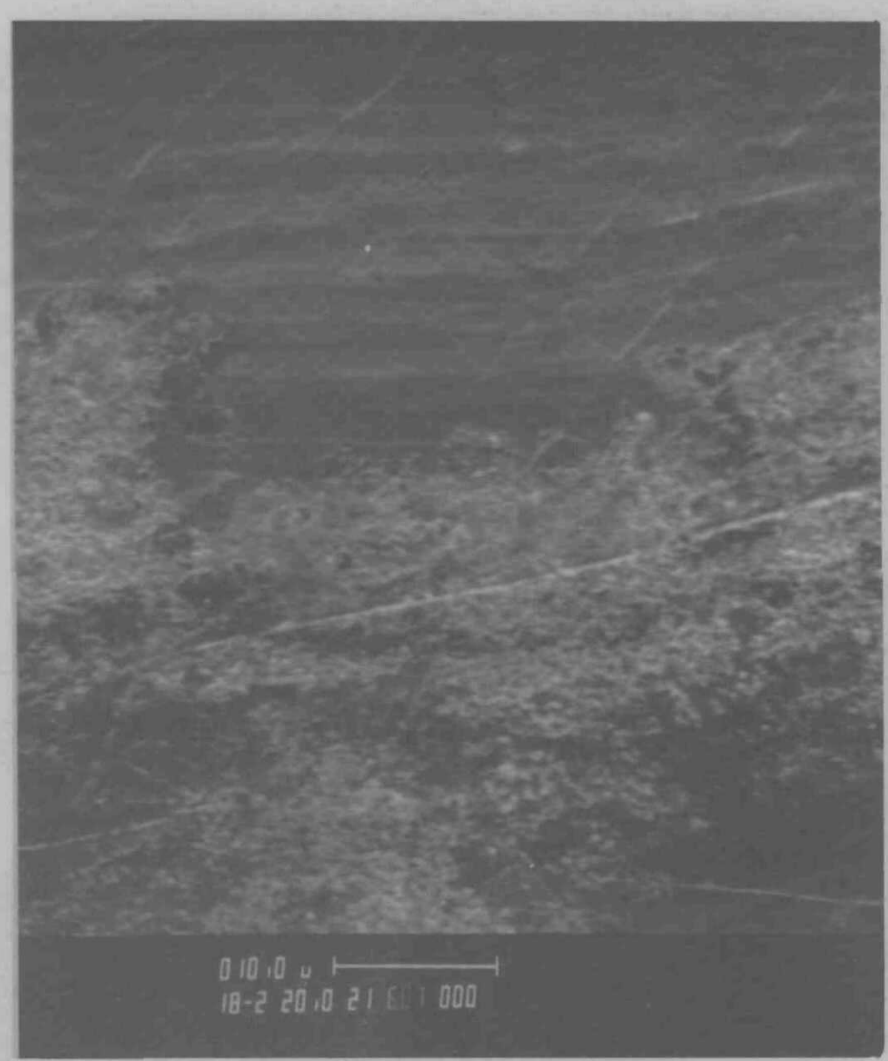

FIGURE 85: TYPICAL REACTION ZONE $\stackrel{\infty}{\omega}$ FOUND IN THE VF-3 CLAD WELD.

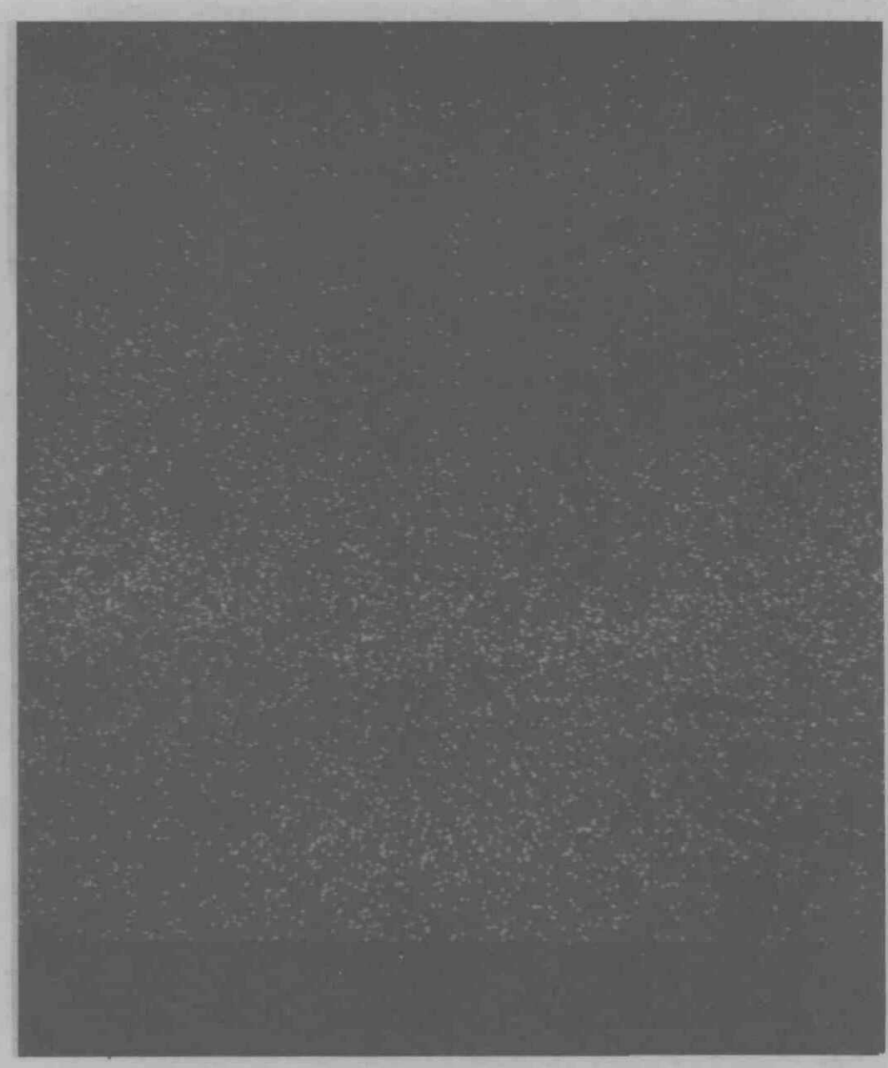

FIGURE 86: ELEMENTAL X-RAY MAP FoR MANGANESE IN THE AREA SHOWN IN FIGURE 85. 


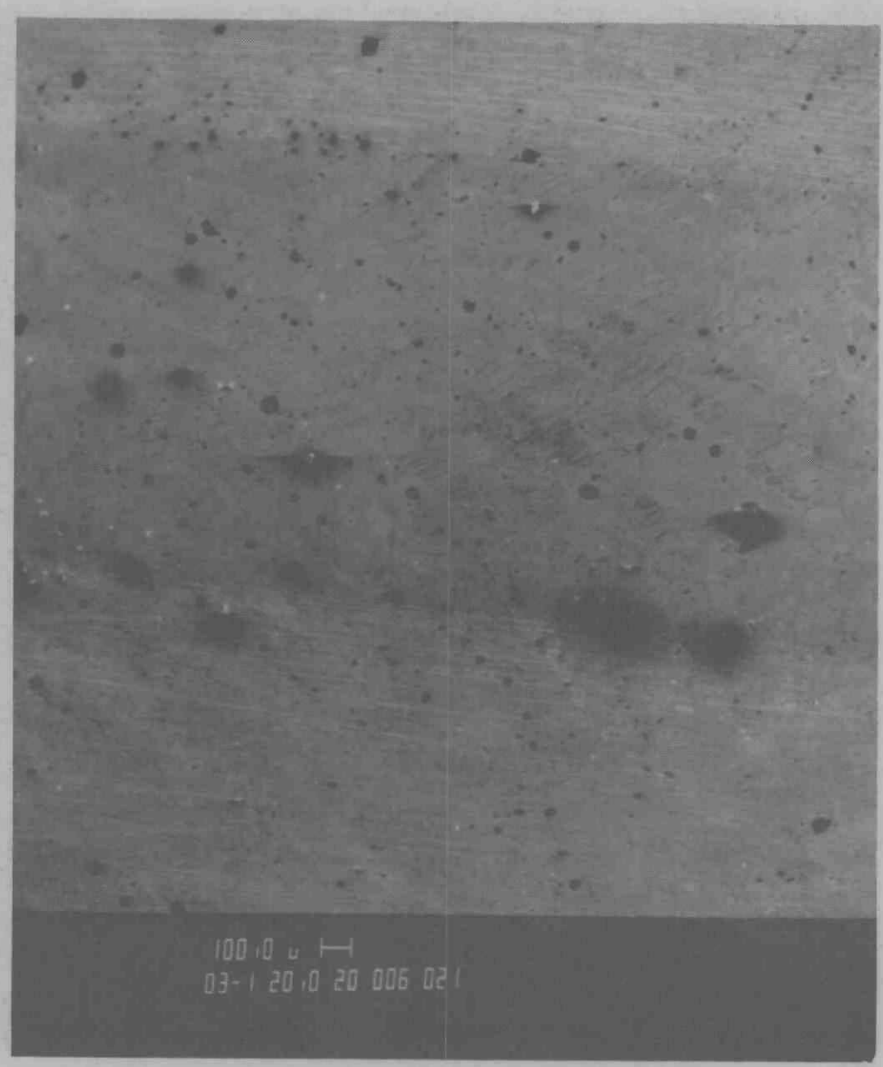

FIGURE 87: WELD ZONE OF THE POST EXAMPLE WELD CLAD OF VF-6 AND VF-7.

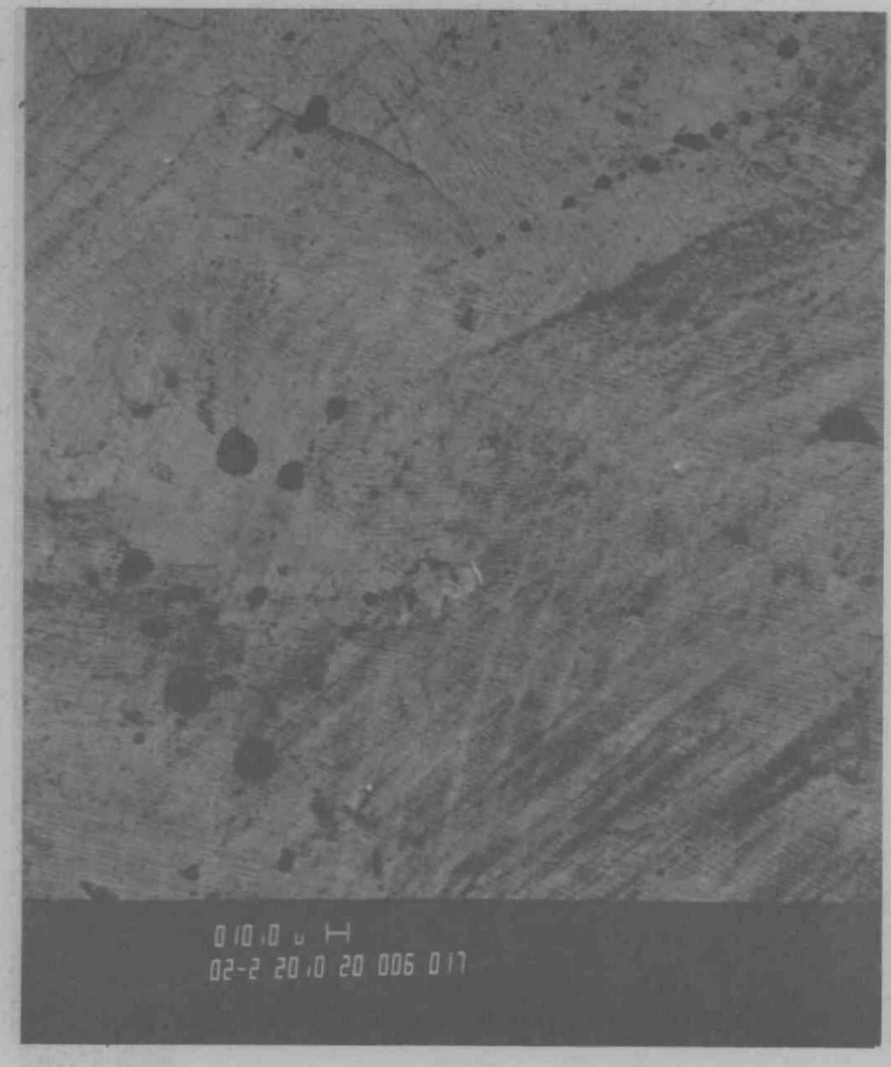

FIGURE 88: WELD ZONE OF THE POST EXAMPLE WELD CLAD OF VF-6 AND VF -7 . 


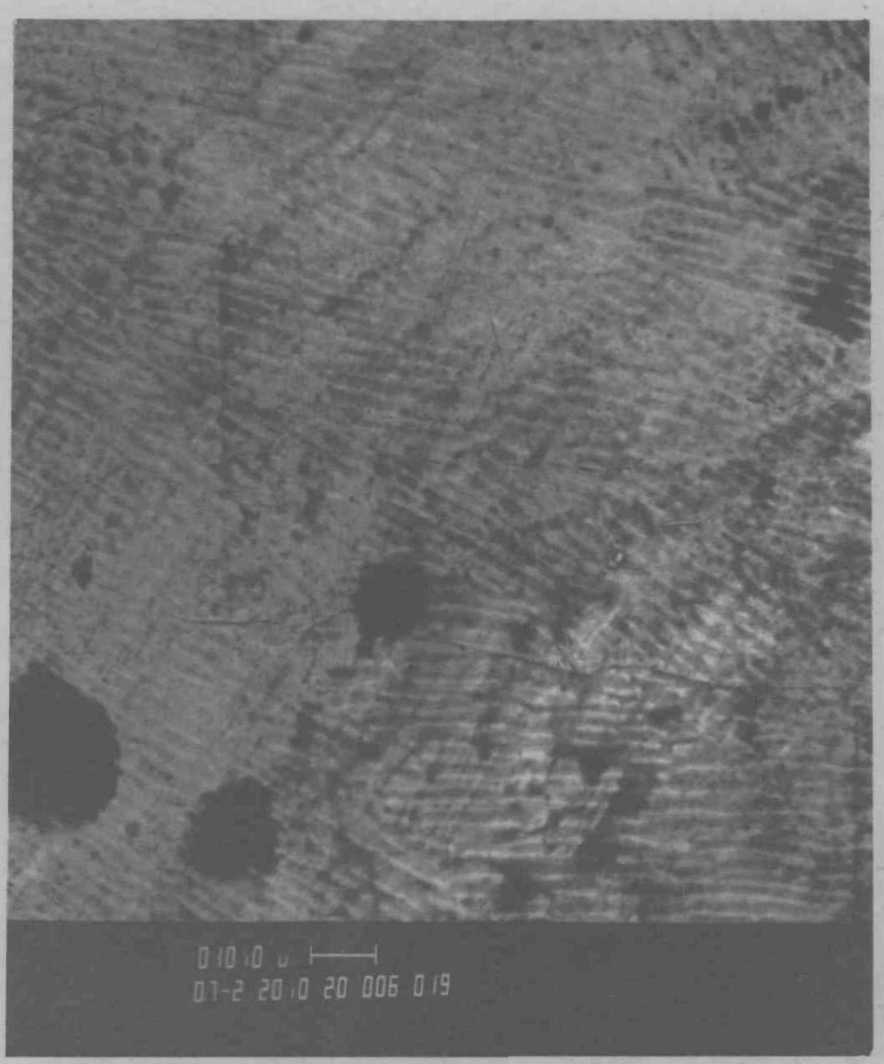

FIGURE 89: WELD ZONE OF THE POST$\infty$ EXAMPLE WELD CLAD OF VF-6 AND VF-7.

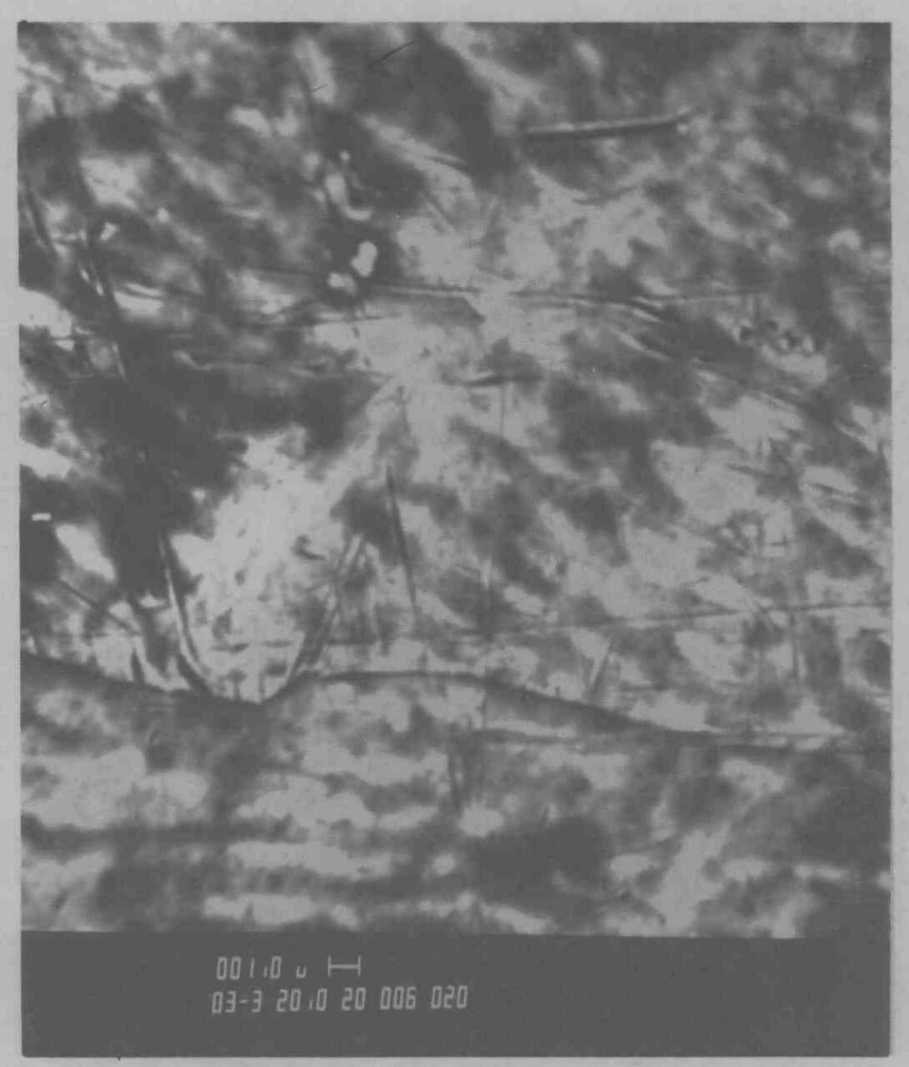

FIGURE 90: WELD ZONE OF THE POSTEXAMPLE WELD CLAD OF VF-6 AND VF-7. 


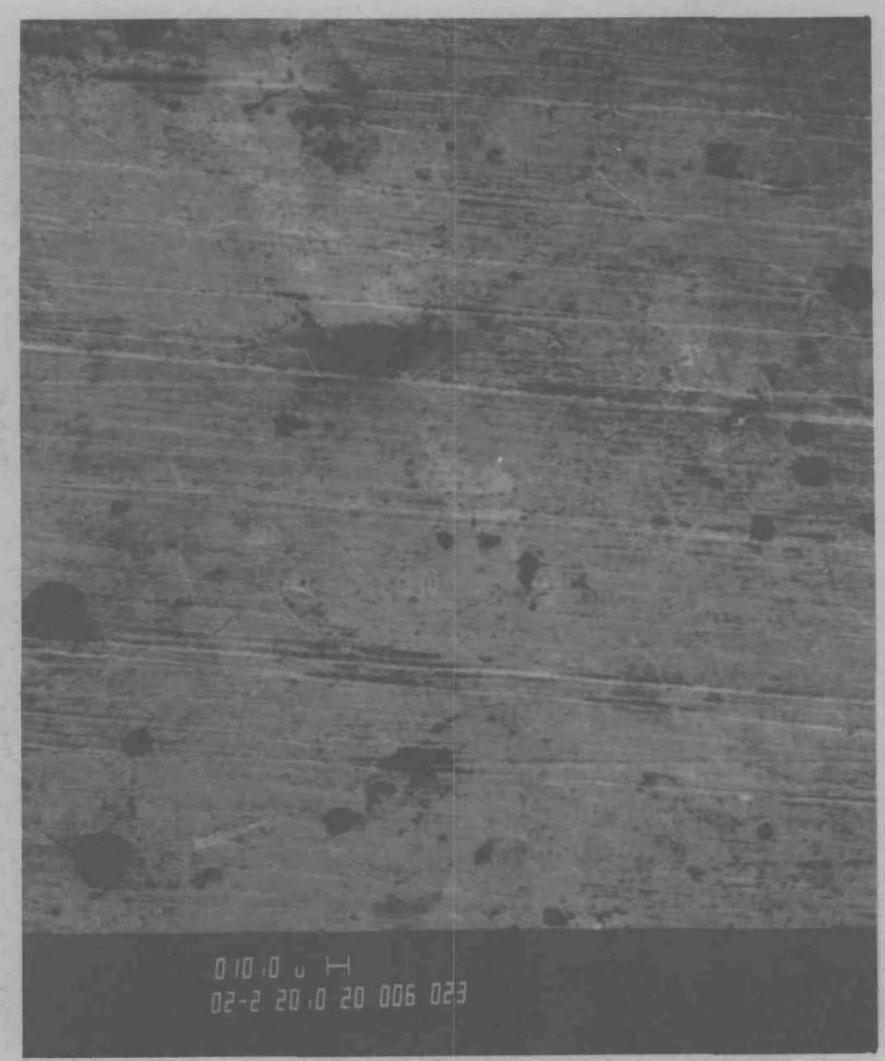

FIGURE 91: ETCHED AREA OF THE EXAMPLE WELD END CAP OF VF-6 AND $\mathrm{VF}-7$.

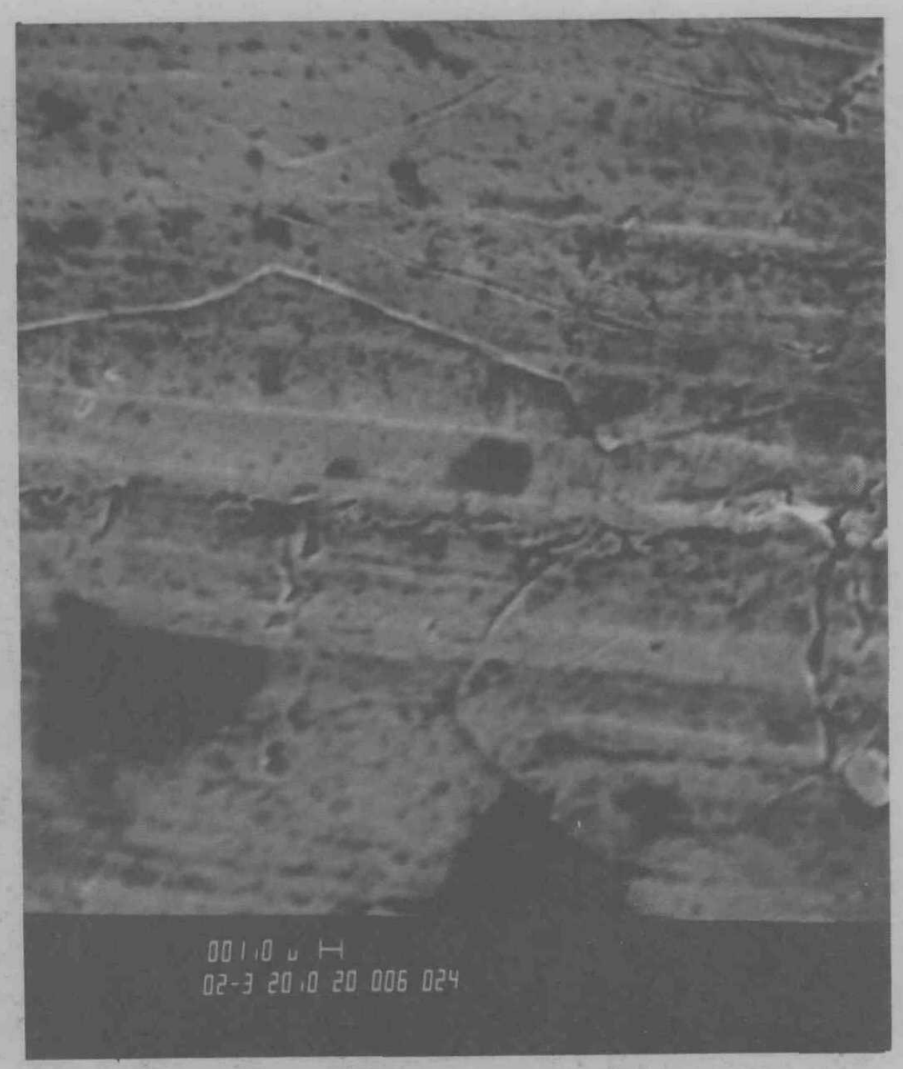

FIGURE 92: ETCHED AREA OF THE POST-EXAMPLE WELD END CAP OF $\mathrm{VF}-6$ AND $\mathrm{VF}-7$. 


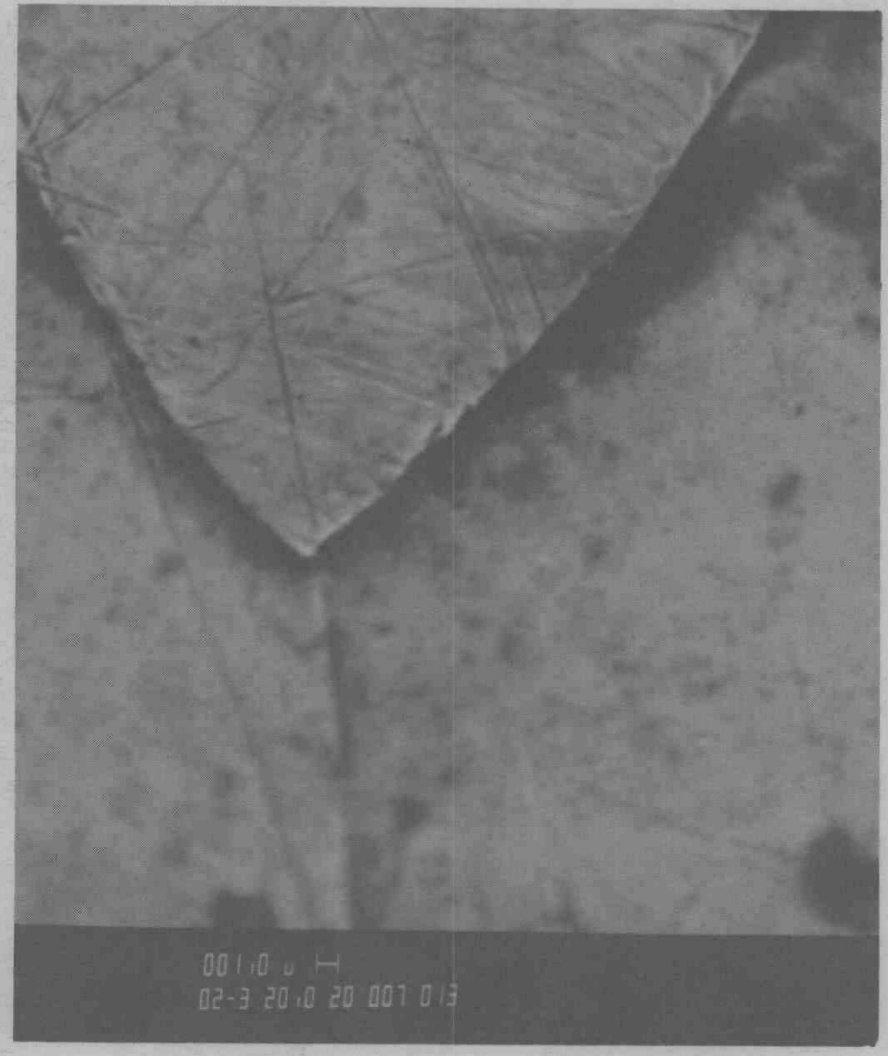

FIGURE 95: WELD ZONE OF THE POSTEXAMPLE WeLd CLAD OF VF-7 Remake.

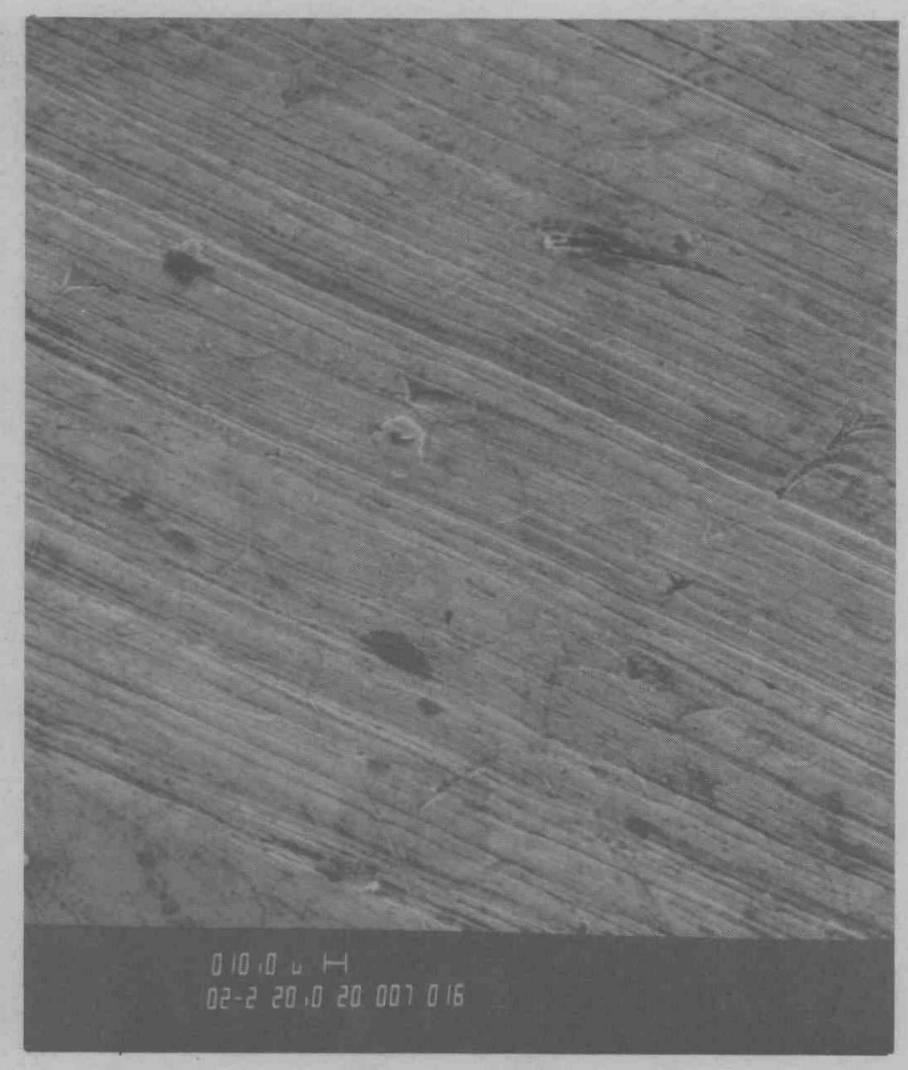

FIGURE 96: ETCHED AREA OF THE POSTEXAMPLE WELD END CAP OF VF $\rightarrow 7$ REMAKE. 


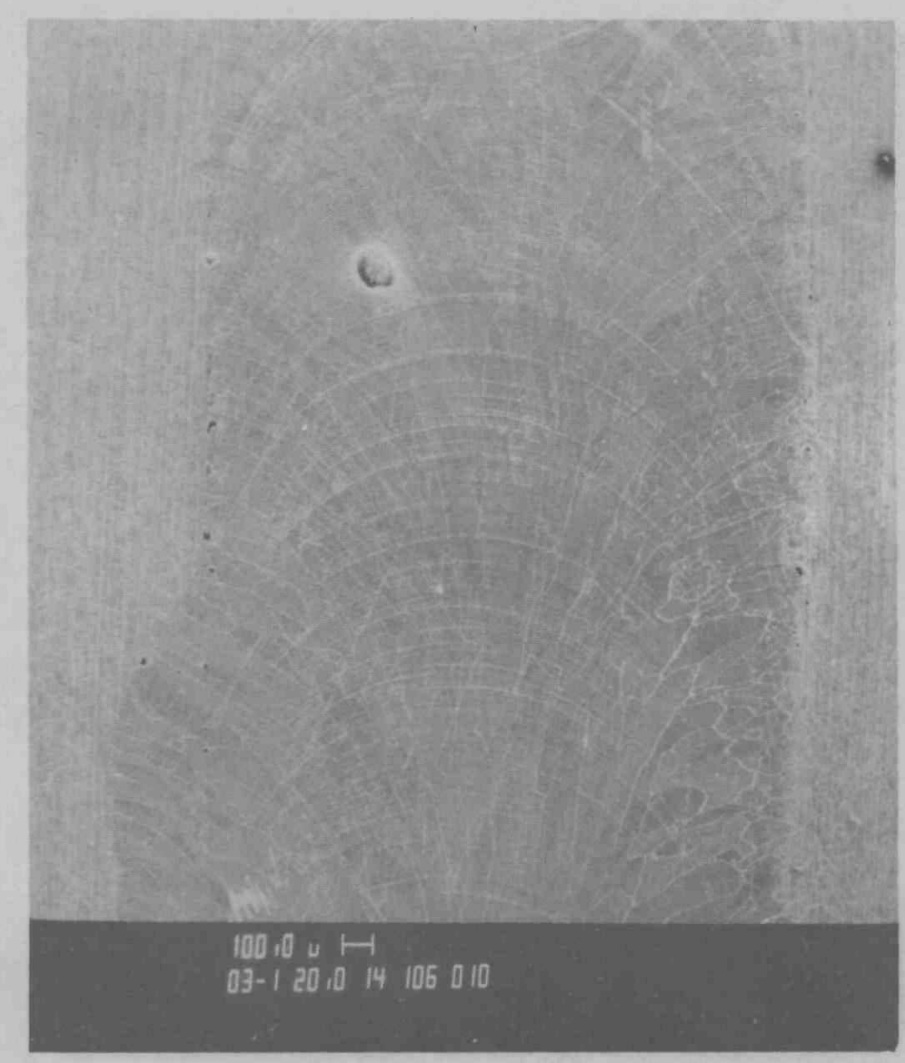

FIGURE 97: POST-TEST SAMPLE OF $\mathrm{VF}-6$ AND $\mathrm{VF}-7$

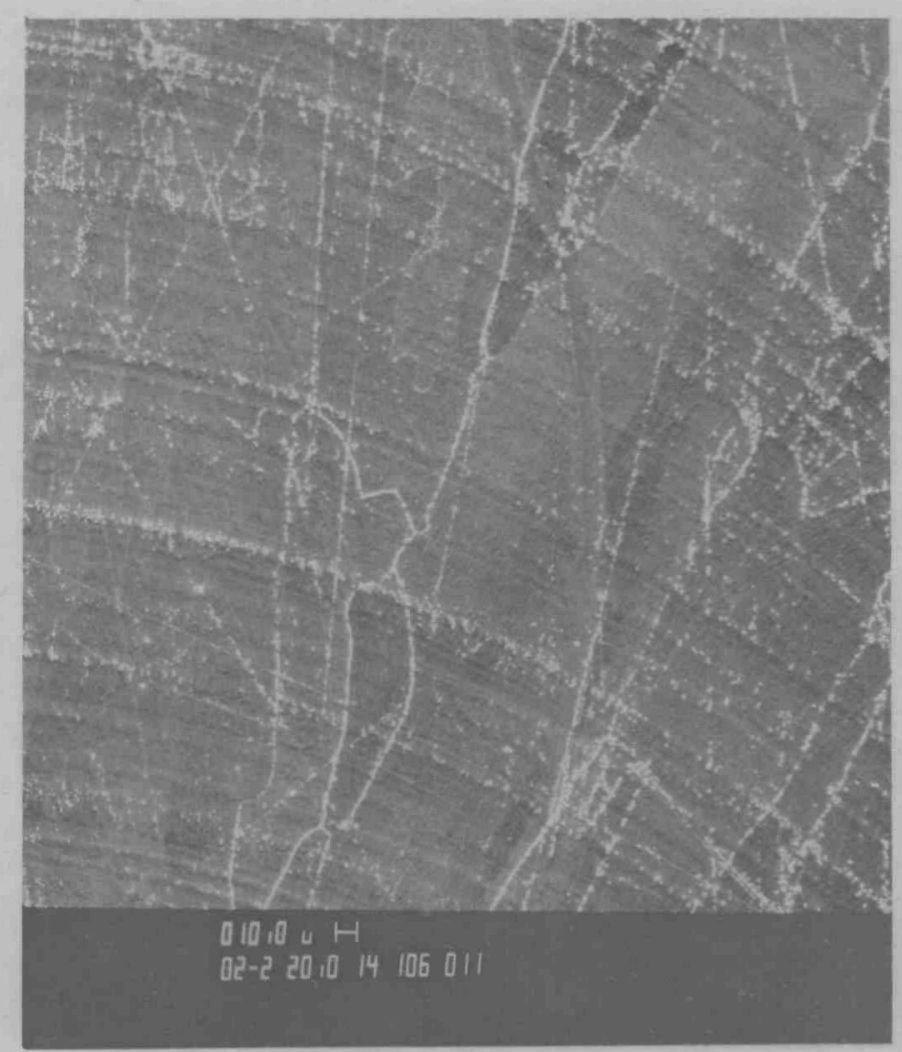

FIGURE 98: POST-TEST SAMPLE OF THE WELD ZONE OF THE POST-EXAMPLE WELD CLAD OF VF- 6 AND VF -7 . 


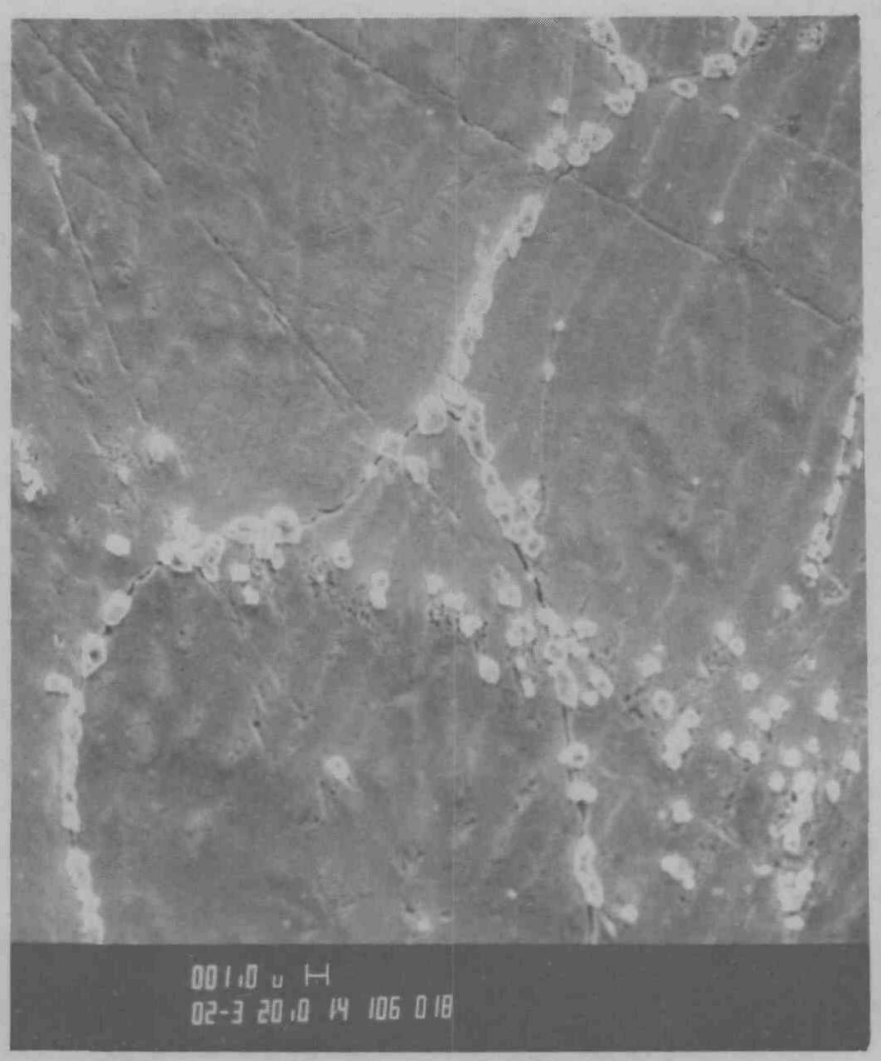

FIGURE 99: POST-TEST SAMPLE OF THE WeLD ZONE OF THE POST-EXAMPLe WELD CLAD OF VF-6 AND VF-7.

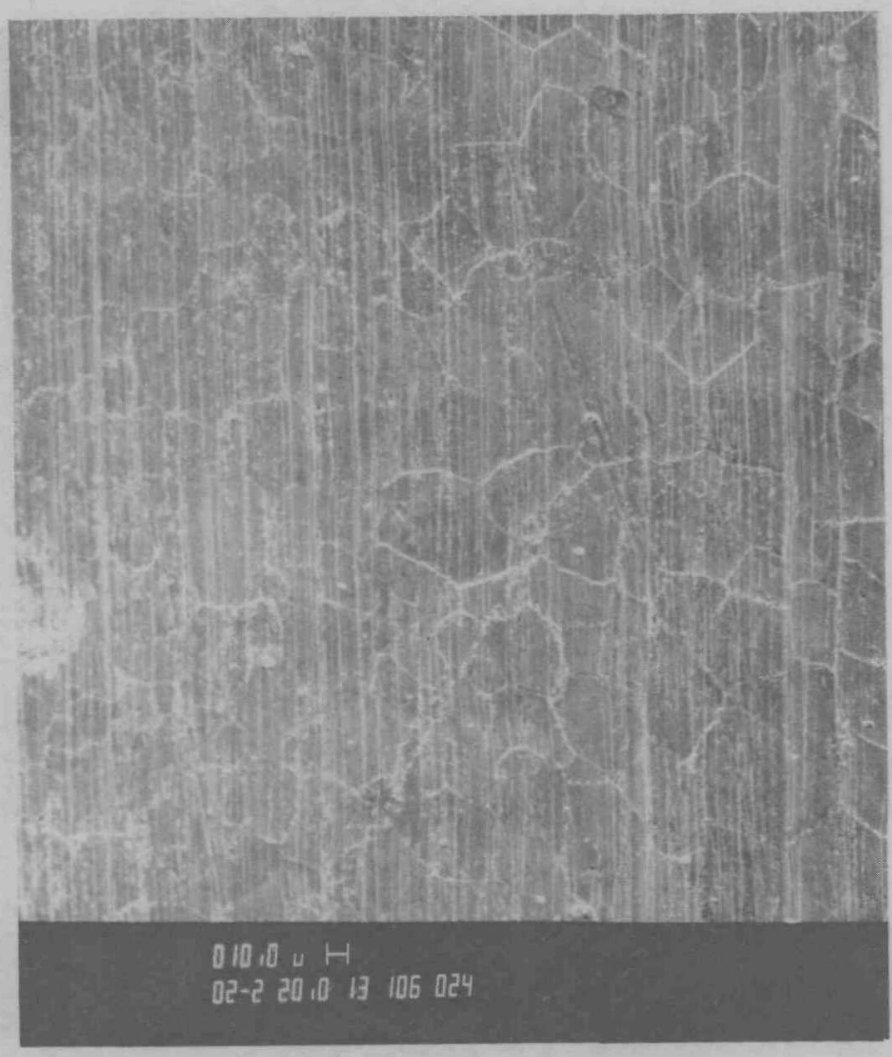

FIGURE 100: POST-TEST SAMPLE OF THE ETCHED AREA OF THE POST-EXAMPLE WELD END CAP OF VF-6 AND VF -7 . 


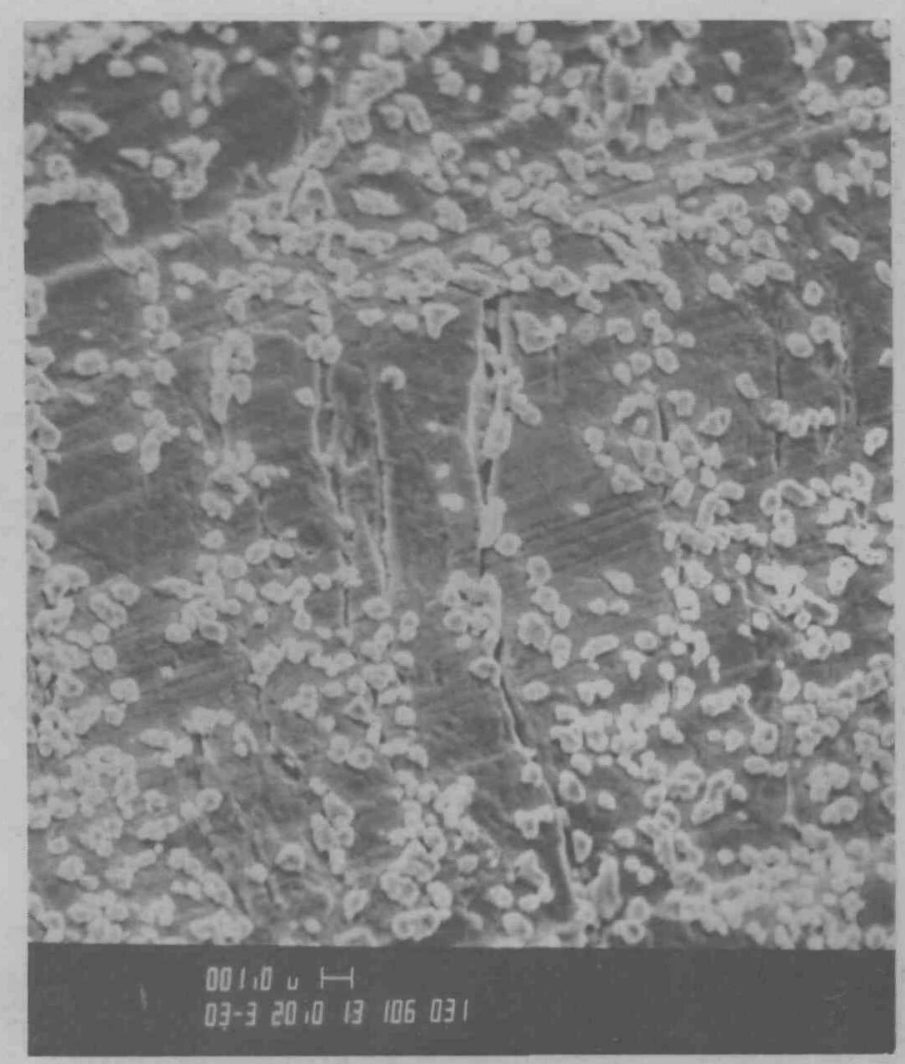

FIGURE 101: POST-TEST SAMPLE OF $\stackrel{\bullet}{\bullet}$
THE POST-EXAMPLE WELD END CAP OF VF-6 AND VF-7.

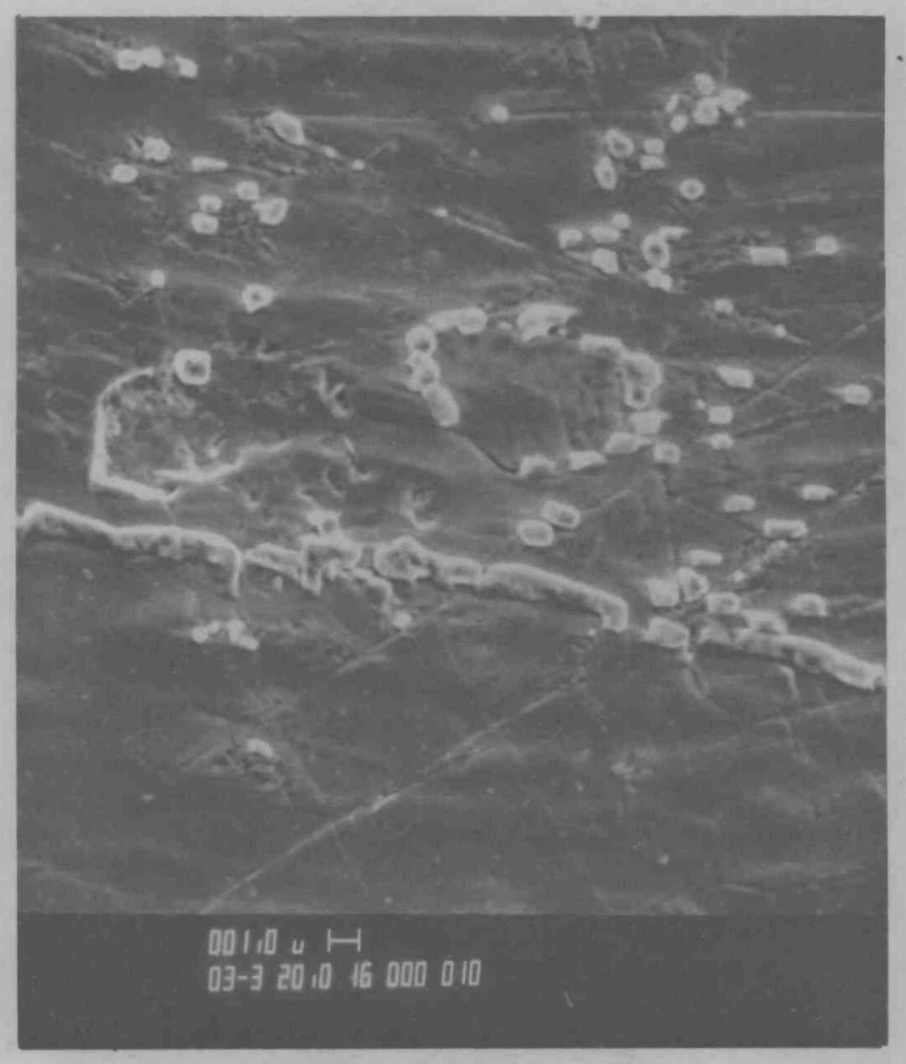

FIGURE 102: POST-TEST SAMPLE OF THE ETCHED AREA OF THE POST-EXAMPLE WELD END CAP OF VF- 6 AND VF -7 . 


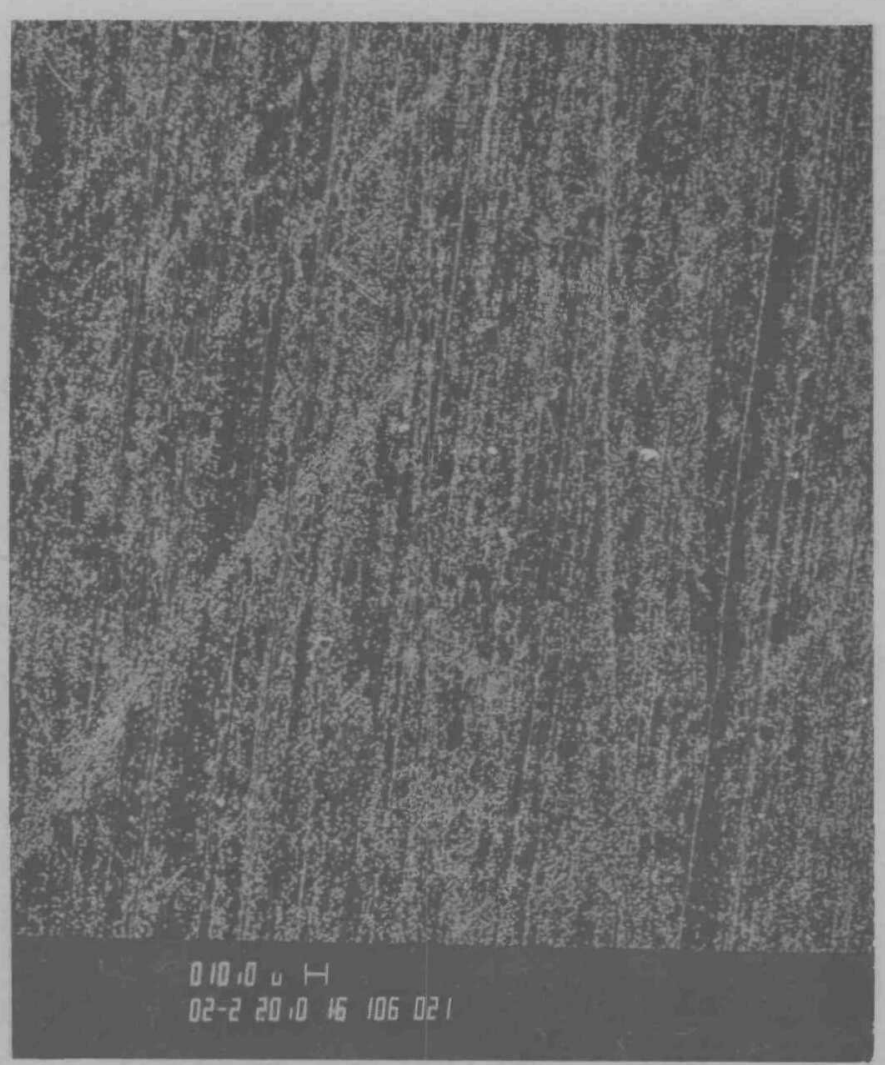

FIGURE 103: POST-TEST SAMPLE OF THE MACHINED AREA OF THE POST-EXAMPLE WELD END CAP OF VF-6 AND VF-7.

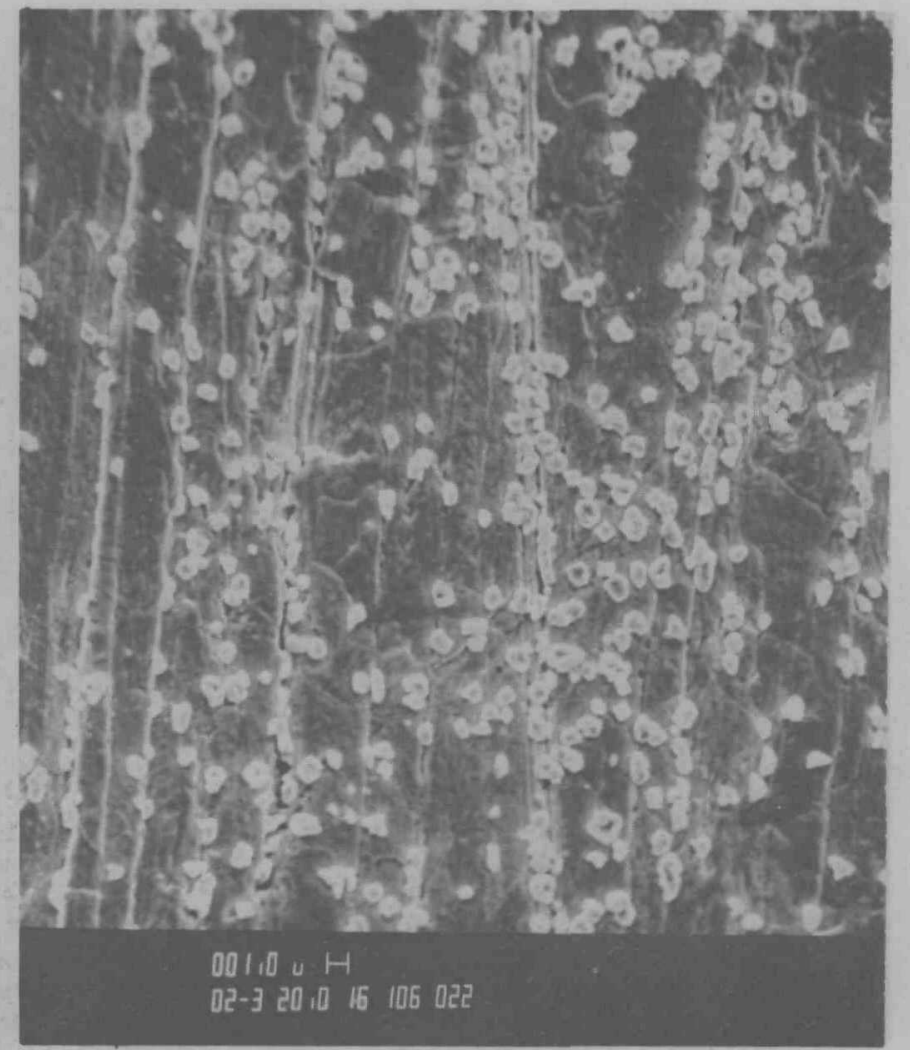

FIGURE 104: POST-TEST SAMPLE OF THE MACHINED AREA OF THE POST-EXAMPLE WELD END CAP OF VF-6 AND VF -7 . 



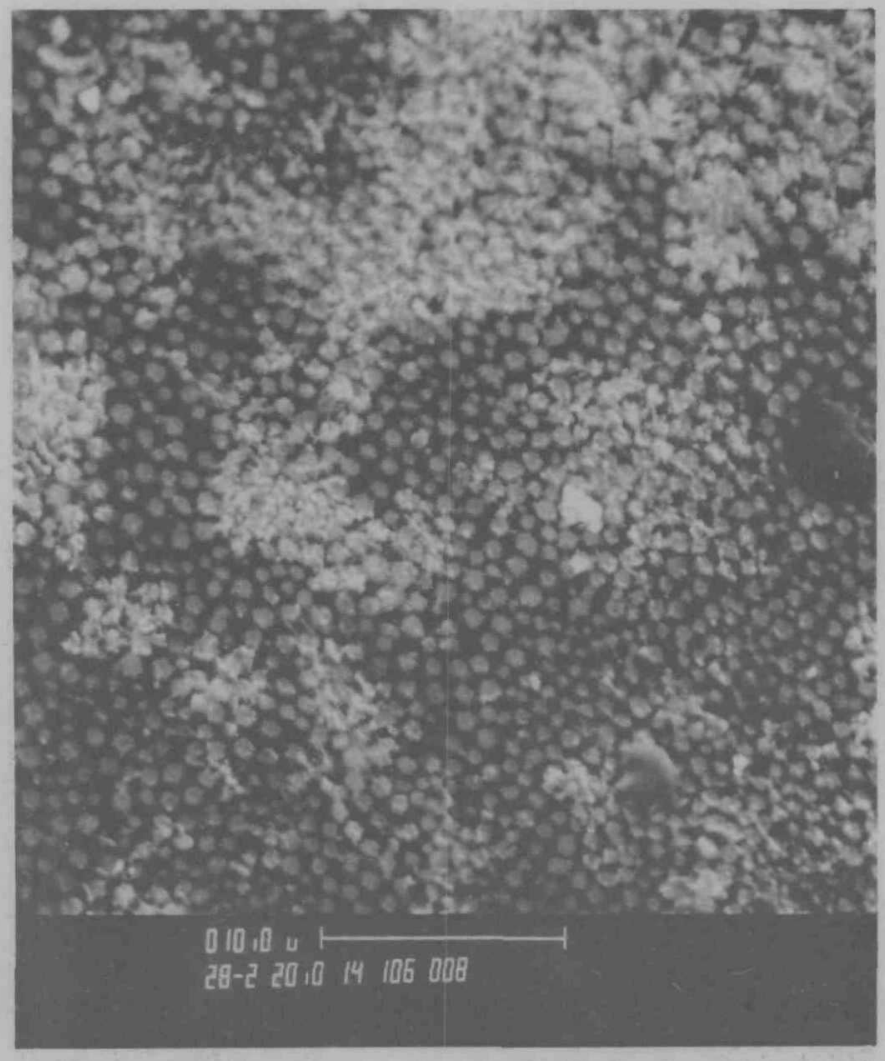

FIGURE 107: PARTICLE IMBEDDED ON THE WELD OF THE POST-EXAMPLE WELD CLAD OF VF-6 AND VF-7.

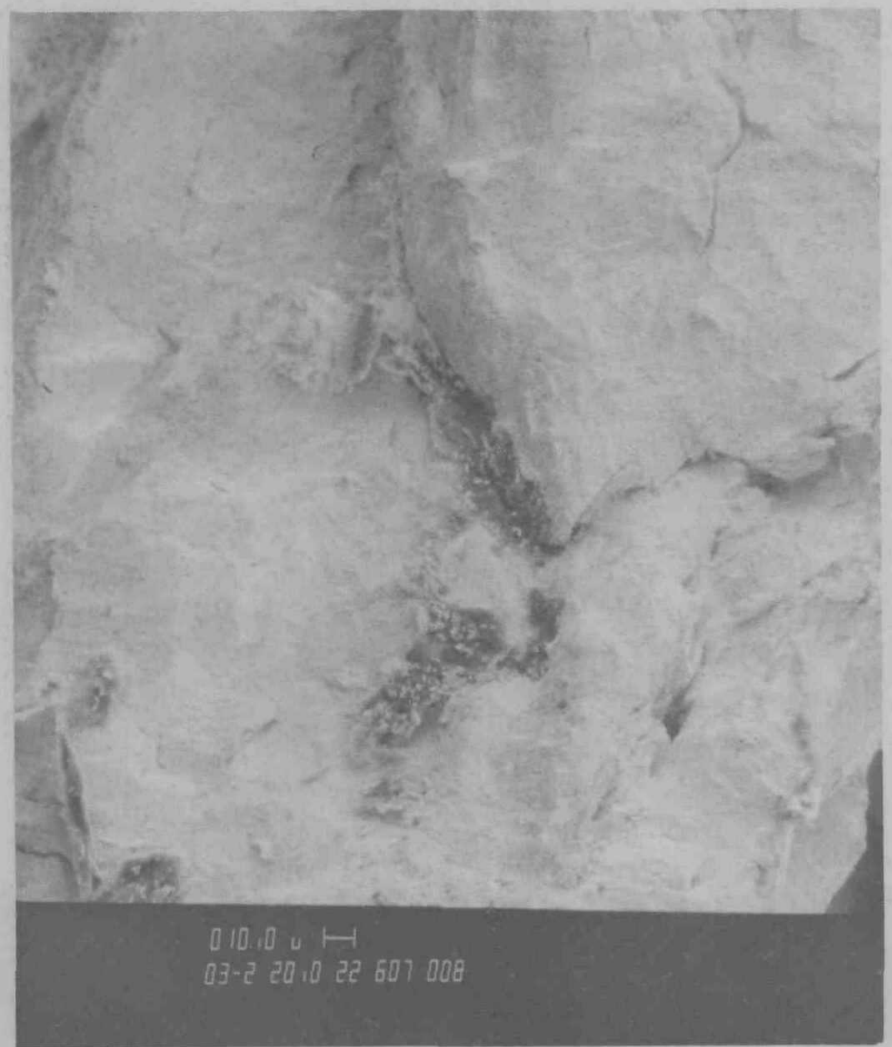

FIGURE 108: POST-TEST FRACTURE CROSSSECTION OF THE WELD OF THE POST-EXAMPLE WELD CLAD OF VF-6 AND VF-7. 


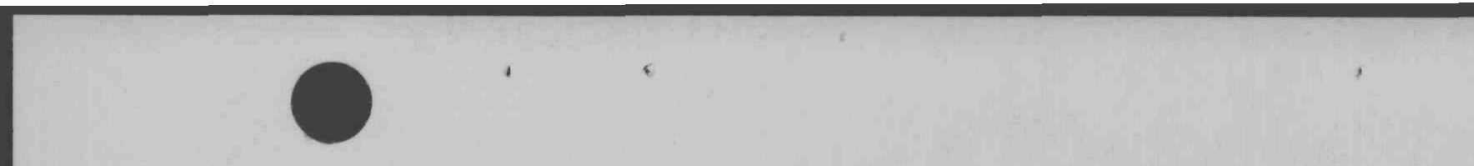

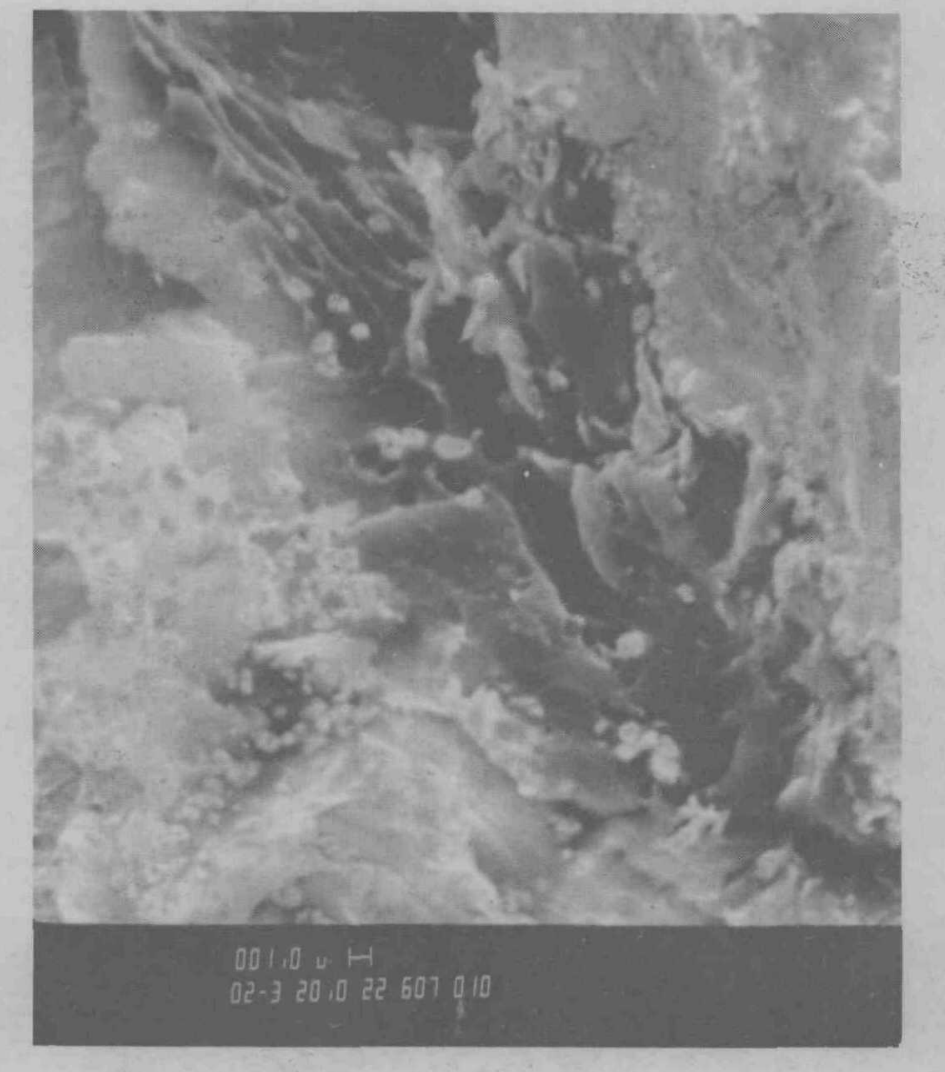

FIGURE 109: POST-TEST FRACTURE CROSS-SECTION OF THE WELD OF THE ษ

\begin{abstract}
POST-EXAMPLE WELD CLAD OF VF- 6
\end{abstract} AND VF-7.

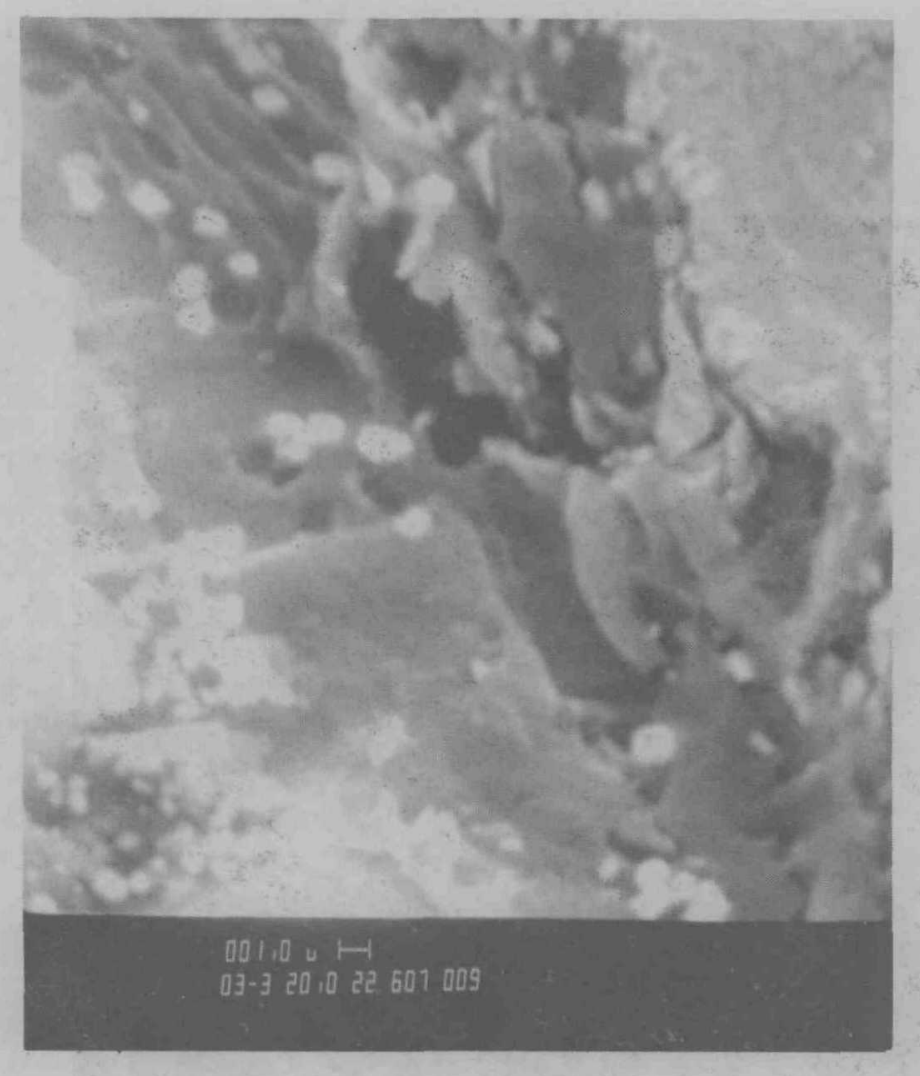

FIGURE 110: POST-TEST FRACTURE CROSS-SECTION OF THE WELD OF THE POST-EXAMPLE WELD CLAD OF VF-6 AND VF -7 . 


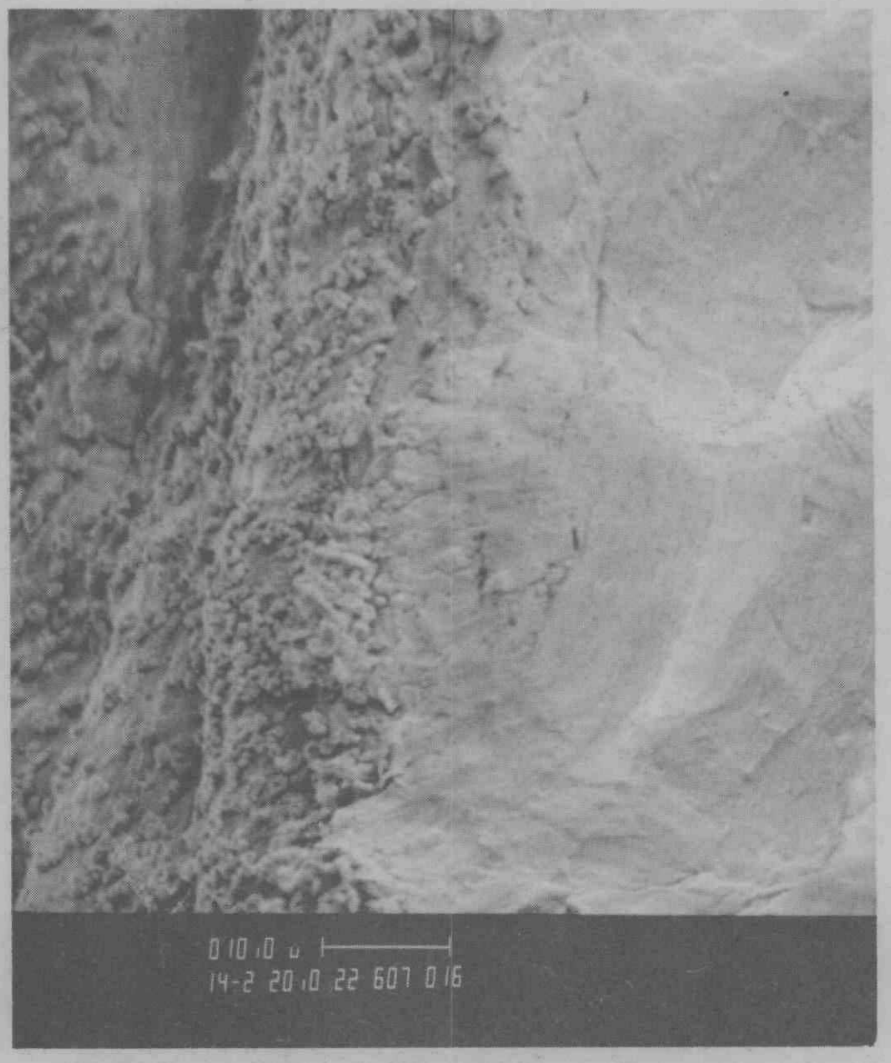

FIGURE 111: POST-TEST FRACTURE CROSS-SECTION OF THE WELD OF the post-example weld Clad of $\mathrm{VF}-6$ AND VF -7 .

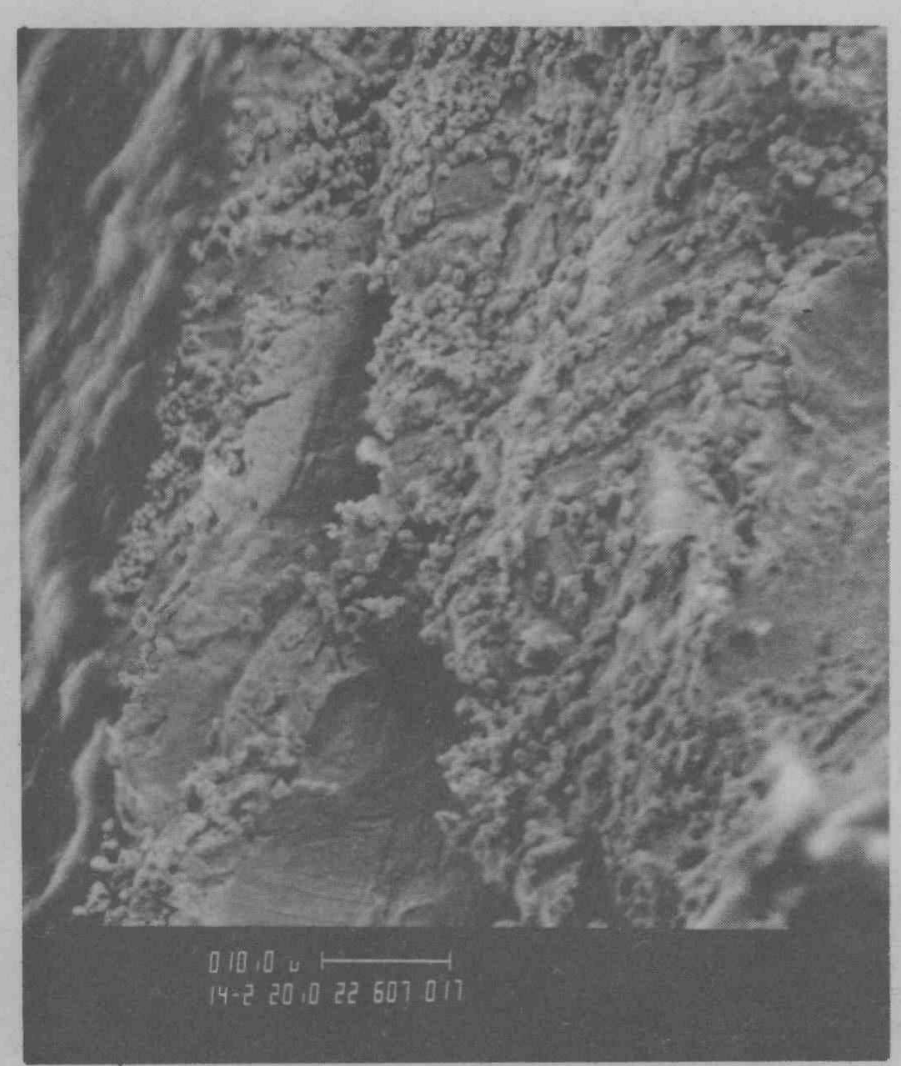

FIGURE 112: POST-TEST FRACTURE CROSS-SECTION OF THE WELD OF THE POST-EXAMPLE WELd CLAD OF VF-6 AND VF-7. 


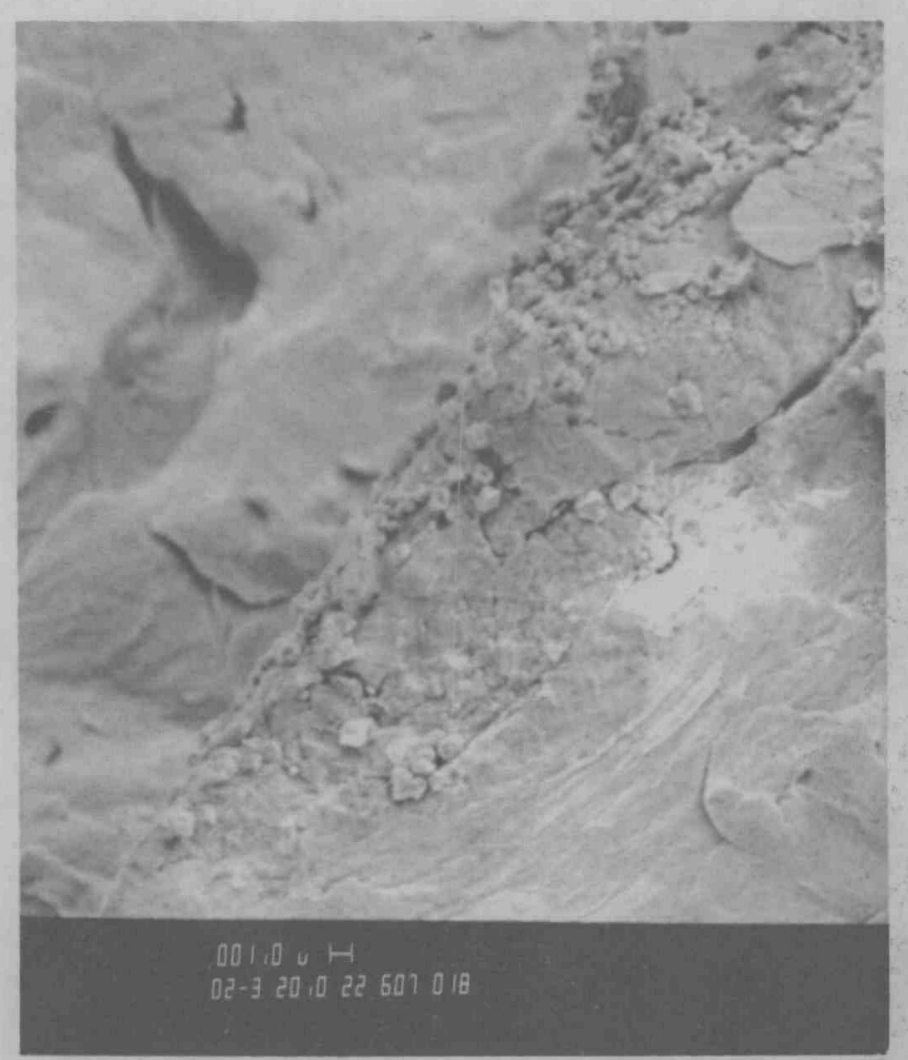

FIGURE 113: POST-TEST FRACTURE CROSS-SECTION OF THE WELD OF THE POST-EXAMPLE WELD CLAD OF VF- 6 AND VF -7 .

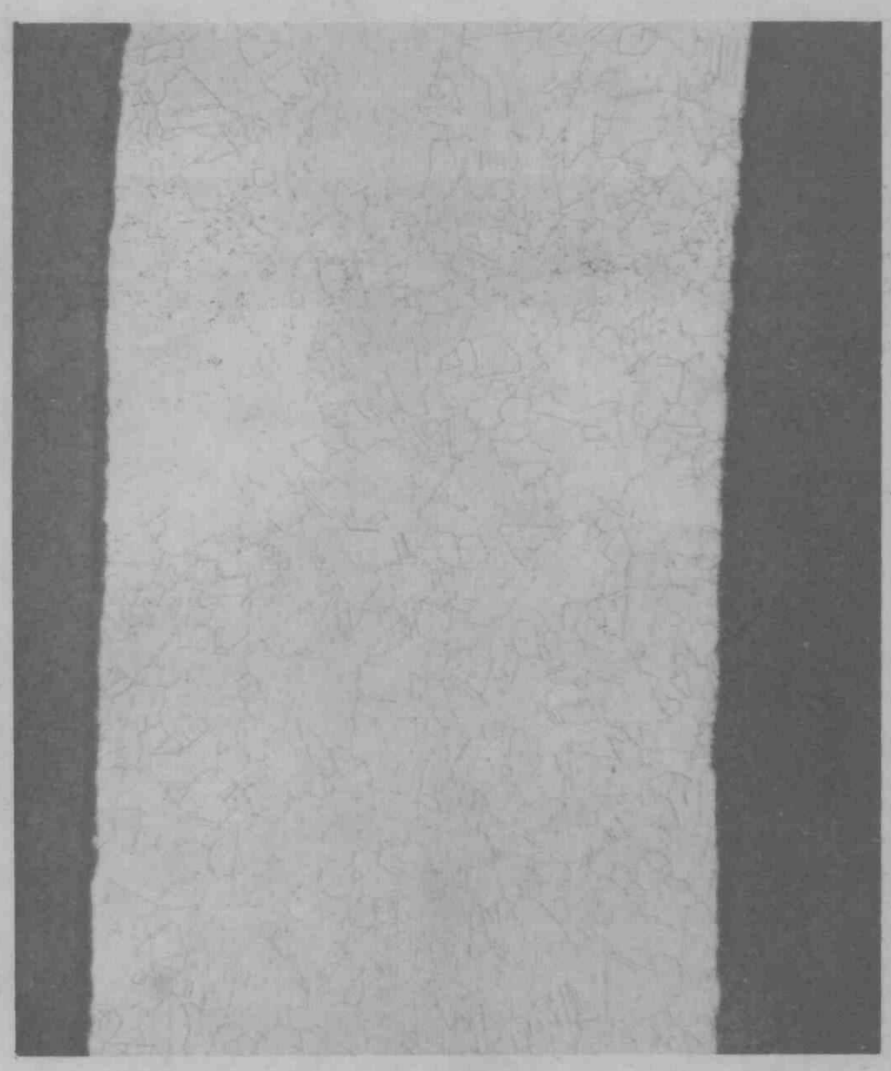

FIGURE 114: CROSS-SECTION OF THE StAINLESS STEEL TEST CONTAINER $(40 \mathrm{X})$. 


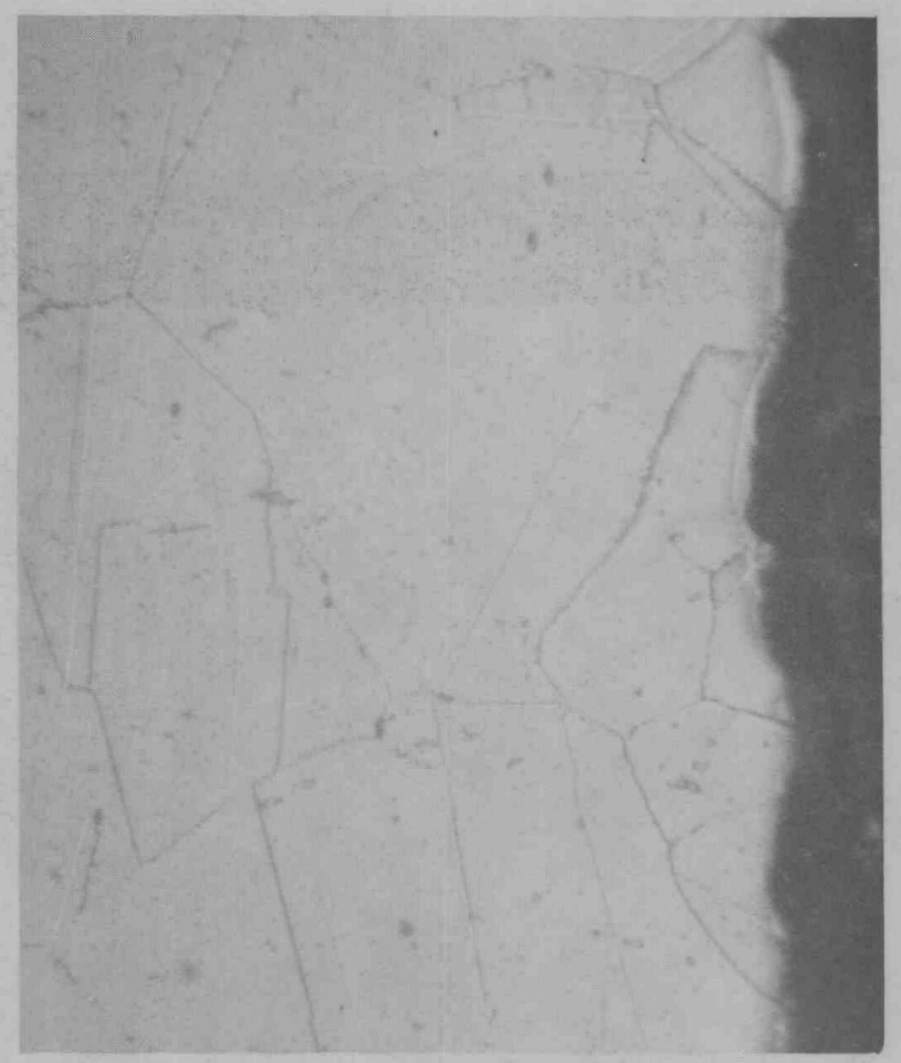

FIGURE 115: INSIDE EDGE OF THE CROSS-SECTION OF THE STAINLESS STEEL TEST CONTAINER (550X).

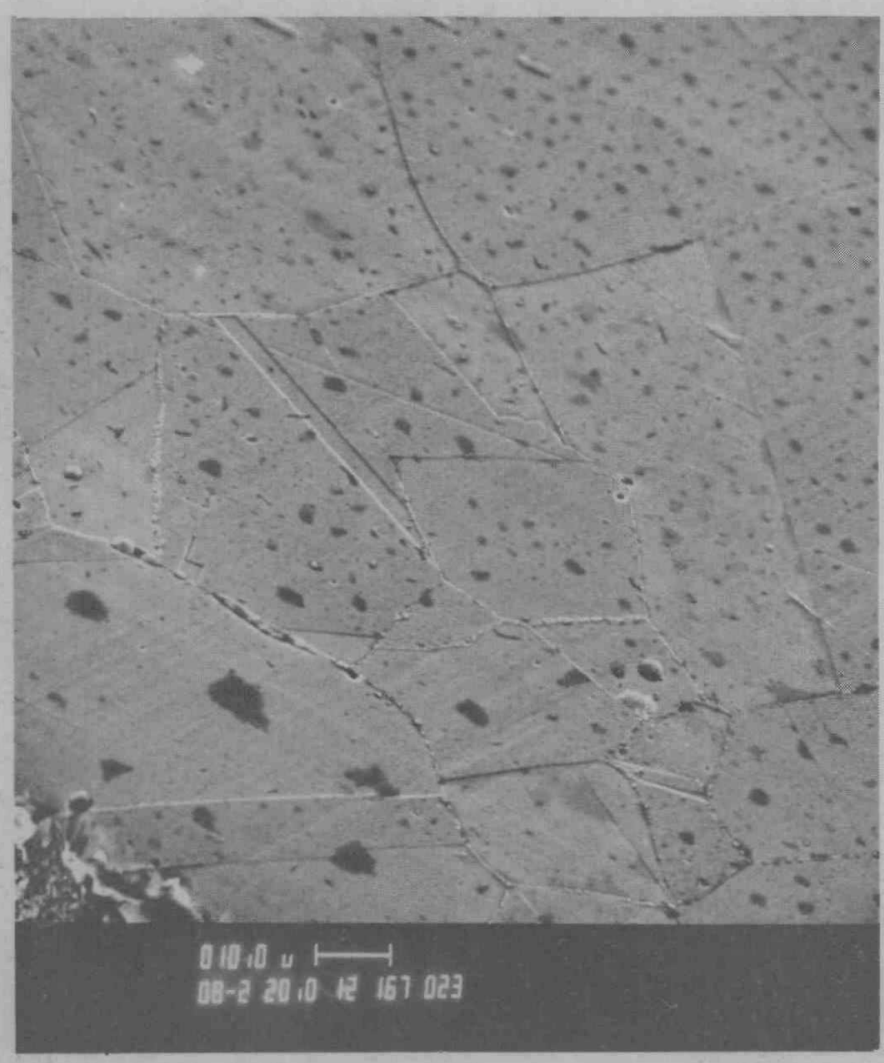

FIGURE 116: INSIDE EDGE OF THE CROSS-SECTION OF THE STAINLESS STEEL TEST CONTAINER. 


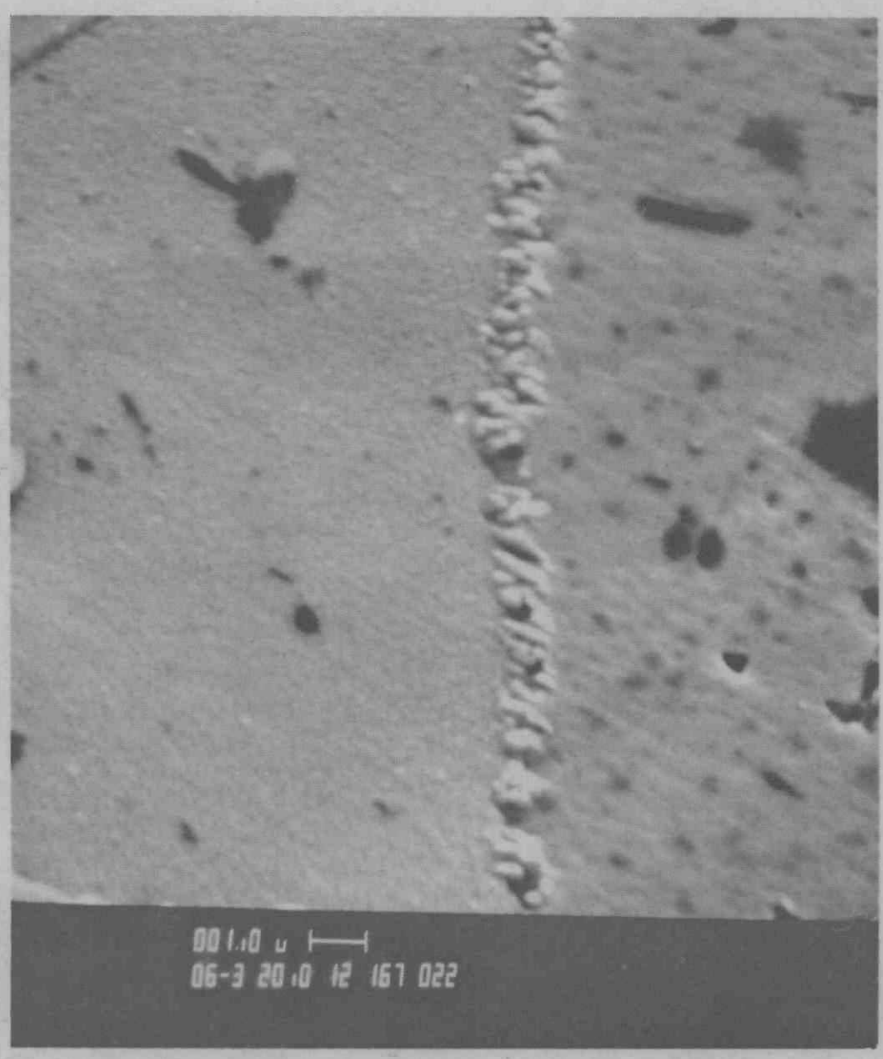

FIGURE 117: INSIDE EDGE OF THE CROSS-SECTION OF THE STAINLESS

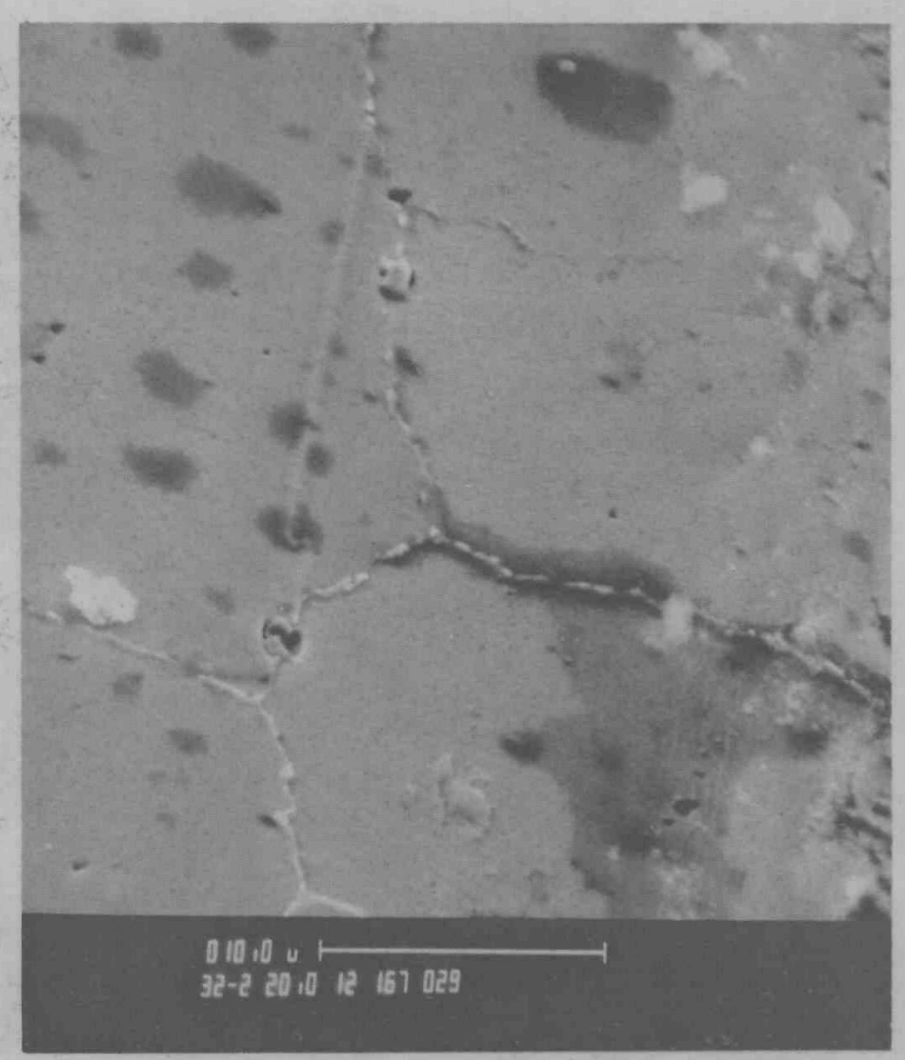

FIGURE 118: DUTSIDE EDGE OF THE CROSS-SECTION OF THE STAINLESS STEEL TEST CONTAINER. 


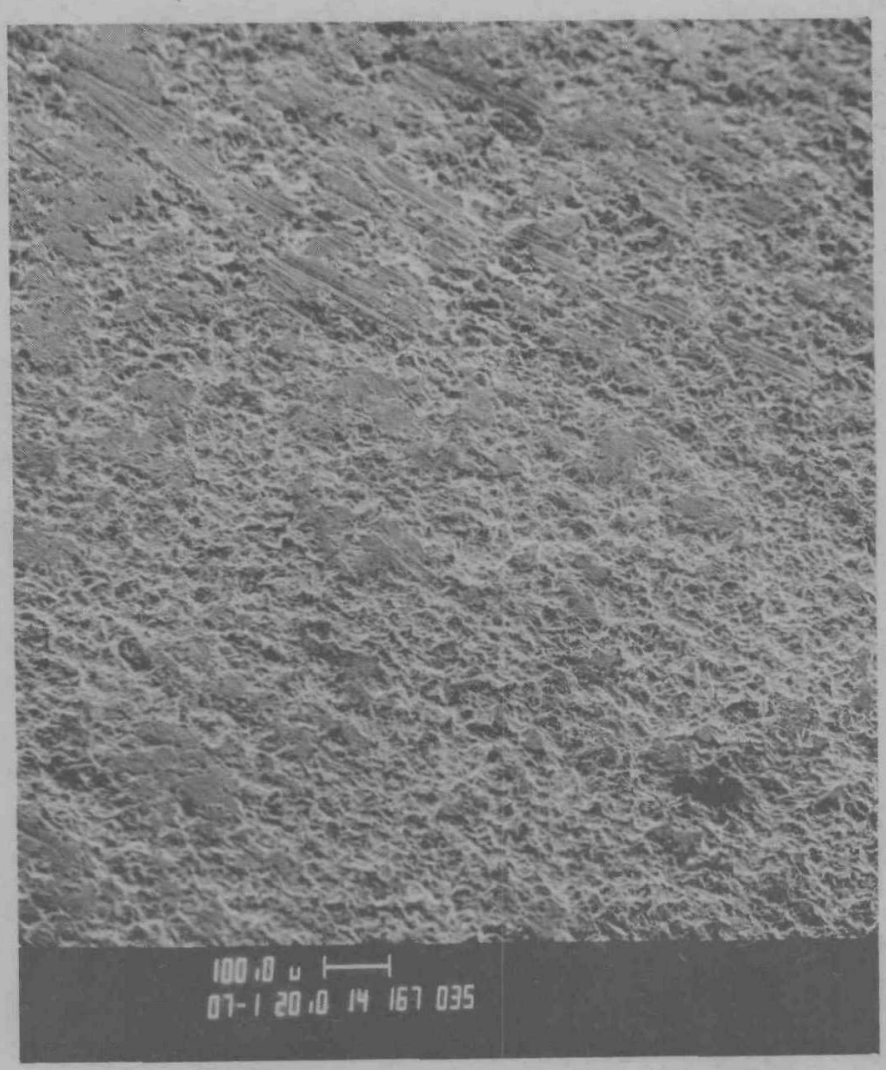

FIGURE 119: INSIDE SURFACE OF THE STAINLESS STEEL TEST CONTAINER.

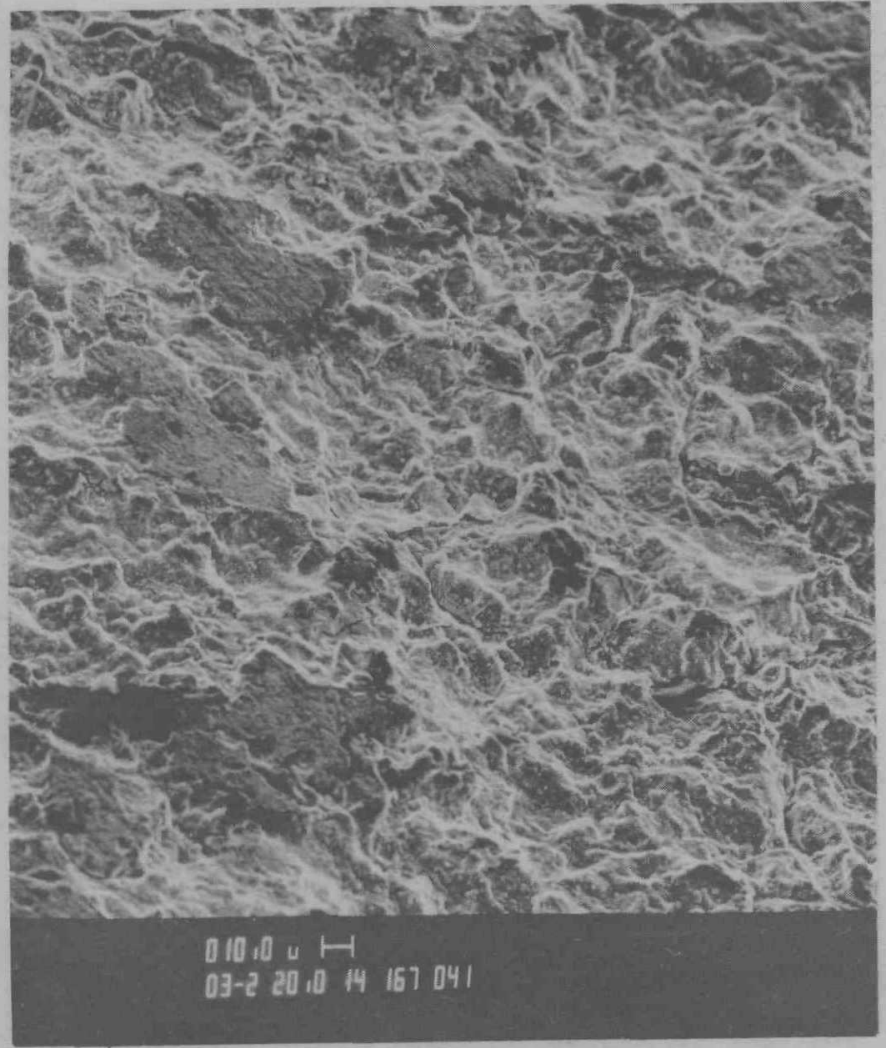

FIGURE 120: INSIDE SURFACE OF THE STAINLESS STEEL TEST CONTAINER. 


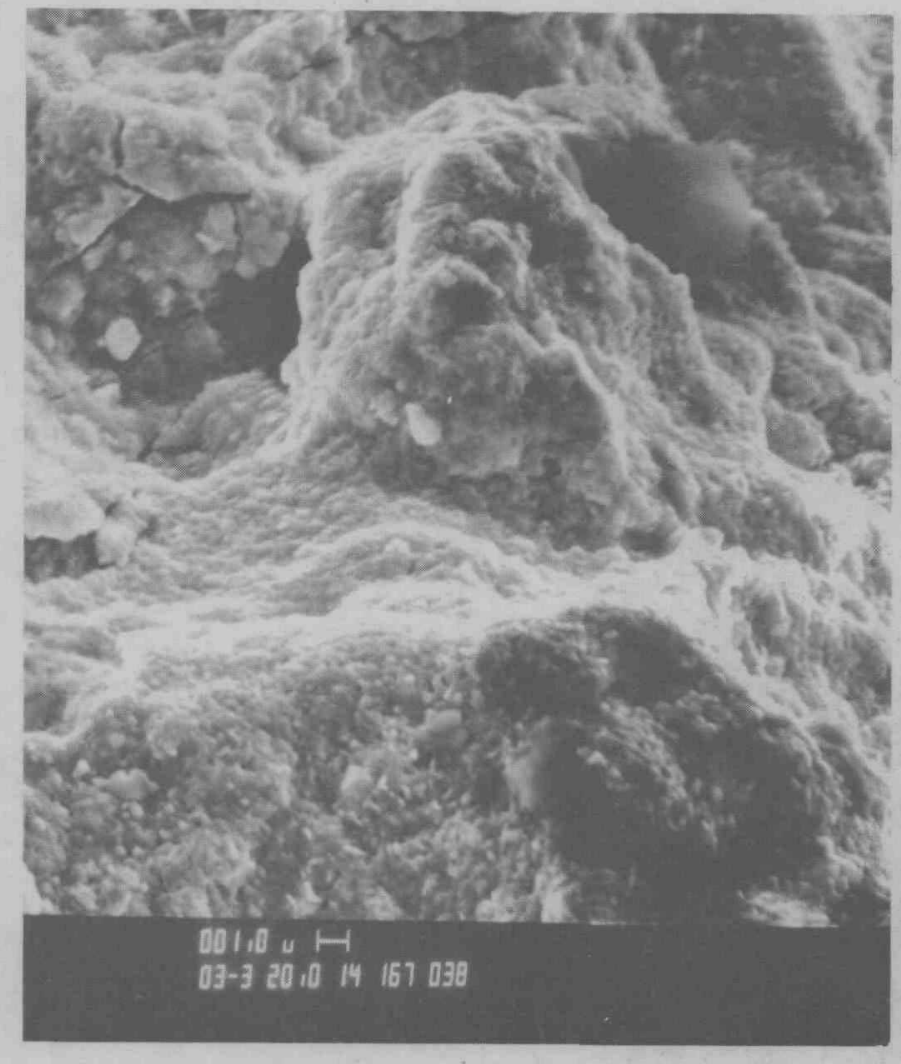

$\vdash$ FIGURE 121: INSIDE SURFACE OF THE

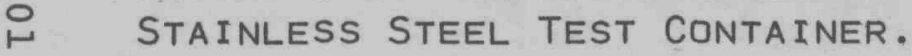

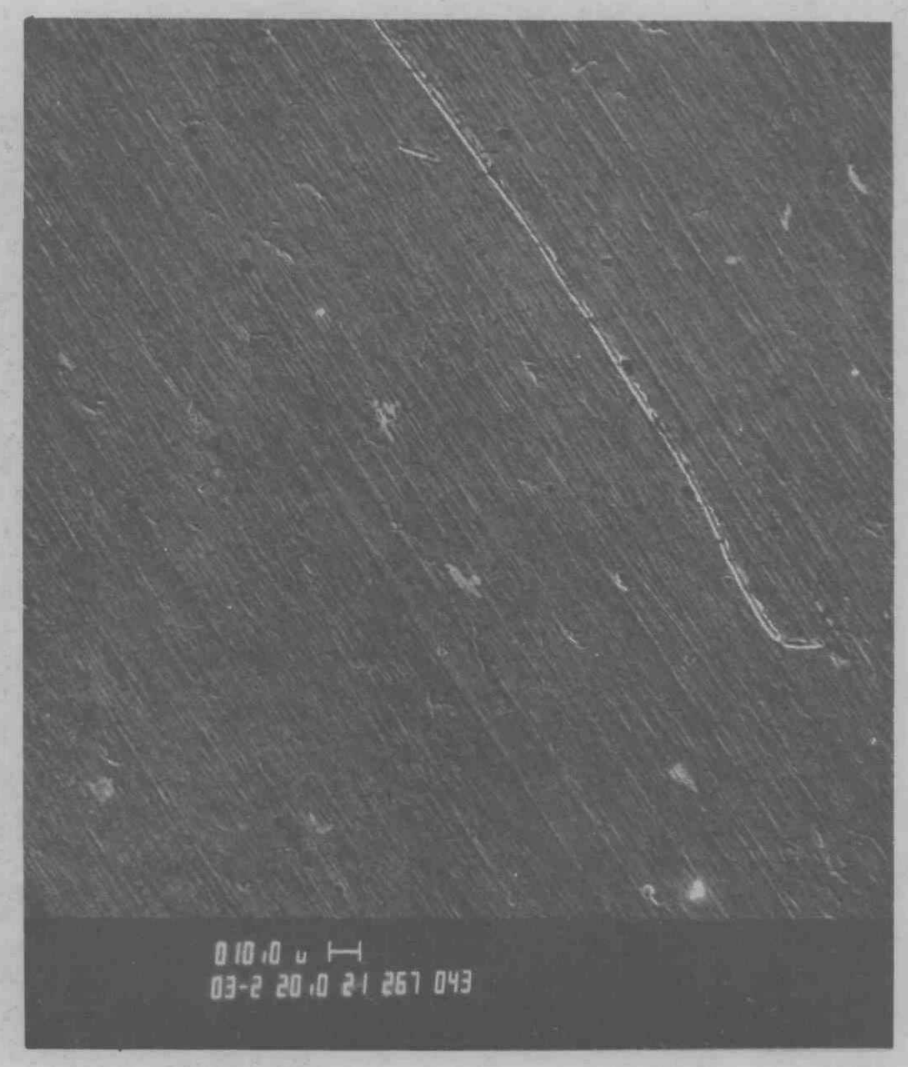

FIGURE 122: INSIDE SURFACE OF AN UnUSEd STAINLESS SteEl Test CONTAiner. 


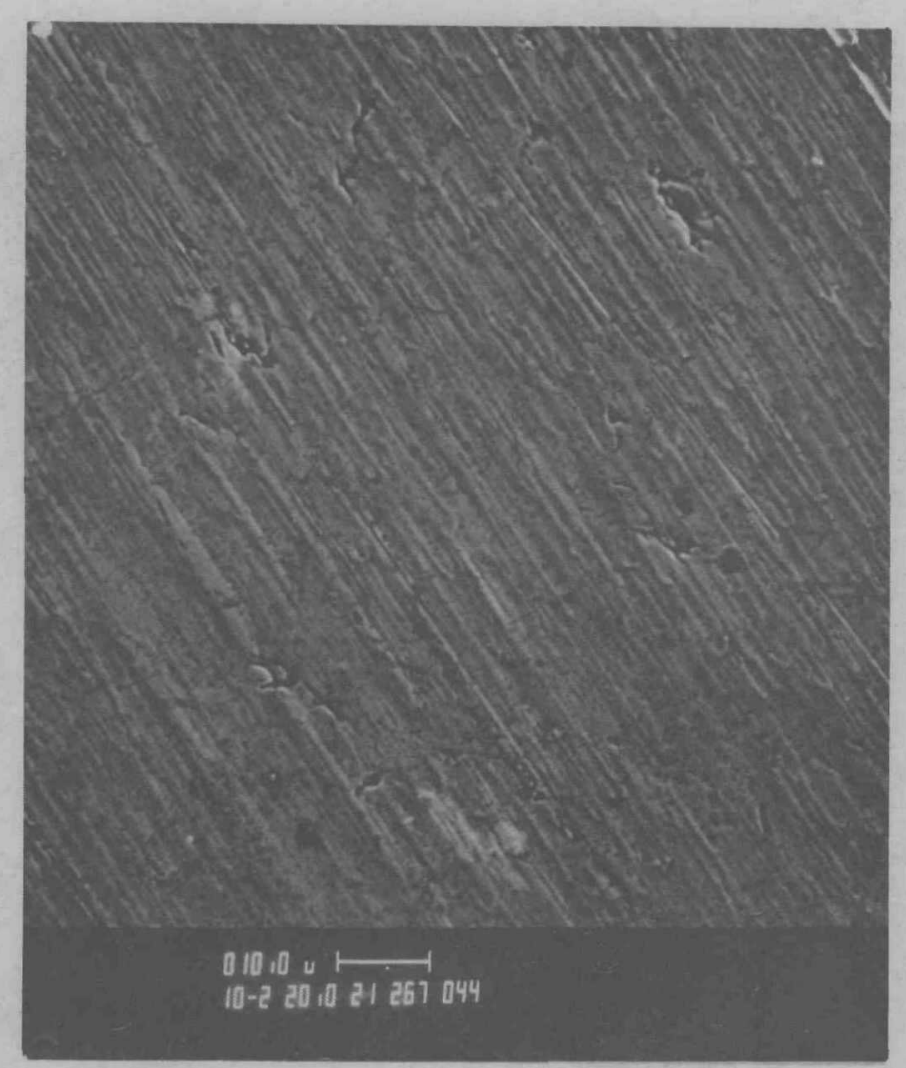

FIGURE 123: INSIDE SURFACE OF AN UNUSED

STAINLESS STEEL TEST CONTAINER. 